\title{
ipen
}

INSTITUTO DE PESQUISAS ENERGÉTICAS E NUCLEARES

Autarquia associada à Universidade de São Paulo

\section{APLICAÇÃO DE MAPAS AUTO-ORGANIZÁVEIS NA CLASSIFICAÇÃO DE PADRÕES DE ESCOAMENTO BIFÁSICO}

Leonardo Ferreira Castro

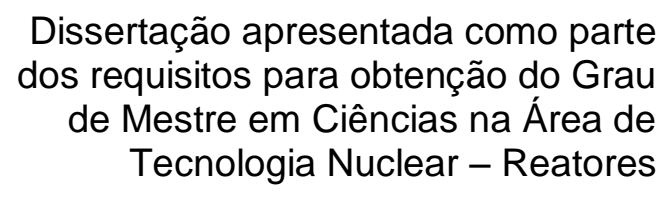

Orientador:

Dr. Roberto Navarro de Mesquita 
"A minha esposa, filha e mãe." 


\section{AGRADECIMENTOS}

Meus sinceros agradecimentos a todos que contribuíram direta e indiretamente para a realização deste trabalho.

Ao Professor Doutor Roberto Navarro de Mesquita por sua orientação e pela oportunidade dada a mim.

E ao CEN/IPEN - Centro de Engenharia Nuclear, pela colaboração na realização deste projeto. 


\title{
APLICAÇÃO DE MAPAS AUTO-ORGANIZÁVEIS NA CLASSIFICAÇÃO DE PADRÕES DE ESCOAMENTO BIFÁSICO.
}

\author{
Leonardo Ferreira Castro
}

\section{Resumo}

O escoamento bifásico de gás-líquido é encontrado em muitos circuitos fechados que utilizam circulação natural para fins de resfriamento. O fenômeno da circulação natural é importante nos recentes projetos de centrais nucleares para a remoção de calor. O circuito de circulação natural (Circuito de Circulação Natural - CCN), instalado no Instituto de Pesquisas Energéticas e Nucleares, IPEN / CNEN, é um circuito experimento concebido para fornecer dados termo-hidráulicos relacionados com escoamento monofásico ou bifásico em condições de circulação natural.

A estimativa de transferência de calor tem sido melhorada com base em modelos que requerem uma previsão precisa de transições de padrão de escoamento. Este trabalho apresenta testes experimentais desenvolvidos no CCN para a visualização dos fenômenos de instabilidade em ciclos de circulação natural básica e classificar os padrões de escoamento bifásico associados aos transientes e instabilidades estáticas de escoamento. As imagens são comparadas e agrupadas utilizando mapas auto-organizáveis de Kohonen (SOM), aplicados em diferentes características da imagem digital. Coeficientes da Transformada Discreta de Cossenos de Quadro Completo (FFDCT) foram utilizados como entrada para a tarefa de classificação, levando a bons resultados. Os protótipos de FFDCT obtidos podem ser associados a cada padrão de escoamento possibilitando uma melhor compreensão da instabilidade observada. Uma metodologia sistemática foi utilizada para verificar a robustez do método. 


\title{
SELF-ORGANIZING MAPS APPLIED TO TWO-PHASE FLOW ON NATURAL CIRCULATION LOOP STUDY.
}

\author{
Leonardo Ferreira Castro
}

\begin{abstract}
Two-phase flow of liquid and gas is found in many closed circuits using natural circulation for cooling purposes. Natural circulation phenomenon is important on recent nuclear power plant projects for decay heat removal. The Natural Circulation Facility (Circuito de Circulação Natural - CCN ) installed at Instituto de Pesquisas Energéticas e Nucleares, IPEN/CNEN, is an experimental circuit designed to provide thermal hydraulic data related to single and two-phase flow under natural circulation conditions. This periodic flow oscillation behavior can be observed thoroughly in this facility due its glass-made tubes transparency.

The heat transfer estimation has been improved based on models that require precise prediction of pattern transitions of flow. This work presents experiments realized at $\mathrm{CCN}$ to visualize natural circulation cycles in order to classify two-phase flow patterns associated with phase transients and static instabilities of flow. Images are compared and clustered using Kohonen Selforganizing Maps (SOM's) applied on different digital image features.

The Full Frame Discret Cosine Transform (FFDCT) coefficients were used as input for the classification task, enabling good results. FFDCT prototypes obtained can be associated to each flow pattern, enabling a better comprehension of each observed instability. A systematic test methodology was used to verify classifier robustness.
\end{abstract}




\section{SUMÁRIO}

\section{CAPÍTULO 1 - Introdução}

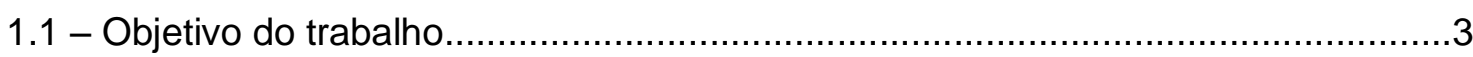

\section{CAPÍTULO 2 - Revisão de Literatura}

2.1 - Estatística multivariada..................................................................................

2.2 - Técnicas Multivariadas versus Inteligência Artificial (SOM).......................6

\section{CAPÍTULO 3 - Fundamentação Teórica}

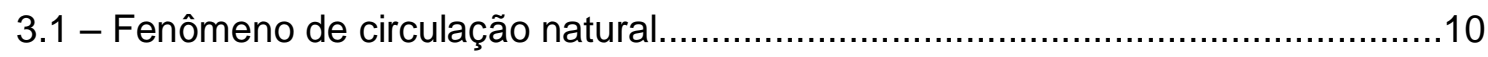

3.1.1 - O escoamento bifásico...............................................................

3.1.2 - Tipos de instabilidades de escoamento bifásico na Circulação

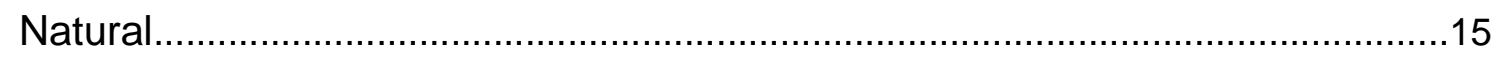

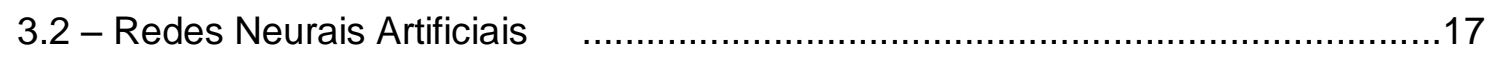

3.2.1 - Histórico sintetizado de RNA..........................................................18

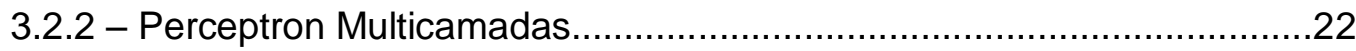

3.2.3 - Algoritmo de aprendizado e treinamento..............................................23

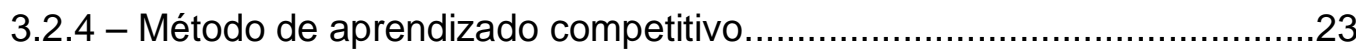

3.2.5 - Mapas auto-organizáveis - SOM....................................................29

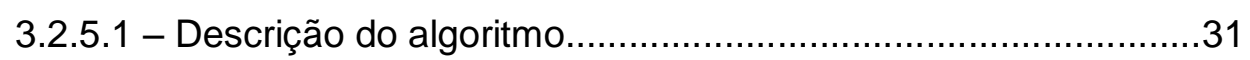

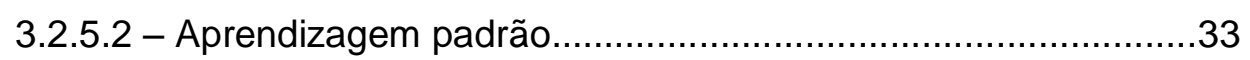

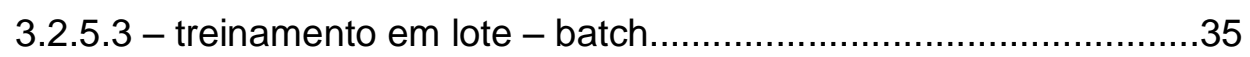

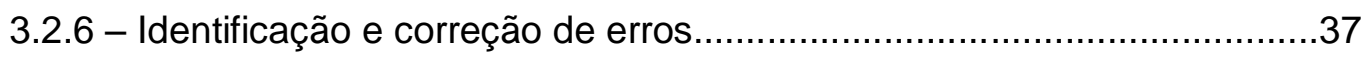

3.2.7 - Regra do Gradiente descendente....................................................

3.3 - Processamento de imagens utilizando DCT ..................................................

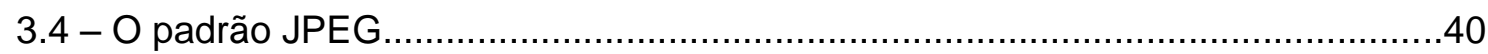

3.4.1 - Sequência ZIG-ZAG.....................................................................41

3.4.2 - Transformada discreta de cosseno de quadro completo (FFDCT)........42

\section{CAPÍTULO 4 - Metodologia}

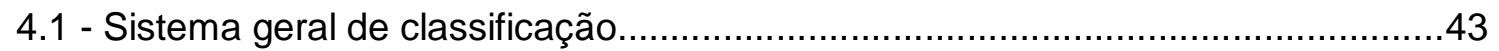

4.2 - Base de dados ............................................................................................ 


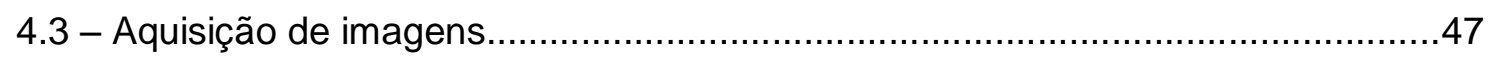

4.3.1 - Circuito de circulação natural (CCN) .............................................48

4.3.2 - Extração de características utilizando FFDCT ....................................51

4.4 - Classificação de escoamento com a SOM....................................................53

\section{CAPÍTULO 5 - Resultados e discussão}

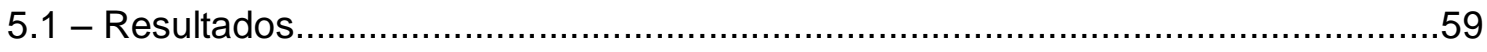

5.1.1 Treinamento com Inicialização Única.................................................60

5.1.1.1 Inicialização Única com $25 \%$ de amostragem.........................60

5.1.1.2 Inicialização Única com 50\% de amostragem........................63

5.1.1.3 Inicialização Única com 75\% de amostragem.........................67

5.1.2 Treinamento com Inicialização Variada................................................71

5.1.2.1 Treinamento com Inicialização Variada com 25\% de

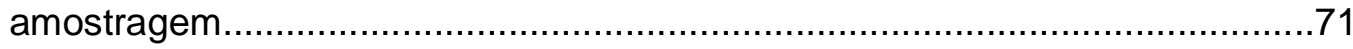

5.1.2.2 Treinamento com Inicialização Variada com $50 \%$ de

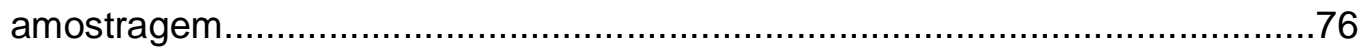

5.1.2.3 Treinamento com Inicialização Variada com $75 \%$ de

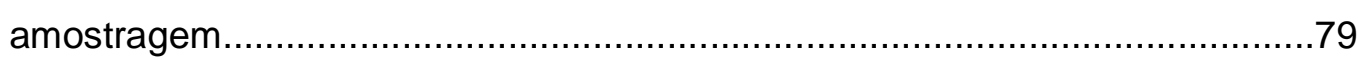

5.1.3 Testes de Classificação para diferentes inicializações...........................83

\section{CAPÍTULO 6 - Conclusões}

6.1 - Trabalhos futuros .95

\section{Anexo}

Anexo I: Banco de imagens - Tipo de escoamento: Incubação......................104

Anexo II: Banco de imagens - Tipo de escoamento: Expulsão......................106

Anexo III: Banco de imagens - Tipo de escoamento: Reenchimento.............108 


\section{LISTA DE FIGURAS}

Figura 3.1.1: Esquema do circuito em regime de circulação natural............................11

Figura 3.1.2:Diagrama de um sistema de arrefecimento de reator PWR....................11

Figura 3.1.1.1 - Tipos de escoamento bifásico vertical: bolhas dispersas (bubble flow), pistonado (slug flow), aglomerados (churn flow) e anular (annular

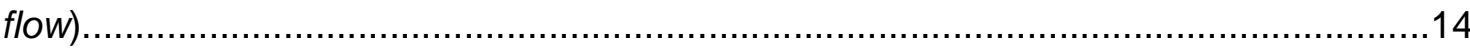

Figura 3.1.3: Imagens adquiridas no CCN, das instabilidades características... ........17

Figura 3.2.1: Modelo do neurônio biológico..............................................................18

Figura 3.2.1.1: Modelo de neurônio artificial..............................................................19

Figura 3.2.1.2: Rede Perceptron de Rosenblatt...................................................20

Figura 3.2.1.3: Exemplos de classes linearmente separáveis e inseparáveis de

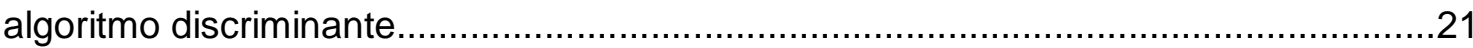

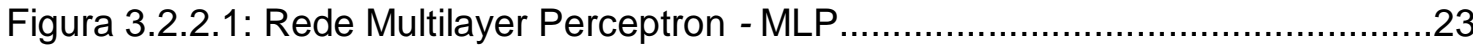

Figura 3.2.4.1: Ilustração de dualidade entre diagrama de Voronoi e triangulação de

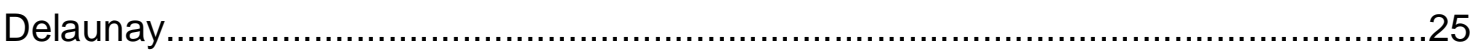

Figura 3.2.5.1: Mapa auto-organizável bidimensional $N \times M$, com entradas $x_{k} \ldots \ldots . .30$

Figura 3.2.5.2: Estruturações topológicas de Mapas Auto Organizáveis......................30

Figura 3.2.5.1.1: Matriz Ud de distâncias topológicas quadradas entre as coordenadas das células para mapas de 54 células em morfologia hexagonal...............................32

Figura 3.4.1.1: Figura ZIG-ZAG em um bloco 8x8 ................................................ 41

Figura 4.1.1: SOM - Fluxograma de classificação - esquema geral..........................43

Figura 4.2.1: Imagem característica da transição entre a fase de reechimento para incubação.

Figura 4.2.2: Comportamento periódico cíclico da temperatura ao longo do tempo em uma instalação de circulação natural bifásico

Figura 4.2.3: Imagens de subtipos de instabilidade adquiridas no CCN: (a-d) incubação (I), (e-h) expulsão e (i-I) refil. .47

Figura 4.3.1.1: Esquema do Circuito de Circulação Natural (CCN) ............................48

Figura 4.3.1.2: Imagem do CCN, com descrição de componentes do sistema...........49

Figura 4.3.2.1 - Imagem original típica da fase Expulsão $(E)$ seguida de suas imagens reconstruídas (de cima para baixo) usando 100, 50, 12 e 6 coeficientes FFDCT........53 Figura 4.4.1 - Vetor característico com 100 coeficientes, obtido através da FFDCT utilizando a técnica de Zig-Zag da matriz M 
Figura 4.4.2: Etapas de classificação utilizando Som

Figura 5.1.1.1.1: Mapa da Matriz Unitária com escala de proximidade entre as células após treinamento - inicialização única com $25 \%$ das amostras .60

Figura 5.1.1.1.2: Mapa da SOM treinada com os protótipos obtidos referentes aos coeficientes FFDC - inicialização única com $25 \%$ das amostras. 61

Figura 5.1.1.1.3: Mapa da SOM treinada com as unidades BMU's assinaladas para cada tipo de instabilidade classificada - inicialização única com $25 \%$ das amostras...62 Figura 5.1.1.1.4: Mapa da SOM treinada com as unidades etiquetadas com cada tipo de instabilidade para classificação - inicialização única com $25 \%$ das amostras.

Figura 5.1.1.2.1: Mapa da Matriz Unitária com escala de proximidade entre as células após treinamento - inicialização única com $50 \%$ das amostras 64

Figura 5.1.1.2.2: Mapa da SOM treinada com os protótipos obtidos referentes aos coeficientes FFDCT - inicialização única com $50 \%$ das amostras. .65

Figura 5.1.1.2.3: Mapa da SOM treinada com as unidades BMU's assinaladas para cada tipo de instabilidade classificada - inicialização única com $50 \%$ das amostras....66 Figura 5.1.1.2.4: Mapa da SOM treinada com as unidades etiquetadas com cada tipo de instabilidade para classificação - inicialização única com $50 \%$ das amostras .67 Figura 5.1.1.3.1: Mapa da Matriz Unitária com escala de proximidade entre as células após treinamento - inicialização única com $75 \%$ das amostras .68

Figura 5.1.1.3.2: Mapa da SOM treinada com os protótipos obtidos referentes aos coeficientes FFDCT - inicialização única com $75 \%$ das amostras. .69

Figura 5.1.1.3.3: Mapa da SOM treinada com as unidades BMU's assinaladas para cada tipo de instabilidade classificada - inicialização única com $75 \%$ das amostras....70 Figura 5.1.1.3.4: Mapa da SOM treinada com as unidades etiquetadas com cada tipo de instabilidade para classificação - inicialização única com $75 \%$ das amostras..........71 Figura 5.1.2.1.1: Mapa da Matriz Unitária com escala de proximidade entre as células após treinamento - Inicialização Variada com $25 \%$ de amostragem .72 Figura 5.1.2.1.2: Mapa da SOM treinada com os protótipos obtidos referentes aos coeficientes FFDCT - Inicialização Variada com 25\% de amostragem. .73 Figura 5.1.2.1.3: Mapa da SOM treinada com as unidades BMU's assinaladas para cada tipo de instabilidade classificada - Inicialização Variada com $25 \%$ de amostragem

Figura 5.1.2.1.4: Mapa da SOM treinada com as unidades etiquetadas com cada tipo de instabilidade para classificação- Inicialização Variada com 25\% de amostragem...75 Figura 5.1.2.2.1: Mapa da Matriz Unitária com escala de proximidade entre as células após treinamento- Inicialização Variada com $50 \%$ de amostragem .76 
Figura 5.1.2.2.2: Mapa da SOM treinada com os protótipos obtidos referentes aos coeficientes FFDCT. - Inicialização Variada com 50\% de amostragem.

Figura 5.1.2.2.3: Mapa da SOM treinada com as unidades BMU's assinaladas para cada tipo de instabilidade classificada - Inicialização Variada com 50\% de amostragem

Figura 5.1.2.2.4: Mapa da SOM treinada com as unidades BMU's assinaladas para cada tipo de instabilidade classificada - Inicialização Variada com 50\% de amostragem .79

Figura 5.1.2.3.1: Mapa da Matriz Unitária com escala de proximidade entre as células após treinamento - Inicialização Variada com 75\% de amostragem .80

Figura 5.1.2.3.2: Mapa da SOM treinada com os protótipos obtidos referentes aos coeficientes FFDCT - Inicialização Variada com 75\% de amostragem....

Figura 5.1.2.3.3: Mapa da SOM treinada com as unidades BMU's assinaladas para cada tipo de instabilidade classificada - Inicialização Variada com $75 \%$ de amostragem

Figura 5.1.2.3.4: Mapa da SOM treinada com as unidades BMU's assinaladas para cada tipo de instabilidade classificada - Inicialização Variada com $75 \%$ de amostragem 


\section{LISTA DE TABELAS}

Tabela 5.1.3.1 - Resultados da classificação da SOM inicialização única com 25\% das amostras. .85

Tabela 5.1.3.2 - Resultados da classificação da SOM inicialização única com 50\% das amostras. .86

Tabela 5.1.3.3 - Resultados da classificação da SOM inicialização única com 75\% das amostras .87

Tabela 5.1.3.4 - Resultados da classificação da SOM (inicialização variada) com 25\% das amostras. .88

Tabela 5.1.3.5 - Resultados da classificação da SOM (inicialização variada) com 50\% das amostras. .89

Tabela 5.1.3.6 - Resultados da classificação da SOM (inicialização variada) com 75\% das amostras. 


\section{LISTA DE ABREVIATURAS E SIGLAS}

AC - Alternate Current

AHWR - Advanced Heavy Water Reactors

ART - Adaptive Ressonance Theory

BMU - Best Match Unit

BWR - Boiling Water Reactors

CCD - Charged-Couple Device

CCITT - Consultative Committee for International Telephony and Telegraphy

CFD - Fluidodinâmica Computacional

CNEN - Comissão Nacional de Energia Nuclear

DC - Direct Current

DIP - Digital Image Processing

ESBWR - Economic Simplified Boiling Water Reactors

IPEN - Instituto de Pesquisas Energéticas e Nucleares

ISO/IEC - International Organization for Standardization and International

Electrotechnical Commissione

JPEG - Joint Photographic Experts Group

KLT - Karhunen-Loève Transform

MGP - Mean of Grayscale Level Profile

NCF - Natural Circulation Facility

PHA - Polycyclic Aromatic Hydrocarbon

RELAP5 - Código termo hidráulico de análise de segurança e acidentes em

plantas nucleares

RLC - Run-Length Coding

RGB - Red-Green-Blue Pattern

RNA - Redes Neurais Artificiais

SBWR - Simplified Boiling Water Reactor

SOM - Self-Organizing Maps

DWT - Discrete Wavelet Transform 


\section{CAPÍTULO 1 - INTRODUÇÃO}

Escoamentos bifásicos de líquido e gás são encontrados em diversos sistemas fechados aonde são utilizados (loops) de circulação natural para resfriamento. Em reatores nucleares o fenômeno de circulação natural é importante para a remoção de calor residual, no caso de perda de alimentação das bombas do circuito primário e em operações a baixa potência (Bastos; Loureiro, 1995).

A nova geração de reatores nucleares compactos inclui circulação natural do seu fluído refrigerante como um mecanismo de segurança em seus projetos, nos sistemas chamados passivos. sistemas chamados passivos (Nayak et al., 2007). Neste fenômeno, a circulação do fluído é causada principalmente por uma força motriz (thermal head) que surge a partir de diferenças de densidade devido ao gradiente de temperatura.

Muitos circuitos de circulção natural são chamados termosifão e têm sido aplicados para resfriamento em processos químicos, eletrônicos, de aquecimento a energia solar, energia nuclear e muitos outros. A queda de pressão a partir de cada fase depende significativamente dos valores de vazios, que por sua vez tem uma influência mútua sobre o padrão de escoamento bifásico.

O estudo das transições entre os padrões de escoamento bifásico e suas instabilidades depende de um bom conhecimento dos padrões de escoamento que podem ser formados durante a movimentação dos fluidos.

A verificação de modelos de transporte entre as fases requer métodos experimentais que sejam capazes de fornecer detalhes do escoamento.

O conhecimento do comportamento e da relação entre parâmetros de escoamento como velocidades das fases, pressão e fração de vazio, ao longo da 
tubulação é alvo de estudo (Mesquita et al., 2012) pela importância nos controles de processos e no projeto de equipamentos.

As instabilidades de escoamento bifásico do ciclo circulação natural são classificadas conforme estabelecido por Delhaye em 1981 (Delhaye et al., 1981). Estas instabilidades são geralmente divididas em dois grupos: do tipo I e tipo II, onde o primeiro grupo refere-se aos efeitos da gravidade que são de grande importância em SBWR (reatores simplificados de água fervente). Fenômenos termodinamicos clássico explicam as conhecidas oscilações de batimento, geysering e chugging, que podem produzir um comportamento repetitivo que nem sempre é periódico. O termo "chugging" é geralmente utilizado para denominar a característica expulsão periódica de líquido refrigerante a partir de um canal de escoamento (Bouré et al., 1973). As recentes melhorias tecnológicas na aquisição e no processamento de imagens tornou possível a descoberta de novos recursos na detecção de padrões de escoamento bifásico através de imagens adquiridas digitalmente.

Para reconhecimento de padrões do escoamento bifásico, existem hoje inúmeros métodos disponíveis que se adéquam às mais diversas finalidades. Alguns exemplos desses métodos são: borbulhamento utilizando ultrassom; fluidodinâmica computacional (CFD); método dos volumes finitos; reconhecimento de imagens através de redes neurais artificiais, entre outros (Jérôme et al., 2005).

A maioria dos grupos de estudos nessa área buscam a detecção (on-line) e a classificação dos padrões de escoamento usando os recursos do processamento digital (Crivelaro et al., 2002). Como a queda de pressão de cada uma das fases é fundamentalmente dependente dos valores da fração de vazios, estimativas dos parâmetros de escoamento e as características transições das fases existe interesse na obtenção do parametro de fração de vazio, assim como o reconhecimento do padrão de escoamento. As estimativas destas características tem sido obtidas com o uso de diferentes técnicas de inteligência artificial. A relação entre os tipos de transições de escoamento e covariâncias tempo-frequência de sinais de fração de vazio foi proposta por Seleghim e Hervieu (1998) e as redes neurais foram utilizadas para detectar transições de fase com base nas alterações de sinal por Crivelaro (Crivelaro et al., 2002). Anemômetro de fio-quente (Yeoh, et al, 2002), sonda de 
condutividade (Dong et al, 2006), eletrodo de múltipla impedância (Fujiwara et al, 2004), velocimetria de partículas e tratamentos ópticos (Ursenbacher et al., 2004) são algumas dessas outras técnicas associadas.

Este trabalho dá continuidade à pesquisa realizada na detecção e classificação de instabilidades de escoamento bifásico em circulação natural utilizando inteligência artificial (sistema de inferência Fuzzy) em imagens digitais desenvolvida por Mesquita et al.( 2012). O reconhecimento de padrões em imagens através de mapas auto-organizáveis (SOM) pode possibilitar a identificação das transições de fase e correlacionar as instabilidades periódicas estáticas (chugging) presentes no ciclo de um circuito de circulação natural. Uma descrição dos primeiros desenvolvimentos realizados neste trabalho foi publicada pelo autor desta dissertação (Castro et al., 2015).

A precisão da previsão do escoamento bifásico e da transferência de escoamento de calor terá melhoramento com o aperfeiçoamento dos modelos de SOM, que exijam previsões precisas das transições de padrão, como fração de vazio. Os métodos de inteligência artificial podem significativamente adicionar recursos na identificação desses padrões sem a necessidade de técnicas muito elaboradas de processamento de imagem. Por outro lado, melhorias no processamento de imagens e na manipulação de banco de dados aumentam as habilidades, melhorando quantitativa e qualitativamente, a fim de estabelecer novos tipos de escoamento e de métodos de identificação.

Uma das motivações deste trabalho é o de estudar a fenomenologia da circulação natural em instalações nucleares. Este estudo se faz necessário, pois a nova geração de reatores nucleares compactos utiliza a circulação natural do fluido refrigerante como sistema de resfriamento e de remoção de calor residual, em caso de acidente ou desligamento da planta.

\subsection{Objetivo do Trabalho}

O objetivo desse trabalho é classificar alguns padrões de escoamento bifásico relacionados às instabilidades de regime de circulação natural através de tratamento 
de imagens com a utilização de técnicas de Inteligência Artificial - Mapas AutoOrganizáveis (SOM).

Este trabalho propõe um algoritmo de reconhecimento automático de padrões de escoamento bifásico para detectar estas instabilidades em um circuito de circulação natural, baseando-se em imagens digitais adquiridas através de uma secção de visualização.

Este método pode vir a auxiliar na solução de vários problemas em vários campos da ciência e da indústria nos quais seja necessária a obtenção de parâmetros de escoamento.

Este trabalho faz parte de uma pesquisa do Centro de Engenharia Nuclear IPEN - SP, onde se busca desenvolver técnicas de processamento digital de imagens aplicadas a escoamentos bifásicos utilizando métodos de inteligência artificial para obtenção de informações qualitativas e quantitativas das fases do escoamento bifásico. 


\section{CAPÍTULO 2 - REVISÃO DE LITERATURA}

2.1 Estatísticas multivariadas.

A estatística multivariada consiste em um conjunto de métodos estatísticos utilizados em situações nas quais um determinado número de variáveis são medidas simultaneamente, em cada elemento amostral. Em geral as variáveis são correlacionadas e quanto maior o número de variáveis, maior a complexidade em analisar por métodos comuns de estatística univariada.

Duas são as principais técnicas citadas na literatura: - grupo de técnicas exploratórias de sintetização (ou simplificação) da estrutura de variabilidade dos dados e, grupo de técnicas de inferência estatística. Dentro do grupo de técnicas exploratórias podem-se destacar a análise de componentes principais, a análise de correlações canônicas, a análise de agrupamentos, a análise discriminante de correspondência (Mingotil, 2005). No grupo de técnicas de inferência estatística se destacam os métodos de estimativa de parâmetros, testes de hipóteses, análise de variância, covariância e de regressão multivariada.

De acordo com Echalar (Echalar et al.,1991), uma base de dados multivariada pode ser interpretada como uma descrição das variabilidades em um sistema por meio das séries temporais das variáveis medidas. A análise de componentes principais tem como principal aplicação a mensuração do grau de inter-relações existentes entre as variáveis envolvidas no processo, e isso é observado nas repetições de certas características em uma série temporal demonstrando que talvez essa informação derive de fatores subjacentes que causem a variabilidade.

$\mathrm{Na}$ análise de componentes principais, a ideia é a substituição das variabilidades de variáveis medidas por outra com um menor número de variáveis, independentes, com combinações lineares que representem esses fatores causais, não explícitos da variabilidade medida. 


\subsection{Técnicas Multivariadas versus Inteligência Artificial (SOM)}

A utilização concomitante da análise multivariada com técnicas de Inteligência Artificial como a rede neural de Kohonen (SOM) pode possibilitar a comprovação e o desenvolvimento de modelos e metodologias que possibilitem uma melhora significativa nos estudos das instabilidades do escoamento bifásico.

Astel (Astel et.al., 2007) utiliza três técnicas de agrupamento para efeito de estudo: previsões de carga e de pontuação com base na análise de componentes principais $(P C A)$, análise de cluster $(C A)$ e mapas auto-organizáveis (SOM). estudo foi realizado utilizando dados de monitoramento da qualidade da água em longo prazo. A vantagem do algoritmo SOM é sua capacidade de classificação e visualização de grandes conjuntos de dados ambientais. Os resultados obtidos permitiram detectar agrupamentos naturais de monitoramento locais com tipo de qualidade da água semelhante e identificar importantes variáveis discriminantes responsáveis pelo agrupamento. Esta separação tem como objetivo a otimização de redes de monitoramento de rios e um melhor rastreamento de mudanças naturais e antrópicos ao longo da calha do mesmo.

Mesquita (Mesquita et.al., 2012) demonstram que é possível implementar um sistema de classificação de instabilidades de escoamento bifásico baseado em padrões de imagens usando características simples em um sistema de inferência difusa, desde que o processamento de imagens adequado seja feito. Sistemas Fuzzy tem uma grande vantagem em relação a outros métodos de inteligência artificial, como permitir que o conhecimento de especialistas sejam explicitamente incluído nas regras de inferência.

O processamento de imagens digitais associado a técnicas de inteligência artificial (redes neurais, lógica fuzzy, neuro-wavelet e máquina de vetor de suporte) tem sido utilizado para identificação e classificação de padrões de regimes de escoamento e também das transições entre eles (Crivelaro, 2002; Mesquita, 2012; Mesquita, 2009; Sunde et al., 2005). 
Tobiszewski (Tobiszewski et al., 2010) faz uma abordagem na qual é possível identificar e avaliar diferentes impactos ambientais sobre a qualidade da água em rios de uma região urbana. As fontes de poluição neste estudo particular são: queima de biomassa, eliminação de fosfogesso, resíduos de refinaria de petróleo e atividade de tráfego. Os resultados obtidos confirmam que uma combinação apropriada de uma abordagem multivariada como SOM com informações especializadas específicas como índices de diagnóstico de PHA (Polycyclic aromatic hydrocarbon) é uma estratégia de avaliação de riscos satisfatória para uma região urbano-industrial.

Nos estudos termodinâmicos Dasari (Dasari et al., 2013) propôs a construção de uma PPN (Rede Neural Probabilística) como ferramenta de previsão de viscosidade em padrão de escoamento bifásico. Foi relatada uma análise detalhada sobre os padrões de escoamento óleo-água moderadamente viscosos em um tubo horizontal circular. Aplicou-se técnicas visuais e de imagem para identificar diferentes padrões de instabilidades, tais como: escoamento embolar, golfadas, escoamento estratificado ondulado, escoamento misto estratificado, dispersão de óleo em água e a dispersão de água no escoamento de óleo. Estes, para uma ampla gama de velocidades superficiais de óleo. A presente investigação sobre o escoamento bifásico de óleo-água moderadamente viscoso é útil para indústrias de petróleo e petroquímica, para a elaboração de projetos de construção de rede de oleodutos, pois possibilita identificar os padrões de escoamento em tubulações.

Nas aplicações industriais, Ghanbarzadeh (Ghanbarzadeh et al., 2012) desenvolveram estudos utilizando lógica Fuzzy em reconhecimentos de imagens com o objetivo de implementação de modelos para aumento de performance de plantas industriais, além de melhorias em segurança operacional. Foram observados quatro regimes de escoamento bifásicos em ar-água: bubbles, slug, churn e anular. Foram implementadas técnicas de processamento de imagens com intuito de extrair informações de cada imagens. Essas informações incluem: o número de bolhas, ou objetos, a área, o perímetro, bem como a altura e largura desses objetos. Os resultados experimentais mostram que estes métodos obtiveram resultados promissores na identificação dos padrões de escoamento em um tubo vertical. 
$\mathrm{Na}$ área de petróleo, Ozbayoglu (Ozbayoglu et al, 2012) propõe uma condição de previsibilidade através de RNA (Redes Neurais Artificiais) com propagação reversa (Backpropagacion) para reconhecimento de líquido em fase de geometria anular e sua fluência em anel excêntrico horizontal em sistemas de circulação natural. Os resultados mostram que o modelo de rede neural com propagação reversa proporcionou melhores resultados que o modelo mecanicista, obtendo classificações com ordem de precisão de $90,38 \%$.

Os coeficientes máximos de reação podem ser obtidos para manter um regime de fluxo disperso-espumante para maximizar a área interfacial total. Assim, a capacidade de identificar regimes de fluxo automaticamente é muito importante, especialmente para manter os sistemas polifásicos operando de acordo com as condições de projeto. Nos reatores químicos gás-líquido, Barbosa (Barbosa, et al., 2010) avaliam a utilização de um mapa (rede neural) auto-organizável adaptado para o problema de identificação em regime de escoamento bifásico horizontal. Os resultados mostram que a rede neural é capaz de identificar corretamente os regimes.

E complementando temos, Schuabb (Schuabb, 2015) que utiliza RNA para a determinação eficiente da quantidade de bolhas de Taylor em uma tubulação. Desta forma seu trabalho pretende garantir que alterações de temperatura e pressão ocorram de modo otimizado, assim, protegendo de acidentes os sistemas que utilizem circuito de circulação natural. Para o cenário descrito em seu trabalho, o método utilizado se apresenta viável e propenso a ser utilizado em campo. As maiores incertezas são geralmente causadas em regiões próximas à fronteira de treinamento, sendo necessário o melhor detalhamento nessa região. Ele não recomenda o aumento do número de camadas, ou de neurônio em cada camada, na tentativa de melhorar o desempenho da rede, pois o ganho no resultado não é compensável ao tempo computacional gasto.

Os trabalhos que abordam os padrões de escoamento bifásico têm sido publicados ao longo dos últimos anos, demonstram o interesse da comunidade acadêmica na qualificação de novos métodos de reconhecimentos através de imagens, podendo ser utilizado qualquer tipo de sinal, conjuntamente com 
interatividade computacional. A principal ideia é a corroborar o desenvolvimento de uma ferramenta autônoma para classificação de padrões de escoamento bifásico capaz de produzir resultados mais precisos e confiáveis. 


\section{CAPÍTULO 3 - FUNDAMENTAÇÃO TEÓRICA}

\section{1 - Fenômeno de circulação natural}

Uma boa parte dos equipamentos utilizados em nosso cotidiano dissipa energia em forma de calor e em muitos casos esse calor é retirado naturalmente dos equipamentos, por um fenômeno físico que chamamos de convecção natural. A convecção natural de um fluido ocorre basicamente pela diferença de densidades entre uma camada de fluido mais quente que sobe e outra mais fria que desce. Quando houver recirculação do fluido, o processo passa a ser chamado de circulação natural. Esse gradiente de densidade é causado termicamente, como acontece nos circuitos do tipo estudado nesse trabalho; ou adiabaticamente, como acontece em reator de pesquisa, onde o núcleo é a fonte que cede calor ao fluido da parte inferior do tanque, e a coluna de fluido acima da chaminé é a fonte fria (Oliveira, A. F. da S., 2012). Nestes sistemas a circulação é estabelecida sem a utilização de qualquer equipamento. Apenas as leis da física fornecem o mecanismo necessário para a motivação do fluido.

Em um sistema de circulação natural conforme mostrado na Figura 3.1.1, a presença da fonte quente e fria causam uma diferença de densidade entre as pernas verticais do sistema e consequentemente uma diferença de pressão entre os pontos $Q_{e}$ e $Q_{s}$. Isto é o que mantêm a circulação do fluido, que poder ser aumentada pela variação de altura entre as fontes quente e fria, ou pela diferença de densidades entre as pernas do loop. Em outras palavras, a circulação natural é o regime de operação onde a força motriz do escoamento é a força de empuxo gerada pela diferença de densidades no fluido. 


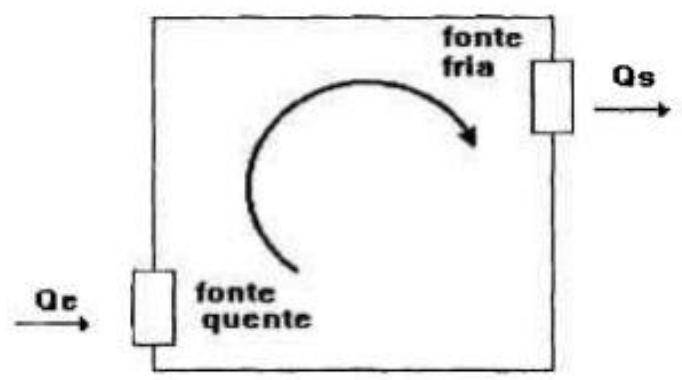

Figura 3.1.1: Esquema do circuito em regime de circulação natural

Em alguns reatores nucleares o fenômeno de circulação natural ocorre e contribui para a remoção de calor residual no caso de perda de alimentação das bombas do circuito primário e em operações à baixa potência.

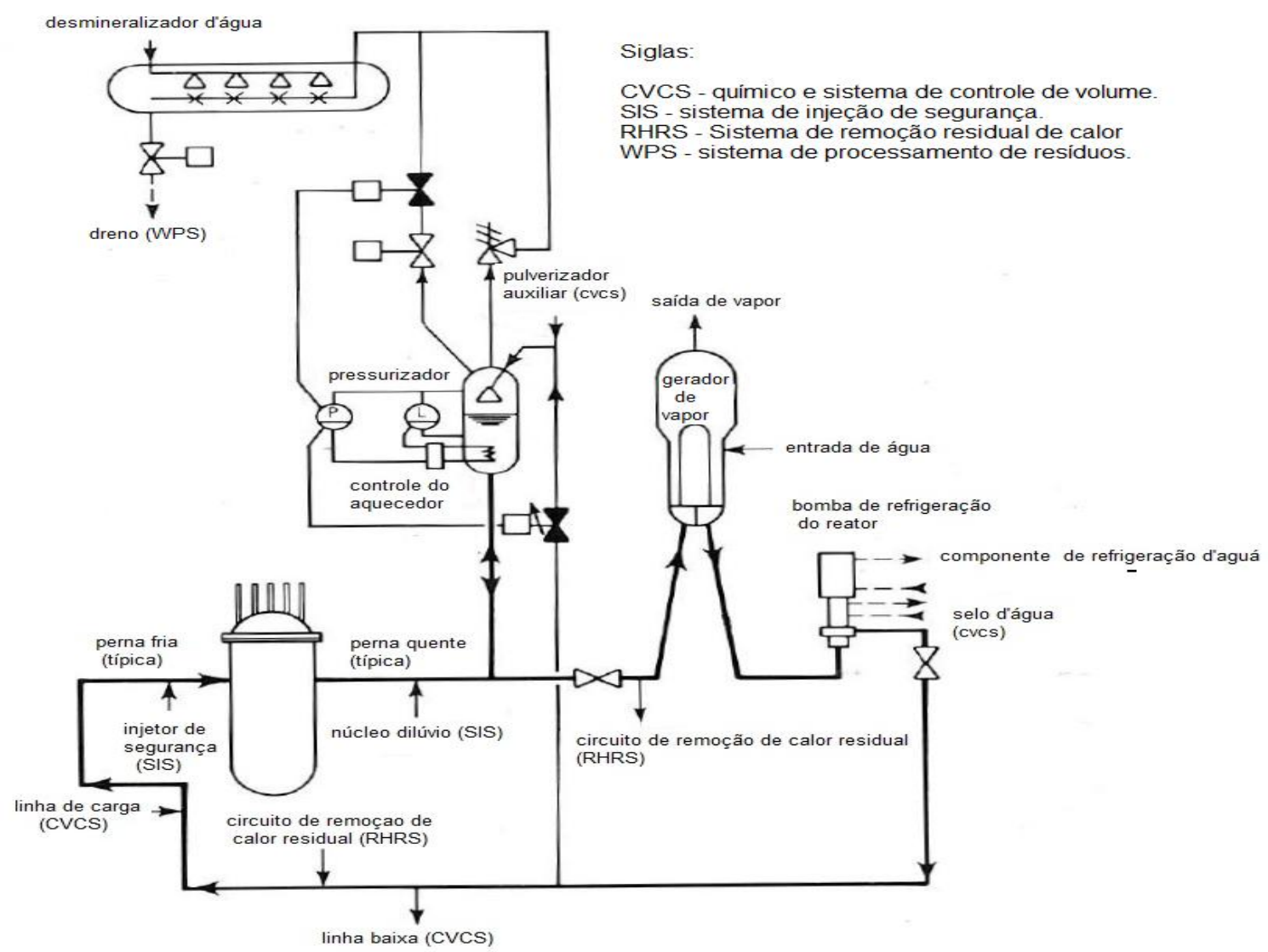

Figura 3.1.2: Diagrama de um sistema de arrefecimento de reator PWR (Masche, 1971). 
A Figura 3.1.2 mostra um sistema de resfriamento de reator tipo PWR onde o fenômeno ocorre e tem contribuição insuficiente para o resfriamento do núcleo.

Hoje em dia os circuitos de circulação natural são utilizados largamente nas indústrias químicas e de geração de energia. $\mathrm{Na}$ indústria nuclear os sistemas de circulação natural são adotados como mecanismos de retirada de calor residual do núcleo de PWR's e PHWR's sejam em caso de acidentes ou no processo de desligamento do reator.

Em reatores nucleares do tipo BWR (Boiling Water Reactors) ocorre à circulação forçada em regime bifásico, e atualmente estão sendo desenvolvidos reatores do tipo água fervente BWR que funcionam apenas com circulação natural. Alguns desses são o ESBWR (Economic Simplified Boiling Water Reactors) fabricado pela General Eletric, o AHWR (Advanced Heavy Water Reactors) projetado na Índia, e o VK-300 desenvolvido pela Rússia.

A utilização de sistemas de circulação natural na indústria nuclear apresenta-se muito vantajosa, pois proporciona uma redução no custo total da implantação, operação e manutenção da planta. Isso se deve ao número reduzido de bombas e sistemas secundários que estes projetos necessitam.

Quanto às características do escoamento, verifica-se que a vazão aumenta com a potência do sistema, ou seja, quanto maior for à potência, maior será a velocidade de escoamento, e consequentemente retirada de calor

Do ponto de vista da segurança, a aplicação de sistemas de circulação natural minimiza os riscos provenientes de falhas nos sistemas de bombeamento e sistemas auxiliares, visto que é um sistema baseado em leis físicas naturais.

\subsection{1 - O escoamento bifásico}

$\mathrm{Na}$ teoria de fluido contínuo, o movimento, assim como o comportamento geral do fluido, é governado pelas leis fundamentais da mecânica e termodinâmica. 
As leis da mecânica usadas são as leis de movimento de Newton, já que essas são geralmente aplicadas para uma partícula de matéria. A abordagem geral em mecânica dos fluidos destaca uma partícula fluida e aplica a lei de Newton a essa partícula, conforme apresentado por Bernardes (2003). As equações de movimento foram finalmente generalizadas por Navier em 1827 e independentemente por Stokes em 1845 (Schlichting e Gersten, 2003), para incluir forças de cisalhamento (consequentemente fricção). As equações de Navier-Stokes são restritas para fluidos Newtonianos, porém muitos fluidos, felizmente, satisfazem este tipo de relação muito bem. Contudo, apesar deles representarem precisamente o movimento de diversos fluidos, as equações são tão complexas que a exata solução só pode ser obtida em poucos casos. E ainda existem, a princípio, sérias objeções às equações de Navier-Stokes. A mais simples expressão para queda de pressão em um tubo, obtida da equação, indica que ela deveria variar em primeiro grau com a velocidade, mas experimentos mostram que apenas sob certas condições a lei de primeiro grau funciona, e sob outras, a resistência varia mais proximamente com o quadrado da velocidade. Essa situação permaneceu até Osborne Reynolds, em 1883, estabelecer por observação direta, que existem dois tipos de escoamento, um relativo a baixa velocidade, no qual as partículas deslizam suavemente ao longo de linhas sempre paralelas a parede, e onde a lei de resistência de primeiro grau é observada, e o segundo relativo a altas velocidades, no qual as partículas executam uma senóide e finalmente uma flutuação quase randômica do movimento sobre uma velocidade média. Os dois tipos de escoamentos do fluido são agora chamados laminar e turbulento, respectivamente.

O próximo avanço significativo veio em 1904 quando Prandtl reconheceu que um escoamento pode ser dividido em duas regiões, uma junta às camadas limites e outra envolvendo o restante do escoamento. Ele então propôs que na região perto da camada limite o efeito da viscosidade é mais importante, mas que a porção principal do fluido pode ser tratada como um fluido perfeito. Com esta abordagem pôde-se então tratar problemas que tinham sido constatados como extremamente complicados aplicando-se a equação de Navier-Stokes no campo de escoamento. 
Genericamente, o escoamento bifásico acontece quando há presença de dois fluidos diferentes ou quando o mesmo fluido apresenta estados diferentes (líquido $e$ vapor, gás e líquido, gás e sólido, líquido e sólido).

Reatores nucleares podem apresentar este escoamento no líquido refrigerante assim como diversos outros processos industriais que envolvam ebulição de líquidos e condensação de vapores.

Os regimes de escoamento bifásico definem diferentes padrões de escoamento que dependem de parâmetros da operação do sistema como: vazão, temperatura, pressão e outros, e dependem também das propriedades dos fluidos como massa, viscosidade, tensão superficial e outros. A geometria do sistema também tem influência importante na definição destes padrões, e normalmente são classificados dependendo das tubulações de escoamento serem horizontais ou verticais.

Os principais tipos de escoamentos bifásicos verticais gás-líquido podem ser classificados como: bolhas dispersas (bubble flow), pistonado (slug flow), aglomerados (churn flow) e anular (annular flow) (Figura 3.1.1.1).
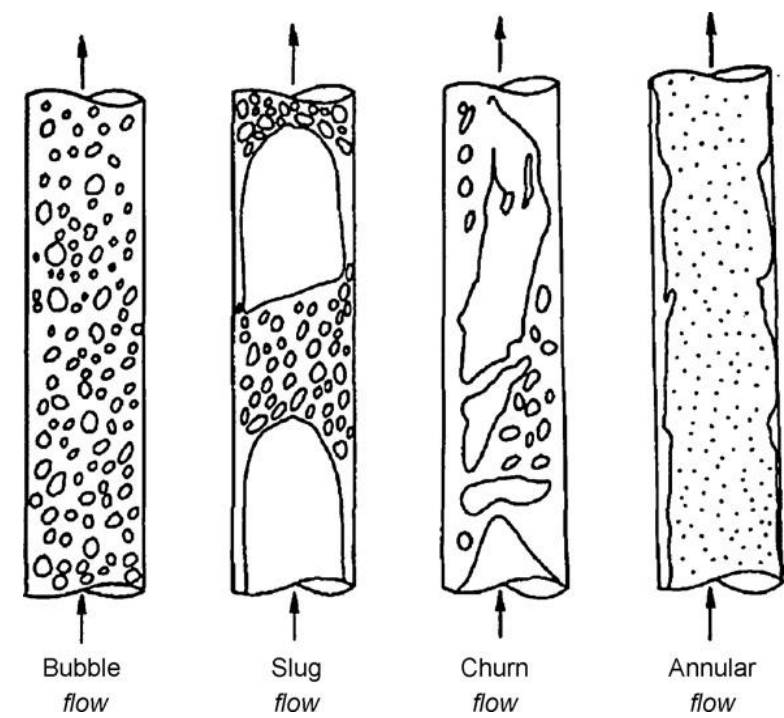

Figura 3.1.1.1 - Tipos de escoamento bifásico vertical: bolhas dispersas (bubble flow), pistonado (slug flow), aglomerados (churn flow) e anular (annular flow) (Taitel et. al., 1980). 
Quando a vazão líquida aumenta são obtidos os seguintes padrões de escoamento:

1 - Escoamento anular, "annular flow", no qual o líquido se desloca parcialmente como um filme anular na parede do tubo, e uma parte se desloca em pequenas gotas distribuídas no gás.

2 - Escoamento pistonado, "slug flow", no qual há bolhas que se movem uniformemente no sentido ascendente e são, às vezes, denominadas "bolhas de Taylor". Bolhas de Taylor são separadas por pistões contínuos de fase líquida, que percorrem toda a extensão do tubo e contêm pequenas bolhas de gás dispersas. Entre a Bolha de Taylor e a parede interna do tubo, existe um filme delgado de fase líquida que escoa em sentido descendente.

3 - Escoamento de bolhas dispersas, "bubble flow", no qual as bolhas de gás são de tamanho aproximadamente uniforme, e fluem na direção do escoamento.

4 - Escoamento em aglomerados, "churn flow", no qual ocorre um conjunto de bolhas de diferentes formas em movimento turbulento com coalescência formando bolhas distorcidas de comportamento aleatório.

Nos padrões de escoamentos verticais estudados neste trabalho estes vários padrões são observados.

\subsubsection{Tipos de instabilidades de escoamento bifásicos na Circulação Natural}

As características comportamentais das instabilidades de escoamentos bifásicos dependem de fatores, tais como: geometria do sistema, condições iniciais e de operação, entre outros. Devido à diversidade de tipos de instabilidades, diferentes critérios de classificação são utilizados. J. M. Delhaye (Delhaye, J M, Giot, M, Riethmuller, M L, 1981) classifica as instabilidades de escoamentos bifásicos em dois grandes grupos: instabilidades microscópicas e macroscópicas. As primeiras se localizam na interface líquido-gás e, a segunda envolve o escoamento bifásico como um todo.

As instabilidades macroscópicas podem ser divididas segundo o caráter dinâmico ou estático utilizados para descrevê-las. Dentro das instabilidades estáticas 
encontram-se as de excursão de escoamento (instabilidade de Ledinegg) e as instabilidades de relaxação (transição devido à mudança de regime de escoamento, "bumping", "chugging" e "geysering").

As instabilidades dinâmicas são divididas em: oscilações de ondas de densidade, oscilações da queda de pressão e oscilações acústicas. "Chugging" ou "geysering", chamadas também de oscilações de expulsão periódica, são instabilidades caracterizadas pela expulsão periódica de refrigerante do canal. O comportamento transitório resultante pode conduzir à expulsão violenta da mistura para fora do canal em uma ou ambas as extremidades. "Chugging" refere-se ao caso onde se produz o fenômeno de expulsão periódica numa situação de escoamento, enquanto "geysering" corresponde à situação onde não existe um escoamento contínuo. "Chugging" e "geysering" apresentam-se como um ciclo com três etapas: incubação, expulsão do refrigerante e reenchimento do canal.

Quando ocorre uma variação de densidade, segundo Delhaye, as instabilidades mais comuns em sistemas bifásicos ocorrem devido à defasagem de tempo entre a ocorrência de uma perturbação e sua consequência sobre a perda de pressão total do sistema considerado. O período destas oscilações é da mesma ordem de grandeza do tempo de trânsito do fluido no sistema.

L. S. Tong (Tong, 1997) classifica as instabilidades de escoamento bifásico como instabilidades periódicas estacionárias e instabilidades aperiódicas. As primeiras apresentam um comportamento cíclico que começa com uma etapa de aumento da fração de vazios produzindo um aumento da queda de pressão. Quando as condições de escoamento estão próximas da transição entre ebulição nucleada e escoamento anular, um aumento temporário da quantidade de bolhas pode mudar a configuração do escoamento e como consequência provocar uma redução da perda de pressão. Esta redução da perda de pressão, por sua vez, produzirá um aumento da vazão e o ciclo se repetirá. As instabilidades aperiódicas são equivalentes às instabilidades de Ledinegg.

As denominações das fases de instabilidades baseiam-se na classificação Boure clássica (Bouré et al., 1973). A criação de uma SOM terá como finalidade o 
mapeamento dos padrões de imagens associadas a estas instabilidades para sistematização dos tipos de escoamento.

A Figura 3.1.3 ilustra alguns padrões de instabilidades observadas no circuito de circulação natural.

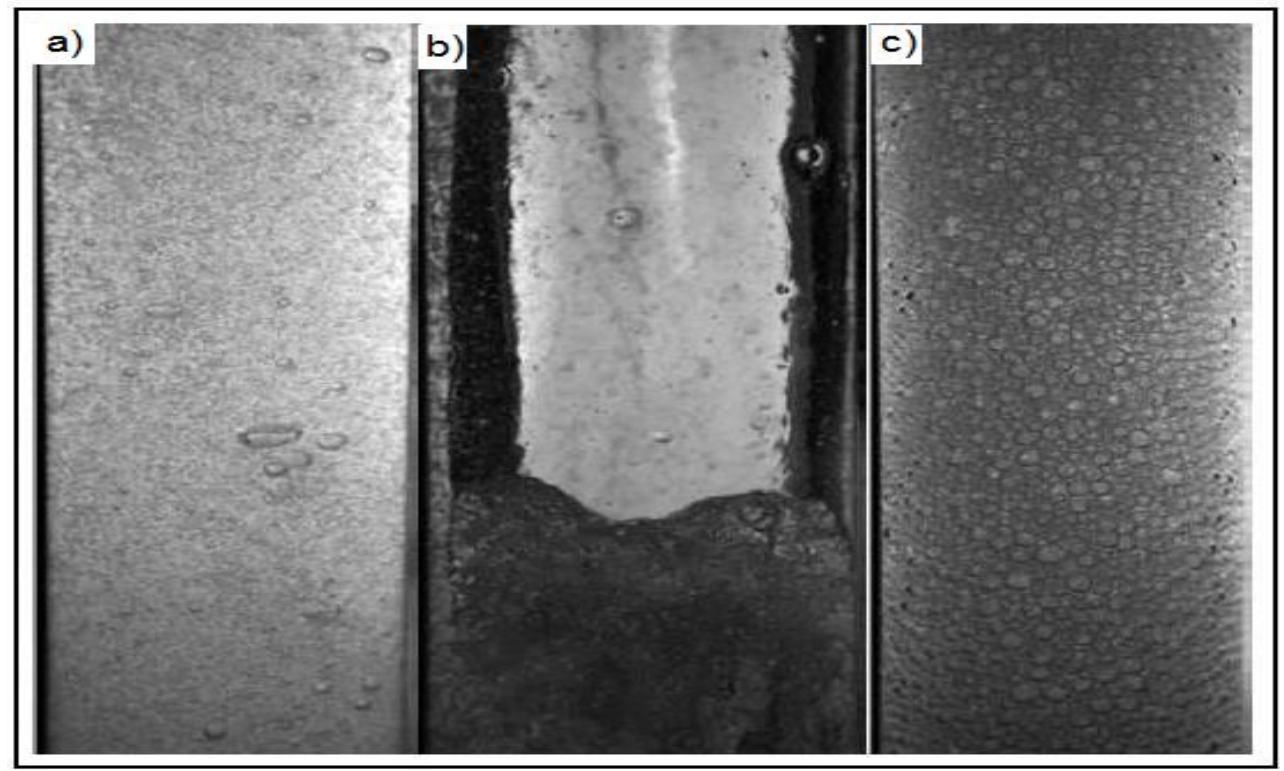

Figura 3.1.3: Imagens adquiridas no CCN, das instabilidades características: a) incubação (I), b) expulsão (E) e c) reenchimento (R)

\section{2 - Redes Neurais Artificiais}

O desenvolvimento dos estudos na área de neurofisiologia no último século estimulou os cientistas de diversas áreas na compreensão dos processos da mente humana e até mesmo, a mimetizá-los no formato de algoritmos. Nestes estudos foram desenvolvidas versões do neurônio biológico que serviram como base de desenvolvimento de diversas técnicas conhecidas como redes neurais artificiais.

A rede neural artificial $(R N A)$ é um sistema computacional constituído, por um conjunto de unidades de processamento individuais (chamadas de neurônio artificial) interconectados entre si com pesos que podem ser modificados de acordo com os parâmetros de qualidade que avaliam a proximidade entre a resposta desejada e a obtida. 
O neurônio artificial possui entradas semelhantes aos dendritos do neurônio biológico, captando as informações provenientes do meio externo Figura 3.2.1, e saídas resultantes semelhantes ao axônio.

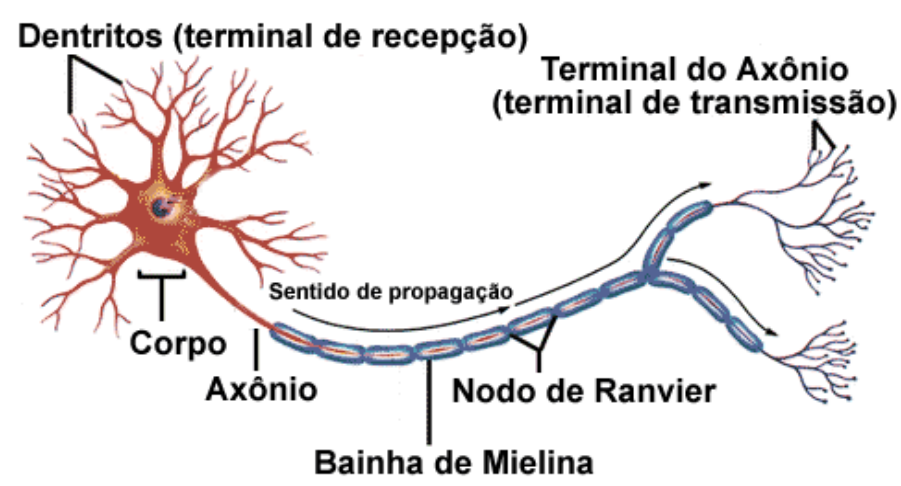

Figura 3.2.1: Modelo do neurônio biológico (Bueno, 2006)

A função interna também se assemelha à soma do neurônio biológico, desempenhando a função de transformar a informação de entrada em uma nova informação.

A RNA tem a capacidade de aprender à medida que os pesos das interconexões entre os neurônios são ajustados conforme a saída desejada. Assim, uma RNA pode ser utilizada na simulação e obtenção de tarefas complexas relacionadas a controle, reconhecimento de padrões e outras tarefas associadas às habilidades humanas normalmente descritas como inteligência.

\subsection{1 - Histórico sintetizado de RNA}

Um dos primeiros modelos de redes neurais foi o proposto por Warren $\mathrm{S}$. McCulloch e Walter H. Pitts em 1943 (McCulloch e Pitts, 1943). Este modelo é constituído por um dispositivo com uma saída binária e entradas com ganhos arbitrários, podendo ser excitatórios ou inibitórios. Na Figura 3.2.1.1, é mostrado um esquema de um neurônio artificial típico. 


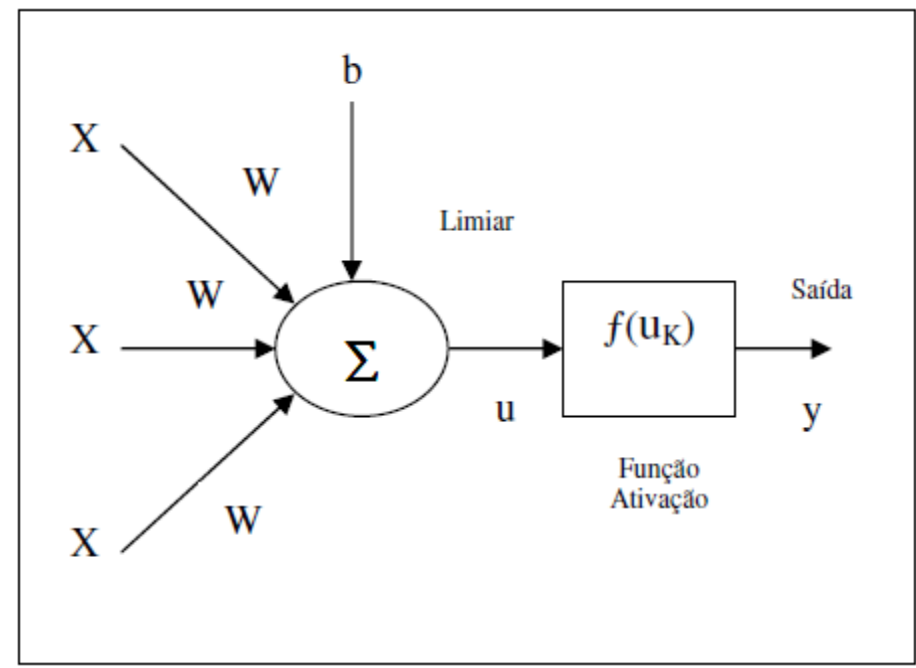

Figura 3.2.1.1: Modelo de neurônio artificial (Bueno, 2006)

Onde: $X_{1}, X_{3}, \ldots, X_{n}$ sinais de entrada.

$W_{K}$ pesos sinápticos de neurônio $K$.

$u_{K}$ integrador linear de saída devido aos sinais de entrada.

$b$ bias e y sinal de saída do neurônio.

O neurônio $K$ pode ser representado pelas equações 1 e 2 .

$$
\begin{array}{r}
u_{K}=\sum_{j=1}^{p} W_{K j} X_{j}+b_{K} \\
y_{K}=\varphi\left(u_{K}\right)
\end{array}
$$

Onde $X_{1}, X_{3}, \ldots, X_{n}$ são os sinais de entrada, $W_{K 1}, W_{K 2}, \ldots, W_{K n}$ são os pesos sinápticos de neurônio $K, u_{K}$ é o integrador linear de saída devido aos sinais de entrada, $b_{K}$ é o bias, $\varphi\left(u_{K}\right)$ é a função de ativação, $y_{K}$ é o sinal de saída do neurônio. O bias tem a função de acrescentar uma tendência à saída $u_{K}$ do combinador linear do neurônio. 
No final da década de 1950, o projeto do Perceptron foi desenvolvido por Frank Rosenblatt (Rosenblatt, 1958) na Universidade de Cornell, a partir dos estudos de McCulloch. Utilizando a proposta do algoritmo de treinamento da rede baseado no estudo do biólogo Donald Hebb de 1949 (Hebb, 1949), que usava o ajuste gradual dos pesos de um discriminador linear. Este projeto utilizava neurônios com pesos ajustáveis para a classificação de padrões linearmente separáveis, inicialmente com 400 células fotoelétricas, e uma arquitetura que consistia de uma camada de neurônios de entrada. A rede era treinada para fornecer saídas de acordo com os dados do conjunto de treinamento, para padrões vetoriais linearmente separáveis. Esquematicamente o perceptron de uma única camada pode ser representado conforme a Figura 3.2.1.2.

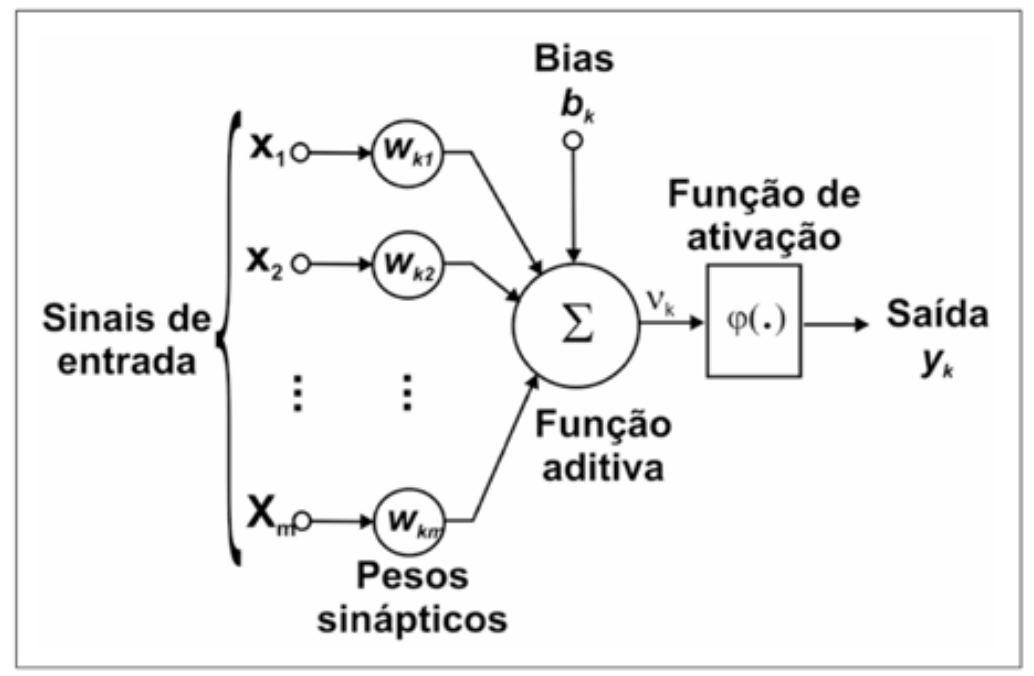

Figura 3.2.1.2: Rede Perceptron de Rosenblatt (Bueno, 2006)

Em 1960 Bernard Widrow e Ted Hoff (Widrow e Hoff, 1960), desenvolveram um modelo neural linear chamado Adaline (Adaptive Linear Element) ou elemento linear adaptativo, e em 1962 a composição de uma rede com múltiplos elementos adaptativos, Madaline (Multiple - Adaline) é constituída. Eles também desenvolveram um algoritmo de aprendizado baseado no conceito de minimização do desvio quadrático médio (Least Mean Square Algorithm - LMS), também conhecido como regra delta ou método do gradiente decrescente para a minimização do erro. 
Em 1969, Minsky e Papert (Minsky e Papert, 1969) publicam o livro intitulado Perceptrons no qual há a restrição a problemas elementares como o ou - Exclusivo e o seu complemento, limitando o teorema desenvolvido por Rosenblatt a classe de problemas linearmente separáveis. No modelo da Figura 3.2.1.3 há exemplos ilustram as classes de limitação citadas.

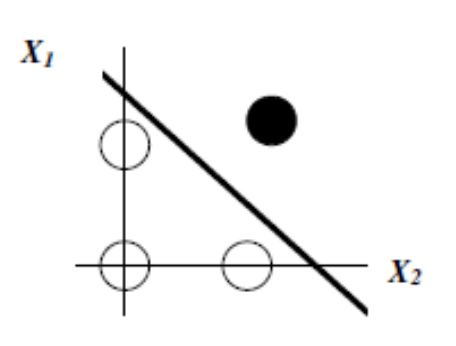

Solução

$X_{1}$

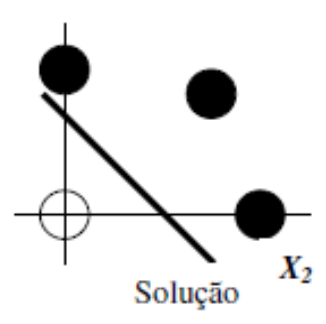

$X_{1}$

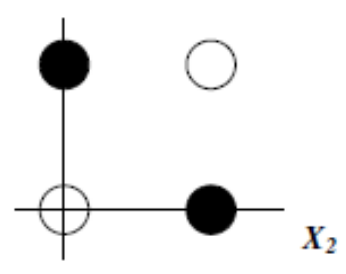

Sem solução

Figura 3.2.1.3: Exemplos de classes linearmente separáveis e inseparáveis de algoritmo discriminante (Filho, 1998).

No decorrer da década de 70 e início dos anos 80 houve diminuição na pesquisa e produção científica sobre redes neurais, entretanto apesar de pouca atividade de pesquisas, neste período alguns trabalhos tiveram um considerável destaque. Para citar, os estudos apresentados por Stephen Grossberg (Grossberg, 2009), que baseado em trabalhos sobre o aprendizado competitivo em 1987 junto com Gail Carpenter, estabeleceram os princípios para uma nova classe de redes neurais denominadas de ART (Adaptive Ressonance Theory).

Antes do modelo proposto por Stephen Grossberg (Grossberg, 2009) haviam publicações de modelos como o proposto por James Anderson (Anderson et al., 1990) baseados em modelos biológicos da memória e de reconhecimento em 1968.

Em 1982 J.J. Hopfield (Hopfield, 1982) utilizou a ideia de uma função de energia para um novo modo de funcionamento das redes recorrentes com conexões sinápticas simétricas, onde os elementos são ligados buscando o aprendizado com "um mínimo de energia", tendo como dados de origem as Redes de Hopfield. No mesmo período, Teuvo Kohonen (Kohonen, 1981) desenvolve o conceito das "redes auto-organizáveis" na qual utiliza algoritmos competitivos. 
Com o desenvolvimento de modelos de memórias associativas, utilizando o conceito de aprendizado competitivo, nos quais as unidades competem para responder a determinada entrada e o elemento vencedor tem os pesos de sua entrada modificados, convergindo para responder com mais força a valores próximos do desejado.

Somente em 1986 houve reinício, das atividades de desenvolvimento das redes neurais artificiais, com o desenvolvimento do algoritmo de retropropagação (backpropagation) por Rumelhart, Hinton e Williams (Rumelhart, et al, 1986), embora este algoritmo já tivesse sido proposto anteriormente em 1974 por Werbos (Werbos, 1974), em sua tese de doutorado, por Parker e LeCun em 1985 (Lecun, 1985). Com a publicação do livro intitulado "Parallel Distributed Processing Explorations in the Microstructures of Cognition", editado por Rumelhart e McClelland, o qual apresentava o progresso das redes neurais ressurgiu o grande interesse pela técnica.

\subsection{2 - Perceptron de Multicamadas}

O Perceptron de Multicamadas (Multilayer Perceptron - MLP) é uma sofisticação do modelo original do Perceptron com a ampliação do número de camadas interconectadas, e ampliou o espectro de problemas de classificação que podem ser resolvidas pela rede.

Um MLP pode ser definido como uma rede interconectada (conexões sinápticas) de neurônios dispostos em neurônios de entrada (receptores do meio externo), neurônios das camadas internas ou unidades de processamento ocultas (camadas ocultas) e neurônios de saída.

$\mathrm{Na}$ camada de neurônios de entrada, os vetores (dados) são recebidos e armazenados, dependendo da arquitetura da rede. Na camada mais interna entre a camada de neurônios de entrada e de saída pode haver uma ou mais camadas intermediárias, chamadas de camadas ocultas. A camada de saída tem a função de 
armazenar as respostas obtidas pela rede. O número de neurônios nessa camada corresponde ao tamanho do vetor de saída. (Bueno, 2006). Na Figura 3.2.2.1 é apresentada uma ilustração de um exemplo de arquitetura de rede MLP.

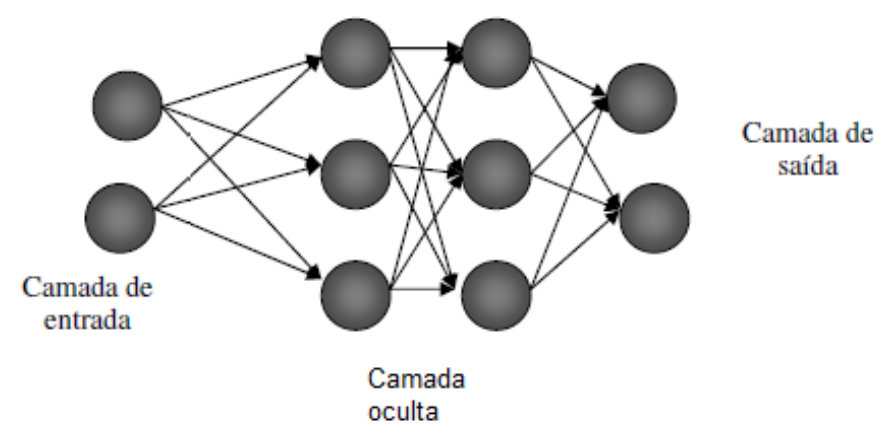

Figura 3.2.2.1: Rede Multilayer Perceptron - MLP (Bueno, 2006)

\subsection{3 - Algoritmo de aprendizado e treinamento}

Conceitualmente, a aprendizagem da rede neural pode ser definida como um processo adaptativo mediante a resposta aos estímulos externos à rede apresentados durante a fase de treinamento. Quando as respostas desejadas aos dados de entrada são conhecidas, o processo de aprendizagem é chamado de supervisionado, pois são apresentadas à rede simultaneamente as entradas e as saídas desejadas para que ela se autoconfigure através da atualização de seus pesos. Esta atualização é feita principalmente por um algoritmo chamado de retropropagação (back-propagation) que propaga para toda a rede o erro medido entre a resposta obtida e a resposta desejada (meta) da rede em questão. Devido à variedade de algoritmos existentes para o treinamento de redes, são citados alguns dos algoritmos mais comuns encontrados na literatura em uma breve apresentação dos algoritmos de aprendizagem há a definição de classes conforme o emprego de cada regra.

\subsection{4 - Métodos de aprendizado competitivo}

Baseado em Fritzke (Fritzke, 1997) alguns dos métodos de aprendizado competitivo serão descritos brevemente com o objetivo de situar o método de 
Kohonen dentro da perspectiva do desenvolvimento destes algoritmos. Esta perspectiva não segue uma linha evolutiva histórica, e sim um conjunto de propriedades comuns que caracterizam estes métodos. Estas redes, $\lambda$ são compostas de $N$ unidades, $\lambda=\left\{c_{1}, c_{2}, \ldots, c_{n}\right\}$, onde cada unidade tem um vetor de referência, $w_{c} \in R^{n}$, indicando sua posição, ou centro de campo receptivo, no espaço de entrada. Entre as unidades da rede existe um conjunto, que pode ser vazio, $C \subset \lambda \times \lambda$, de conexões de vizinhança que são simétricas e sem peso. Para uma unidade $C$ define-se o conjunto $N_{c}$ dos vizinhos topológicos diretos. Os sinais de entrada $\mathrm{n}$-dimensionais são considerados como sendo gerados ou por uma função de distribuição de probabilidade $p(\xi), \xi \in R^{n}$, ou a partir de um conjunto de dados de treinamento, $D=\left\{\xi_{1}, \xi_{2}, \ldots, \xi_{M}\right\}, \xi_{i} \in R^{n}$. Para um dado sinal de entrada, o vencedor $s(\xi)$ entre as unidades de $\lambda$ é a unidade com o vetor de referência mais próximo definido pela relação, equação 3 :

$$
s(\xi)=\arg \min _{c \in A}\left\|\xi-w_{c}\right\|
$$

onde $\|$.$\| define o vetor-norma Euclidiano.$

Um conceito de geometria computacional importante nesta descrição é a chamada região de Voronoi. Dado um conjunto de vetores, $w_{1}, w_{2}, \ldots, w_{n} \in R^{n}$, a região de Voronoi, $V_{i}$ de um vetor particular, $w_{i}$, é definida como o conjunto de pontos $R^{n}$ para o qual o vetor $w_{i}$ é o vetor mais próximo, equação 4 :

$$
V_{i}=\left\{\xi \in R^{n} / i=\arg \min _{j \in\{1, \ldots, N\}}\left\|\xi-w_{j}\right\|\right\}
$$

A partir da suposição de que cada região de Voronoi, Vi, é uma área convexa, define-se a Tecedura de Voronoi ou Tecedura de Dirichlet como a partição de $R^{n}$ formada por todos os polígonos de Voronoi. Este conceito é aplicável a dimensões arbitrariamente superiores (Bueno, 2006). 
Outra definição consequente é a Triangulação de Delaunay, que é definida pela conexão de todos os pontos para os quais as regiões de Voronoi compartilham uma borda, Figura 3.2.4.1. Esta triangulação tem propriedades especiais, pois é a única triangulação na qual os círculos circunscritos de cada triângulo não contêm outro ponto além dos vértices do triângulo. Omohundro (Omohundro, 1990) demonstrou que esta triangulação é ótima para a interpolação de funções. O método de aprendizado Hebbiano gera um subgrafo da triangulação de Delaunay que é limitada àquelas áreas do espaço de entrada onde se encontram os dados (Fritzke, 1997).

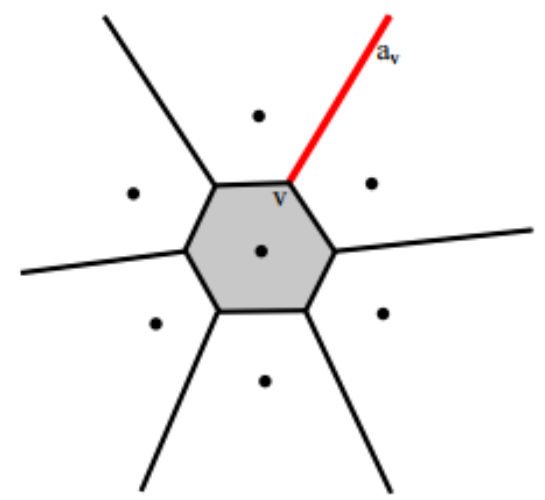

(a)

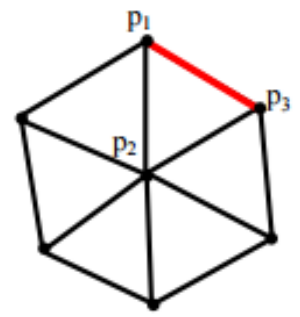

(b)

Figura 3.2.4.1: Ilustração de dualidade entre (a) diagrama de Voronoi e (b) triangulação de Delaunay (Bueno, 2006)

Ainda segundo Fritzke, os métodos de aprendizado competitivo podem ser divididos em "brutos" e "suaves". Os métodos "brutos" seriam caracterizados pela atualização de apenas uma unidade (a vencedora) para cada sinal de entrada. Os métodos "suaves" atualizariam mais de uma unidade para cada sinal de entrada. Outra característica que divide estes métodos é a dimensionalidade fixa ou não da rede. O mapa Auto-organizável de Kohonen se insere nesta última categoria.

Os principais objetivos destes algoritmos são a minimização do erro, a maximização da entropia e o mapeamento de características. Algumas variações quanto ao método de atualização deram origem a um dos algoritmos mais importantes deste tipo, chamado Aprendizado Generalizado de Lloyd (Linde et al., 
1980; Forgy, 1965; Lloyd, 1957), que utiliza o treinamento em lote. Este método funciona movendo todos os vetores de referência para a média aritmética de seus conjuntos de Voronoi.

Em situações em que o conjunto de dados, $D$, é muito grande, o método de atualização em lote se torna pouco prático. Neste caso a atualização dos vetores é feita apenas para a unidade "vencedora" utilizando um taxa de atualização, $\lambda$. Se esta taxa é constante e está entre 0 e 1 , o valor de cada vetor $w_{c}$ representa uma média que decai exponencialmente, daqueles sinais de entrada para os quais $c$ foi a "vencedora". Este sistema se mantém adaptativo e é, em princípio, apto a funcionar sobre uma distribuição de sinais não estacionária $p(\xi)$. No entanto, esta taxa de atualização constante implica em problemas quanto à convergência (Fritzke, 1997).

Outro método que não mantém esta taxa de atualização constante é o conhecido "k-means" (MacQueen, 1967), no qual a taxa de aprendizado é individual para cada vetor de referência. Esta taxa é dada por $\lambda=1 / t$, onde o parâmetro $t$ é o número de sinais para os quais esta unidade em particular foi à vencedora até então.

Neste caso, cada vetor de referência é sempre exatamente a média aritmética dos vetores de entrada para os quais $C$ foi o "vencedor". Portanto apesar de $w_{c}(t)$ representar a média aritmética dos sinais de entrada, equação abaixo, equação 5 , alguns destes podem estar em regiões de Vorohoi pertencentes a outras unidades de referência. A razão para isto é que cada adaptação de $w_{c}$ muda as bordas da região de Voronoi $V_{c}$.

$$
w_{c}(t)=w_{c}(t-1)+\lambda(t)\left(\xi_{t}^{c}-w_{c}(t-1)\right)=\frac{\xi_{1}^{c}+\xi_{2}^{c}+\ldots+\xi_{t}^{c}}{t}
$$

Este algoritmo teria um problema na convergência já que a série harmônica infinita de $1 / t$ diverge. No entanto, foi demonstrado que este algoritmo converge 
assintoticamente para uma configuração onde cada vetor de referência $w_{c}$ é posicionado de forma que coincida com o valor esperado $(E)$ de sua região de Voronoi $V_{c}$ (MacQueen, 1967), ou seja, equação 6:

$$
E(\xi / \xi) \in V_{c}=\int \xi p(\xi) d \xi
$$

Outro tipo de taxa de decaimento do aprendizado foi proposto por Ritter (Ritter, 1991) para mapas auto-organizáveis. Eles propuseram uma taxa de decaimento descrita por:

$$
\lambda(t)=\lambda_{i}\left(\lambda_{f} / \lambda_{i}\right)^{t / t_{\max }}
$$

onde $\lambda_{i}$ e $\lambda_{f}$ são os valores inicial e final da taxa de aprendizado, enquanto $t_{\max }$ é o número máximo de passos de adaptação adotado com as distâncias aos vetores de referência. Algumas unidades da rede são atualizadas de acordo com 0 ordenamento obtido.

Outro método "suave" é o chamado Aprendizado Competitivo "Hebbiano" (Martinez e Schulten, 1991; Martinez e Schulten, 1994). Normalmente este método é utilizado em conjunto com outros. Neste método não há mudança nos vetores de referência, o que poderia ser interpretado como uma taxa de aprendizado igual a zero. As mudanças acontecem nas bordas de vizinhança geradas entre as unidades da rede. Martinez e Schulten (1994) provaram que o grafo gerado por este algoritmo preserva a topologia num sentido geral, onde cada borda pertence à triangulação de Delaunay correspondente a um dado conjunto de vetores de referência.

Uma justaposição entre os dois métodos anteriores é chamada de Redes de Representação Topológica. Neste algoritmo, cada passo de adaptação gera uma conexão entre a unidade "vencedora" e segunda unidade mais próxima (aprendizado "Hebbiano"). Os vetores de referência são atualizados sendo utilizado um mecanismo para remover as bordas não mais válidas. 
Uma mudança neste algoritmo que altera o número de unidades do mapa durante o processo de auto-organização é proposta por Fritzke (1994). Este método alia o mecanismo de crescimento de células ("growing cell structures") com a geração de topologias de aprendizado "Hebbiano" de Martinez e Schulten (1994). Para determinar onde inserir as novas unidades, medidas de erro local são utilizadas durante o processo de adaptação, e a inserção é feita próxima à unidade com maior acúmulo de erro.

Outros métodos sem uma dimensionalidade de rede fixa são conhecidos, como o proposto por DeSieno (1988), onde "vencedores" frequentes ganham uma "consciência pesada" por ganhar tanto, e, portanto, adiciona um termo de penalidade à distância ao sinal de entrada. Isto leva eventualmente, a uma situação onde cada unidade ganha aproximadamente com a mesma frequência (maximização da entropia).

Os métodos "suaves" com dimensionalidade fixa determinam previamente a dimensão $k$ da rede a ser treinada. Uma das vantagens da rede de dimensão fixa é que ela define um mapeamento a partir do espaço de entrada $\mathrm{n}$-dimensional (com $\mathrm{n}$ sendo arbitrariamente grande) para o espaço k-dimensional. Isto torna possível obter uma representação de baixa dimensionalidade dos dados que pode ser utilizada para propósitos de visualização.

Dentro do universo de algoritmos competitivos o mapa auto-organizável de Kohonen é o mais conhecido e aplicado. Ele apresenta dimensionalidade fixa e é "suave" (atualiza mais de uma unidade do mapa por iteração). A topologia é restrita a uma grade bidimensional que não muda durante a auto-organização. A distância nesta grade é utilizada para determinar o quão fortemente a unidade é atualizada quando uma unidade próxima é a "vencedora". A medida de distância utilizada originalmente foi a chamada norma Li (também conhecida como distância de Manhattan), dada pela seguinte expressão:

$$
d_{L_{1}}=|x-u|+|y-v|
$$


onde $(x, y)$ e $(u, v)$ são pontos em um plano de duas dimensões. No entanto, outras distâncias também podem ser utilizadas como a distância $L_{2}$, ou distância Euclidiana simples.

\subsection{5 - Mapas auto-organizáveis - SOM}

Segundo da Silva (da Silva, 2008), Mapa Auto Organizável de Kohonen é uma RNA com duas camadas (Kohonen, 2001): a camada de entrada $I$ e a de saída $U$. A entrada da rede corresponde a um vetor no espaço d-dimensional em $\mathfrak{R}^{d}$, representado por $x_{k}=\left[\xi_{1}, \ldots, \xi_{d}\right]^{T}, k=1, \ldots, n$, sendo $n$ número de vetores de entrada. Cada neurônio $j$ da camada de saída possui um vetor de código $w$, também no espaço $\mathfrak{R}^{d}$, associado ao vetor de entrada $x_{k}, W_{j}=\left[w_{j 1}, \ldots, w_{j d}\right]^{T}$.

Os neurônios da camada de saída estão interconectados por uma relação de vizinhança que descreve a estrutura do mapa. Por exemplo, na Figura 3.2.5.1 tem-se um mapa com a camada de saída $U$, bidimensional, retangular, de dimensões $N \times M$. Nesta figura somente estão representados os vetores de código $w$, conectados ao neurônio $j$.

O SOM foi idealizado a partir da analogia com a região do córtex cerebral humano. Descobriu-se que esta parte do cérebro aloca regiões específicas para atividades específicas e que, para uma determinada ativação cerebral, o grau de ativação dos neurônios diminuía à medida que se aumentava a distância da região de ativação inicial (Kohonen, 2001). 


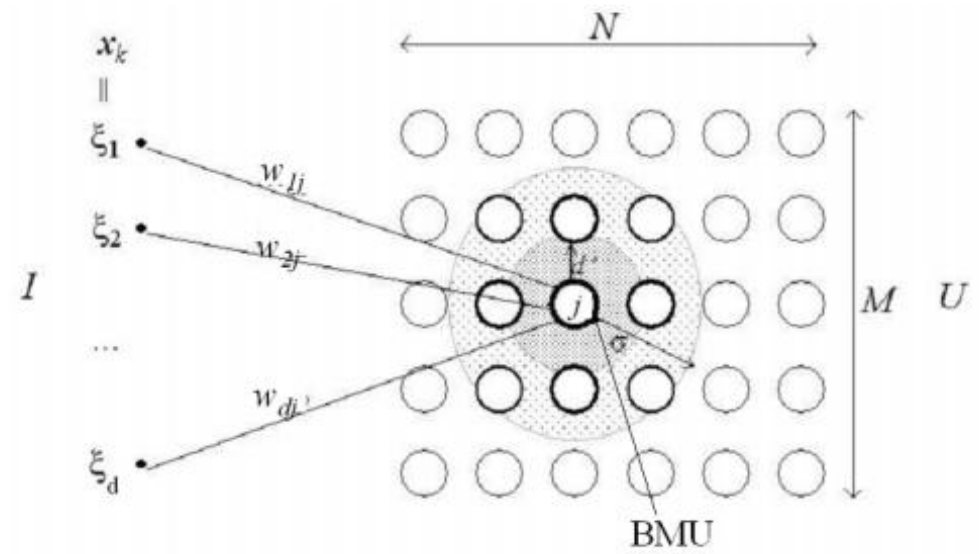

Figura 3.2.5.1: Mapa auto-organizável bidimensional $N \times M$, com entradas $x_{k}$ (Filho, 1998)

Existem diferentes topologias para estruturação de um Mapa Auto Organizável, sendo que a estrutura mais comum é a de duas dimensões. Na Figura 3.2.5.2 vê-se uma rede SOM unidimensional (a), uma rede bidimensional com organização hexagonal dos neurônios, com 6 vizinhos (b) e uma rede bidimensional com disposição retangular dos neurônios, com 4 vizinhos (c).

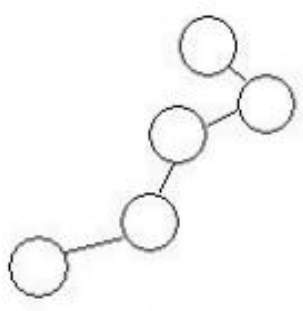

(a)

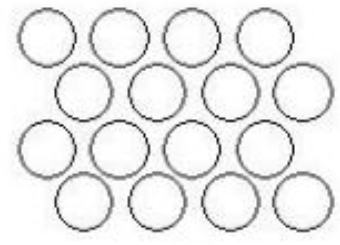

(b)

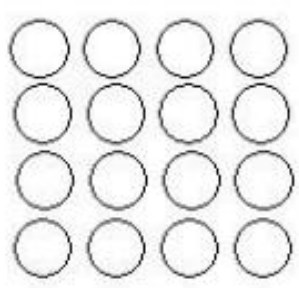

(c)

Figura 3.2.5.2 - Estruturações topológicas de Mapas Auto Organizáveis; a) unidimensional, b) bidimensional hexagonal e c) bidimensional retangular.

Desde o seu surgimento, em 1982, o SOM vem sendo aplicado numa ampla variedade de problemas de engenharia, medicina etc. Destacam-se as potencialidades de visualização de dados multivariados, análise de agrupamentos, mineração de dados, descoberta de conhecimento e compressão de dados. 


\subsubsection{1 - Descrição do algoritmo}

Segundo Mesquita (Mesquita, 2002) o funcionamento do algoritmo utilizado corresponde ao treinamento "em lote" disponível em um "toolbox" implementado na plataforma Matlab (SOM Toolbox team, 2012). Algumas tentativas foram feitas utilizando o treinamento sequencial, mas o algoritmo de lote demonstrou ser mais rápido, mostrando resultados melhores de classificação e com tempo de execução computacional menor.

O algoritmo para a simulação da SOM deste toolbox é resumidamente descrito a seguir: a partir do mapa hexagonal e da matriz da suas coordenadas constrói-se uma matriz das distâncias $U_{D}$, que é simétrica - Figura 3.2.5.1.2 - e representa as distâncias quadradas entre as unidades do mapa. A diagonal dessa matriz é igual a zero considerando que representa a distância de cada célula a ela mesma. As segundas diagonais apresentam valores unitários que representam a distância entre os primeiros vizinhos.

A partir de $U_{D}$ gera-se a matriz de vizinhança de ativação $(H)$ que corresponde à atenuação de $U_{D}$ em função do raio de atualização onde:

$$
H=e^{-U_{d} / 2 r(t)}
$$

onde a variável raio $(r)$ assume valores decrescentes à medida que o treinamento evolui. 


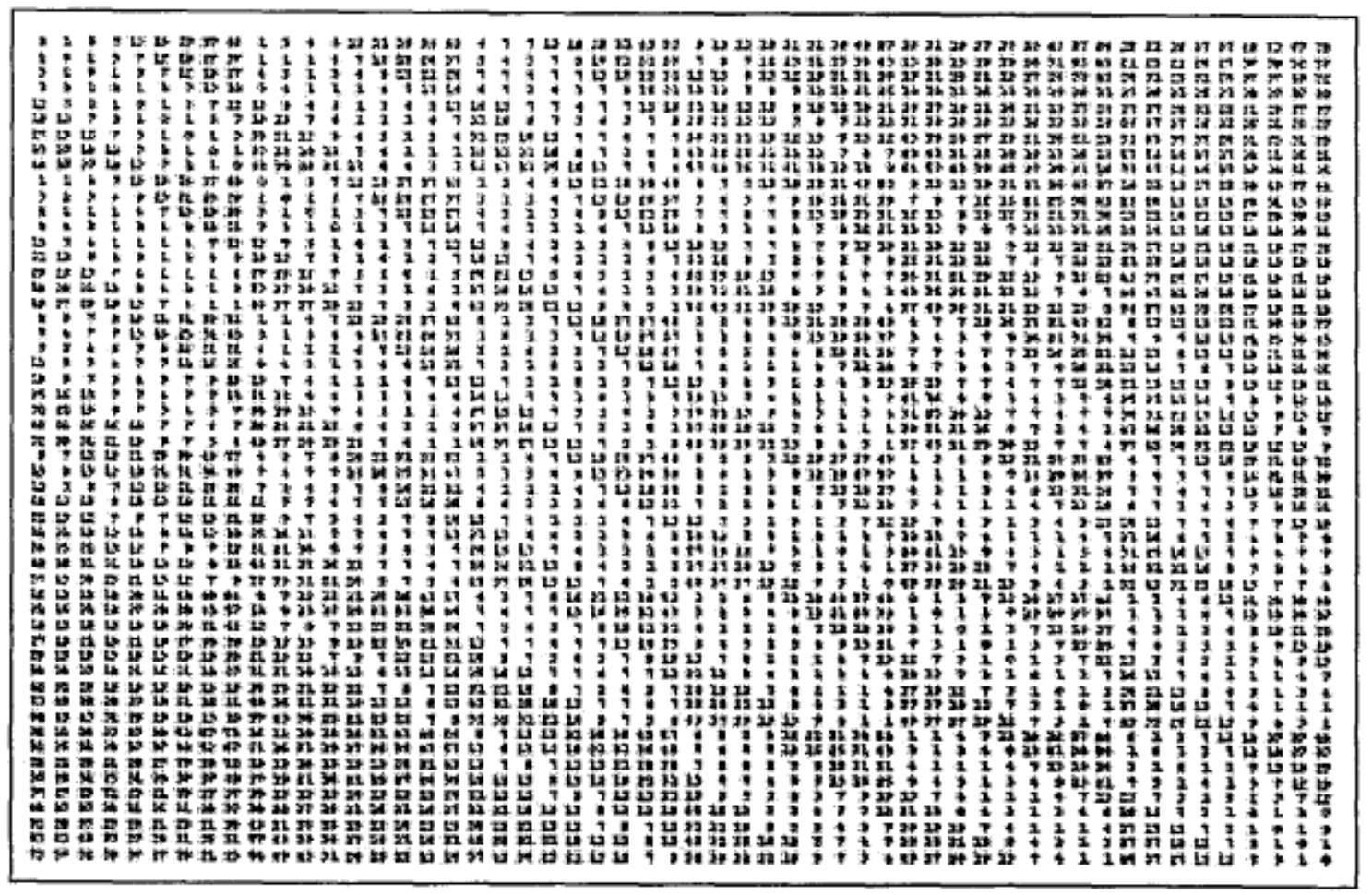

Figura 3.2.5.1.2: Matriz $U_{D}$ de distâncias topológicas quadradas entre as coordenadas das células para mapas de 54 células $(54 \times 54)$ em morfologia hexagonal (Mesquita, 2002)

O próximo passo é a criação de uma matriz $M$ de dimensão $54 \times d$ dim, onde $d$ dim é representação dos números de dimensões dos vetores de treinamento. Cada linha, nesta matriz, corresponde a um respectivo protótipo de cada unidade do mapa, que são aleatoriamente inicializados e já na primeira iteração assumem valores que se aproximaram dos vetores de treinamento.

Cria-se então a matriz Dists a partir das distâncias quadradas entre os protótipos $(M)$ e os dados de treinamento Dists $=(M-D)^{2}$.

Subsequentemente, é calculada a matriz $P$ com valores unitários que correspondem aos índices da matriz que denotam o par unidade do mapa com o vetor de treinamento. Um valor unitário no elemento $(13,5)$ da matriz, indica que a unidade de índice 13 é a unidade de melhor ajuste ("best match unit" - BMU) do vetor de treinamento de índice 5. 
Com a matriz $P$ pode-se calcular a soma dos valores do conjunto de Voronoi por $P^{*} D$, que representa para cada célula, a soma dos vetores que a "escolheram" como BMU.

Através desta matriz atenuada e utilizando o vetor de ativação, a atualização é feita por:

$$
M=\frac{H^{*}\left(P^{*} D\right)}{H^{*} P}
$$

Para o algoritmo sequencial, o passo de atualização acontece através de reposição de cada unidade do mapa pela média dos vetores que estão em sua vizinhança. A contribuição, ou ativação, dos vetores de dados pode ser variada de acordo com uma função de vizinhança. Esta ativação é dada pela matriz $H$. Para cada unidade do mapa o novo vetor peso $m$ é dado pela seguinte equação:

$$
M=\frac{\sum_{i=1}^{N} h_{i} d_{i}}{\sum_{i=1}^{N} h_{i}}
$$

onde $N$ é o número de células, e $h_{i}$ é a ativação e $d_{i}$ são os vetores de dados de treinamento.

\subsubsection{2 - Aprendizagem padrão}

Aprendizagem padrão ou sequencial do algoritmo básico de treinamento do SOM resume-se a três etapas. Na primeira, competitiva, os neurônios da camada de saída competem entre si, segundo algum critério, geralmente a distância Euclidiana, para encontrar um único vencedor, também chamado de BMU (Best Match Unit). $\mathrm{Na}$ segunda, cooperativa, é definida a vizinhança deste neurônio. Na última fase, 
adaptativa, os vetores de código do neurônio vencedor e de sua vizinhança são ajustados.

A relação de vizinhança entre os neurônios é estabelecida de acordo com alguma função. A função de vizinhança tem como principal objetivo controlar o nível de atuação dos neurônios em torno do neurônio vencedor do processo competitivo. Seguindo o modelo neurocerebral tem-se que o nível de atuação dos neurônios vizinhos decai à medida que o mesmo se distancia do BMU.

Ainda segundo Mesquita (Mesquita, 2002), "seja $h_{j, i}$ a vizinhança topológica centrada no neurônio $i$ e com um conjunto de neurônios cooperativos $j, j \in J$. Seja $d_{i, j}$ a distância lateral entre o neurônio vencedor $i$ e o neurônio $j$. Para que $h_{j, i}$ atenda aos requisitos neurobiológicos, a mesma tem que ser simétrica em relação ao ponto de valor máximo e $\left(d_{i, j}=0\right), h_{j, i}$ e deve decair monotonicamente com o aumento da distância lateral $\left(d_{i, j}\right)$, decaindo para próximo de 0 quando $d_{i, j} \rightarrow \infty$.

A função gaussiana $h_{j, i}=\exp \left(-d_{i, j}^{2} / 2 \delta^{2}\right)$ satisfaz estas exigências e é invariante à translação. $\delta$ representa o raio da vizinhança topológica e o grau que os neurônios vizinhos do BMU participam do processo de aprendizagem adaptativa. A rede SOM converge mais rapidamente com este tipo de função se a vizinhança (Mesquita, 2002) for definida em uma função monotonicamente decrescente em relação ao tempo $\delta(t)=\delta(0) \exp \left(-t / \tau_{i}\right)$, sendo $\tau_{i}$ uma constante.

Seja $\Xi$ o conjunto dos padrões de entrada composto por $x_{k}, k=1, \ldots, n$, temse o algoritmo de aprendizagem padrão ou sequencial, como segue:

i) Os vetores de código, $W_{j}=\left[w_{j 1}, \ldots, w_{j d}\right]^{T}$, são iniciados linearmente. 
ii) Para cada época t:

a) Para todo $x_{k} \in \Xi, k=1, \ldots, n$, para o tempo discreto t, encontre o neurônio vencedor c segundo a distância Euclidiana:

$$
c=\arg \min _{j}\left\{\left\|x_{k}-w_{j}\right\|\right\}, j=1, \ldots, m
$$

onde $m$ corresponde ao número de neurônios na rede. A ordem de apresentação dos padrões deve ser aleatória.

b) Os vetores de código wj do neurônio vencedor e dos seus vizinhos são, então, atualizados segundo a equação:

$$
W_{j i}(t+1)=w_{j i}+\alpha(t) h(t)\left[x_{i k}(t)-w_{i j}(t)\right]
$$

onde $\alpha(t)$ é uma função que determina a taxa de aprendizagem na iteração $t$ e $h(t)$ é a função que determina a vizinhança entre o neurônio vencedor $c$ e seus vizinhos.

\subsubsection{3 - Treinamento em lote - batch}

O processo iterativo no qual um número de amostras $x$ é primeiro classificado nas respectivas regiões de Voronoi, $V_{i}$, e posteriormente a atualização dos $m$ protótipos é feita iterativamente pelo algoritmo chamado "Batch Map" (Kohonen, 1993) e supõe que todas as amostras estejam disponíveis quando o treinamento começa. Os passos deste algoritmo são os seguintes (Kohonen, 2001):

i) Para os vetores de referência iniciais, tomam-se, por exemplo, as 
primeiras $K$ amostras de treinamento, onde $K$ é o número de vetores de referência.

ii) Para cada unidade de mapa, coleciona-se uma lista de cópias de todas as amostras de treinamento $x$ cujo vetor de referência mais próximo pertence à unidade $\mathrm{i}$.

iii) Toma-se para cada novo vetor de referência à média sobre a união das listas em $N$.

iv) Repete-se a partir de ii algumas vezes.

É relativamente fácil perceber que este algoritmo descreve o mesmo processo geral de treinamento que atualiza uma região de Voronoi por iteração. Se uma nova função de vizinhança $h_{c i t}(t)$ é utilizada, e $\overline{x_{j}}$ é a média de $x(t)$ no conjunto de Voronoi $v_{j}$, pode-se pesá-lo por um número $n_{j}$ de amostras $v_{j}$ e a função de vizinhança. Desta forma obtêm-se a equação:

$$
m_{i}^{*}=\frac{\sum_{j} n_{j} h_{j l} \overline{x_{j}}}{\sum_{j} n_{j} h_{i j}}
$$

A soma em $j$ é feita para todas as unidades da SOM ou pode ser feito de forma que $h_{i j}$ seja truncada, ou ainda a soma pode ser efetuada sobre a vizinhança $N_{i}$ na qual é definida. Se não for utilizado o peso da vizinhança tem-se o seguinte:

$$
m_{i}^{*}=\frac{\sum_{j \in N_{i}} n_{j} \overline{x_{j}}}{\sum_{j \in N_{i}} n_{j}}
$$


Este algoritmo é particularmente efetivo se os valores iniciais dos vetores de referência já estão grosseiramente ordenados, mesmo que ainda não representem a distribuição das amostras. Também é importante notar que o algoritmo por lote não contém parâmetro de taxa de aprendizado e, portanto, não tem problemas de convergência e se direciona a valores assintoticamente mais estáveis que os valores $m_{i}$ da SOM original (Kohonen, 2001).

\subsection{6 - Identificação e correção de erros}

Consistem no processo de modificação dos pesos em função direta das saídas. É estimado por meio do cálculo da diferença entre a saída real gerada e a saída desejada, fornecida em um aprendizado supervisionado. Matematicamente o princípio pode ser expresso como na equação 18:

$$
e_{K}=d_{k}-y_{k}
$$

Onde para um estímulo $\mathrm{k}$,

$$
\begin{aligned}
& e=\text { sinal de erro; } \\
& d=\text { saída desejada apresentada durante o treinamento; } \\
& y=\text { saída real da rede após a apresentação do estímulo de entrada. }
\end{aligned}
$$

\subsection{7 - Regra de gradiente descendente}

Esta regra constitui-se de um processo de alteração dos pesos (wi), onde ocorre a minimização do erro pelo método do mínimo erro médio quadrático, e pode ser expressa pela equação 19:

$$
E_{\left(w_{i}\right)}=\frac{1}{2} \sum\left(x_{0}-x_{p}\right)^{2}
$$

Onde $x_{0}$ é o valor observado e $x_{p}$ é o valor previsto. 
3.3 - Processamento de imagens utilizando DCT (transformação discreta de cossenos)

O processamento de imagens é uma denominação genérica para o tratamento de dados digitais que são advindos de imagens adquiridas diretamente por câmeras digitais ou outro processo de interesse passível de digitalização. Assim, existem diferentes fenômenos e técnicas em diferentes áreas da engenharia, medicina e industriais que utilizam imagens digitais como expressão de propriedades importantes do objeto de estudo ou monitoramento. A imagens digitais é normalmente (bidimensional) e é considerada uma função $f(x, y)$, na qual $\mathrm{f}$ representa a intensidade ou nível de cinza na coordenada espacial $(x, y)$. O processo de digitalização envolve amostragem e quantização e envolve muitas diferentes etapas e formatos associados aos arquivos digitais. Estes arquivos em geral são codificados e contém formatos proprietários.

Nesta área, a filtragem no domínio da frequência é muito comum, e consiste na utilização da transformada de Fourier que decompõe um sinal em componentes de frequência. O desenvolvimento de algoritmos rápidos para o cálculo da transformada de Fourier em 1965 representou um grande impulso na aplicação de transformadas em processamento digital de sinais (Nam e Rao, 1991). Similarmente, o surgimento em 1974 da Transformada Cosseno Discreta (Discrete Cosine Transform - DCT) e seus algoritmos eficientes impulsionaram em especial aplicações em processamento de sinais, processamento de imagens e compressão de dados (Nam e Rao, 1991). Desde então, verificam-se experimentos com resultados promissores utilizando DCT em problemas como reconhecimento de padrões, compressão, filtragem e reconstrução. Uma característica importante de algumas transformadas refere-se à sua capacidade de gerar coeficientes descorrelacionados, concentrando a maior parte da energia do sinal em um reduzido número de coeficientes, ou seja, correspondem a uma abordagem capaz de reduzir a correlação presente nos sinais. Quando o sinal se comporta como um processo estocástico com determinadas propriedades, pode-se mostrar que a Transformada KLT (Karhunen-Loève Transform) é ótima no sentido de que obtém descorrelação máxima e concentra a energia em um número mínimo de coeficientes (Nam e Rao, 
1991). A DCT é uma função linear e inversível, $I R \rightarrow I R$, que expressa sinais como uma soma de funções cossenos discreta. O sinal original é convertido para o domínio da frequência pela DCT, e é possível converter o sinal de volta para o domínio do tempo aplicando-se a DCT inversa.

Após a transformação para o domínio da frequência se obtém os coeficientes da DCT, que refletem a importância das frequências presentes no sinal original. Os primeiros coeficientes referem-se às frequências mais baixas do sinal, que representam o comportamento geral do sinal original. Os últimos coeficientes referem-se às frequências mais altas do sinal, que geralmente representam as informações mais detalhadas ou finas do sinal, que em muitos casos representam predominantemente ruído (Gonzalez et al., 2002). Dessa forma, no caso específico de se reduzir a dimensionalidade após a aplicação da DCT, os coeficientes de mais baixa frequência serão geralmente os mais apropriados para se representar os diferentes padrões, que no caso desse trabalho correspondem às diferentes imagens de fases.

Em Nam e Rao (1991) há quatro definições para DCT: DCT-I, DCT-II, DCT-III e DCT-IV. A DCT-II tem sido mais usada em processamento de sinais e de imagens devido em especial à sua forte capacidade de compactação de energia: muitas das informações do sinal tendem a se concentrar em poucos componentes de baixa frequência. Por esse motivo, o padrão JPEG usa a DCT-II na sua implementação.

A definição da DCT-II é apresentada na equação 20. Nesse contexto, a imagem original corresponde à matriz de escala de cinza $f(x, y)$, de dimensões $a \times b$, com $a * b=N$. A aplicação da DCT-II produz a matriz $F(u, v)$, também de dimensão $a \times b$. As variáveis $x$ e $y$ são as coordenadas no domínio espacial e $u$ e $v$ são as coordenados no domínio da frequência. 


$$
\begin{aligned}
& F(u, v)=\alpha(u) * \alpha(v) * \sum_{x=0}^{a-1} \sum_{y=0}^{b-1} f(x, y) * \cos \frac{(2 x+1) u \pi}{2 N} * \cos \frac{(2 y+1) v \pi}{2 N} \\
& \alpha(u), \alpha(v)=\left\{\begin{array}{l}
\sqrt{\frac{1}{N}}, u, v=1 \\
\sqrt{\frac{2}{N}}, \text { demais casos }
\end{array}\right.
\end{aligned}
$$

O primeiro coeficiente, $F(1,1)$, é referenciado como coeficiente DC (Direct Current) e depende apenas do brilho da imagem. Os demais coeficientes de $F(u, v)$ indicam a amplitude correspondente do componente de frequência de $f(x, y)$ e são referenciados como coeficientes AC (Alternate Current).

\section{4 - O padrão JPEG}

O padrão JPEG (Joint Photographic Experts Group), estabelecido juntamente pelo ISO/IEC (International Organization for Standardization and International Electrotechnical Commission) e organizações de CCITT (Consultative Committee for International Telephony and Telegraphy), é um dos mais importantes padrões de compressão de dados dos anos 90. O padrão de compressão de imagens JPEG manipula imagens em tons de cinza e imagens coloridas de resolução e tamanho variado. O padrão JPEG é usado em artes gráficas, editoração eletrônica, imagens médicas, e várias outras aplicações. Esse padrão é usado comumente em compressão com perda de qualidade da imagem. Porém, também há um modo de compressão sem perda e com desempenho de compressão reduzido.

O procedimento completo para a compressão de uma imagem tem a DCT como uma de suas componentes. Inicialmente a imagem é subdividida em blocos $(8 \times 8)$, os quais são então transformados pela DCT gerando um conjunto conhecido como coeficiente DCT. Esses coeficientes são então quantizados, isto é, sofrem uma redução em valor, sendo mantidos apenas os mais relevantes. O padrão JPEG faz essa redução por zona. É nesta fase que há uma significativa diminuição do espaço exigido para o armazenamento, com consequente perda de informação. Os coeficientes são reordenados para a codificação por entropia obedecendo à 
sequência Zig-Zag, após a reordenação, são codificados pela codificação de Huffman. Isto se repete até que se esgotem todos os blocos das imagens, quando se tem a imagem comprimida com extensão JPG. O processo de recuperação da imagem "original" segue os passos na direção contrária, aplicando no final a transformada inversa do cosseno. Uma exposição bastante didática e prática desse padrão podem ser encontradas em (Nelson, 1991).

\subsection{1 - Sequência ZIG-ZAG}

Uma razão pela qual o algoritmo de JPEG comprime tão efetivamente é que um número grande de coeficientes na imagem de DCT é truncado para zero durante a fase de quantização dos coeficientes. Tantos valores são ajustados para zero que o comitê JPEG elegeu para manipular estes valores diferentemente de outros valores dos coeficientes. Como a quantização reduz a magnitude dos coeficientes da DCT e aumenta o número de coeficientes com valores zero, se os dados forem reordenados com a sequência Zig-Zag, mostrada na Figura 3.4.1.1 abaixo, os coeficientes de baixa frequência são colocados na frente dos coeficientes de alta frequência.

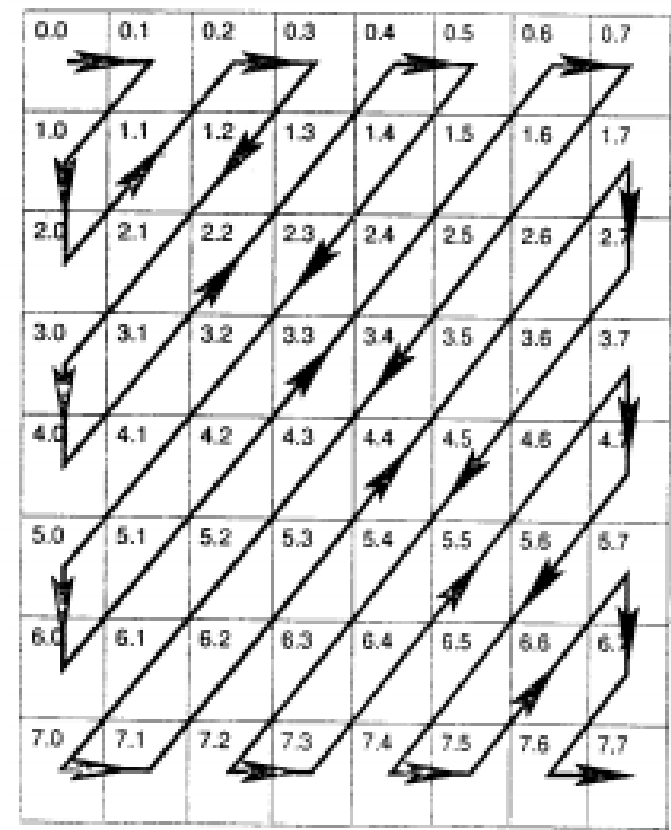

Figura 3.4.1.1: Figura ZIG-ZAG em um bloco 8x8 (Nelson, 1991) 


\subsubsection{Transformada discreta de cosseno de quadro completo (FFDCT)}

Neste trabalho foi utilizada a Transformada Discreta de Cosseno de Quadro Completo (Full Frame DCT - FFDCT) que é a aplicação do DCT a toda imagem de uma única vez. Uma das desvantagens desta técnica é o aumento do tempo para o cálculo do DCT, porém atualmente com o aumento dos recursos computacionais disponíveis estes tempos se mostraram reduzidos (tempos aproximados de 2s para converter uma imagem em cinza, típica, utilizando a função DCTII do programa Matlab (The Mathworks, Inc., 2014) em um microcomputador com o processador Intel I5).

Um dos motivos da escolha desta transformada para este trabalho são os relatos de que este método evita a formação de artefatos na imagem (Beretta et al, 1995). Como o método foi utilizado para extração de características, a preservação da informação presente na imagem é importante. O FFDCT é utilizado principalmente em imagens médicas para evitar a formação de artefatos quando da compactação de arquivos e em marca d'água em imagens digitais (Ahmad et. al., 2009, Chen e Pratt, 1984, Watson, 1994). 


\section{CAPÍTULO 4 - Metodologia}

\section{1 - Sistema geral de classificação}

Uma representação da metodologia de classificação deste trabalho utilizando redes auto-organizável - SOM - é mostrada na Figura 4.1.1, onde uma sequência de passos (formação de banco de dados, aplicação da transformada de cossenos sobre a imagem e treinamento da rede - SOM) precede a utilização da SOM para a classificação dos padrões de imagens.

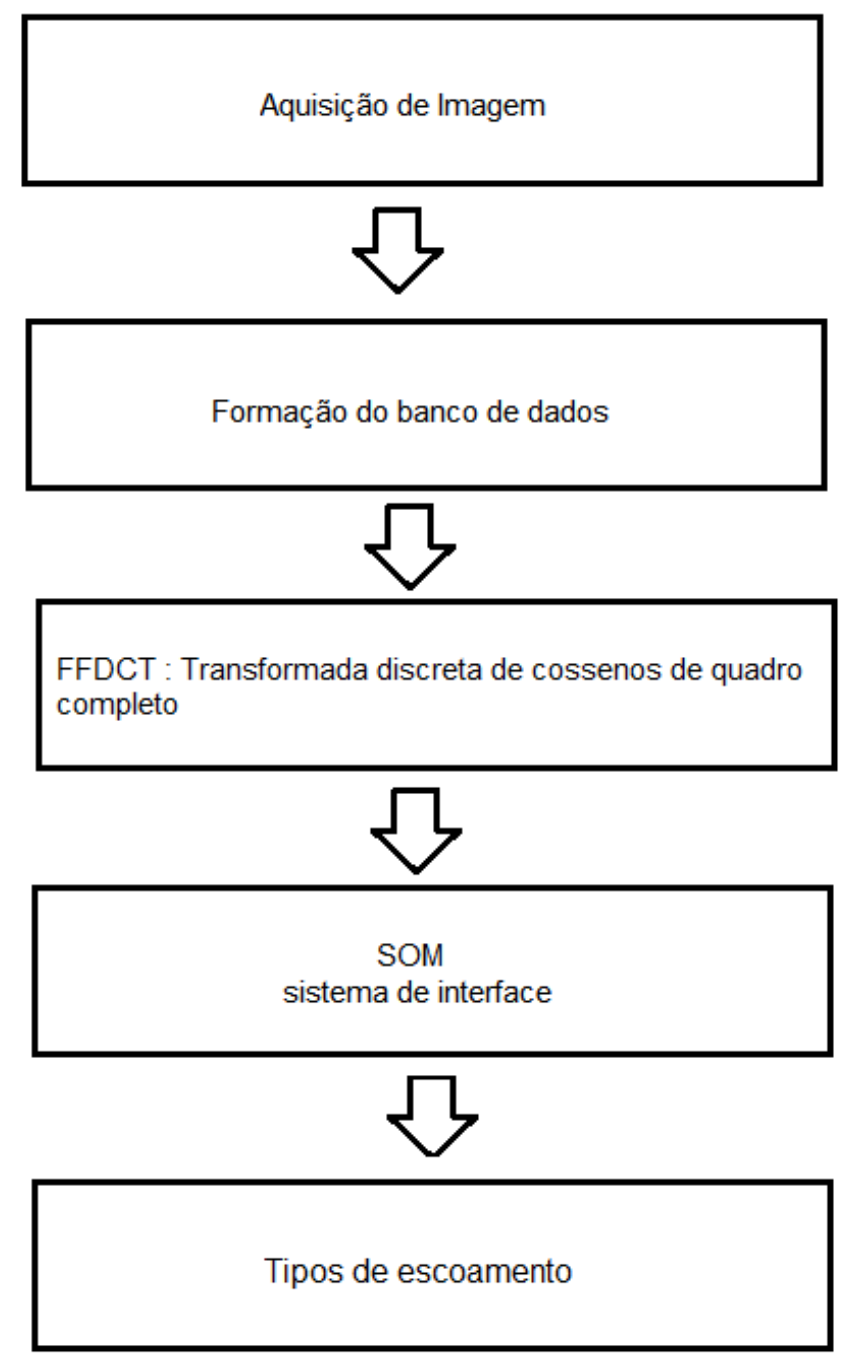

Figura 4.1.1: SOM - Fluxograma de classificação - esquema geral 


\section{2 - Base de dados}

A base de dados foi organizada a partir de experimentos realizados em 2009 no Circuito de Circulação Natural (CCN) do Centro de Engenharia Nuclear (CEN) do Instituto de Pesquisas Energéticas e Nucleares (IPEN-SP) por Mesquita (Mesquita et al., 2009).

O banco de dados de imagens foi organizado com base na fenomenologia dos três principais tipos de instabilidades observadas nos experimentos com escoamento bifásico no $C C N$ : incubação $(I)$, expulsão $(E)$ e refil $(R)$. A organização da base de dados foi mantida exatamente como a utilizada para classificação utilizando inferência Fuzzy (Mesquita et. Al., 2012) visando uma comparação entre os métodos de classificação.

As imagens foram adquiridas em simultâneo com as medições de temperatura do circuito sincronizado com o tempo. A potência de aquecimento foi elevada até $7270 \mathrm{~W}$ com temperatura ambiente de $25^{\circ} \mathrm{C}$. A vazão de resfriamento de $140 \mathrm{l} / \mathrm{h}$ foi mantida constante durante o experimento por aproximado $9500 \mathrm{~s}$.

O comportamento periódico foi confirmado pela detecção da transição fase de instabilidade denominada de reenchimento $(R)$ para incubação (I) através das imagens do padrão de transição, Figura 4.2.1. Esta detecção é descrita com mais detalhes em Mesquita (Mesquita et al., 2012).

As imagens utilizadas neste trabalho estão dispostas nos bancos de imagens dos Anexos I (tipo Incubação), II (tipo Expulsão) e III (tipo Reenchimento) desta dissertação. 


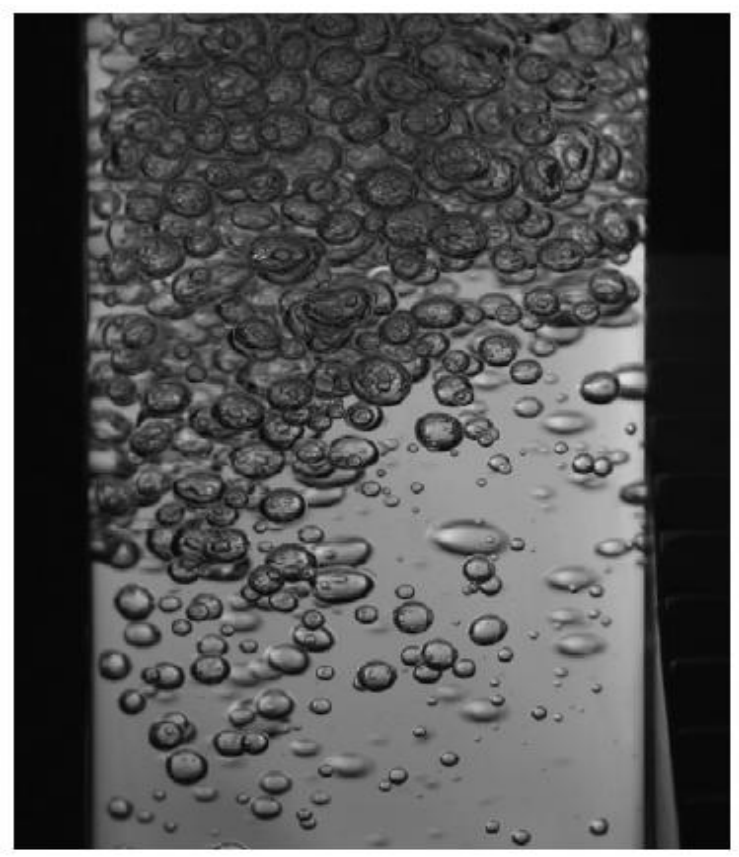

Figura 4.2.1: Imagem característica da transição entre as fases de reenchimento e incubação.

O comportamento cíclico da instabilidade (chugging) da circulação natural em escoamento bifásico foi observado no $\mathrm{CCN}$ através de medições de temperatura (Figura 4.2.2). Um período $T$ regular de $49 s$ para um ciclo completo de chugging foi estimado (Mesquita et. al., 2009). O ciclo é composto de uma fase de incubação para $T$ até $(T+30) s$, fase de expulsão $(T+30) s$ até $(T+35) s$ e uma fase de reenchimento, que dura os restantes $14 s$ do período do ciclo completo. Na Figura 4.2.2 as temperaturas T12 e T20 são medidas internas ao tubo de vidro e TP2 é medida na superfície externa da parede do tubo. Estes sensores estão localizados na mesma região do tubo em que as imagens foram adquiridas. 


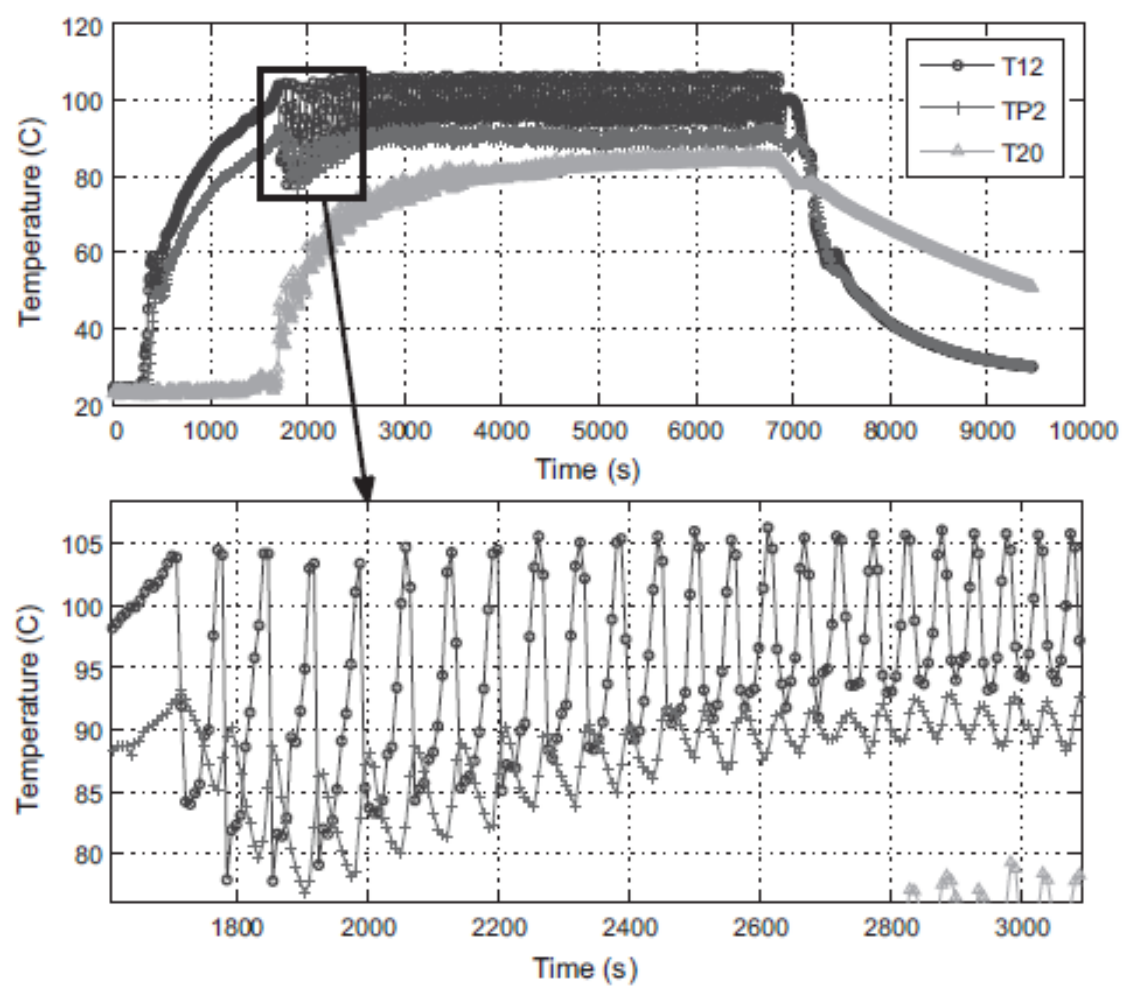

Figura 4.2.2: Comportamento periódico cíclico da temperatura ao longo do tempo no circuito de circulação natural bifásico (Mesquita et al., 2012)

O banco de dados de imagens foi composto de imagens selecionadas relacionadas com cada subtipo referente à fase de instabilidade do ciclo de circulação. As imagens selecionadas foram obtidas em momentos correspondentes ao tempo médio de cada fase da instabilidade. As imagens de períodos correspondentes às transições de fases da instabilidade não foram considerados neste trabalho, da mesma forma como foi feito na classificação Fuzzy (Mesquita et. al, 2012). A partir de 2530 imagens, 32 imagens de amostra foram escolhidas para caracterizar cada subtipo de escoamento.

As imagens na Figura 4.2.3 mostram quatro imagens para cada subtipo de instabilidade. A partir dessas imagens é possível notar que não são visuais as semelhanças e diferenças entre os mesmos exemplos de fases de instabilidade de circulação natural. 

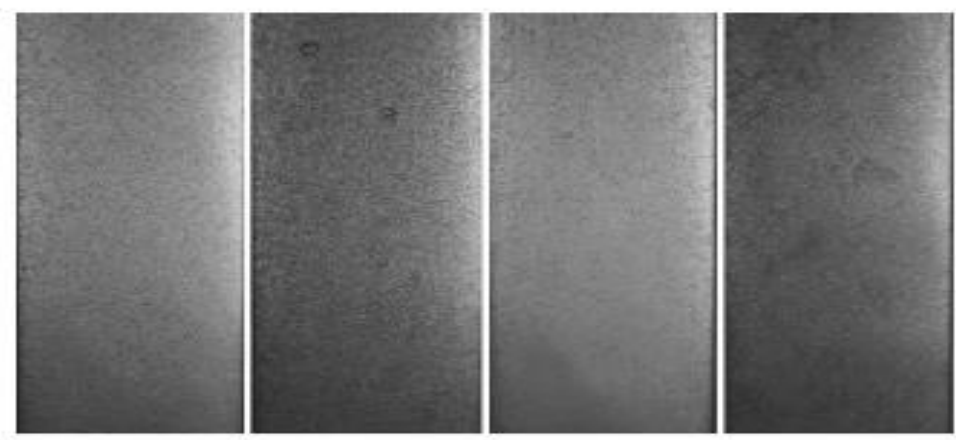

(a) I8884

(b) 19062

(c) $\mathbf{I 9 2 3 9}$

(d) 19257
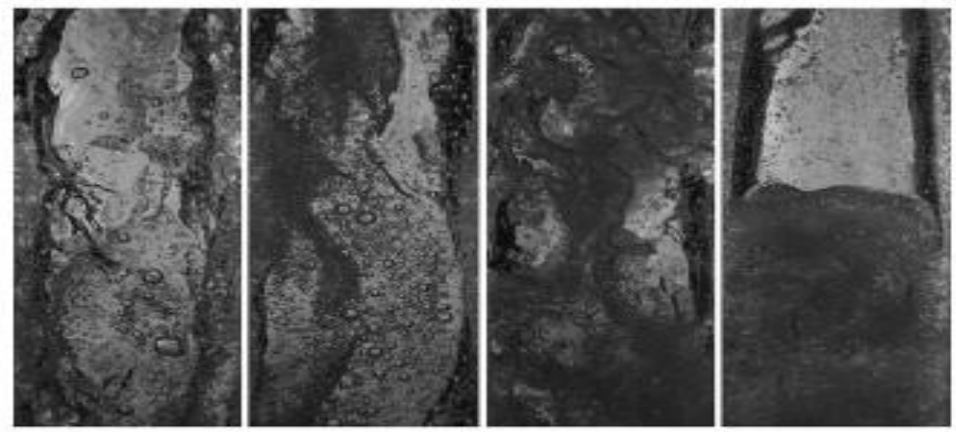

(e) E8812

(f) $\mathrm{E} 8901$

(g) E9070

(h) E9156
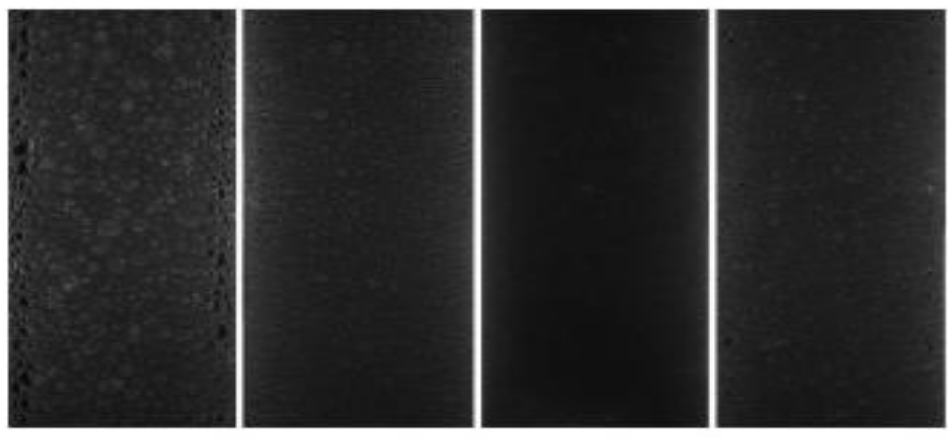

(i) R8821

(j) R.9084

(k) R9236

(1) R9324

Figura 4.2.3: Imagens de subtipos de instabilidade adquiridas no CCN: (a-d) incubação (I), (e-h) expulsão e (i-l) reenchimento (Mesquita et al., 2012)

\section{3 - Aquisição de Imagens}

As aquisições das imagens foram feitas usando uma câmera digital de alta resolução com $250 \mu$ s de velocidade do obturador. As lentes foram configuradas para permitir foco macro e que aquisições de imagens fossem feitas. 
O modo de aquisição típico da seção do tubo longitudinal gerou imagens de $3888 \times 2592$ pixels com uma resolução de aproximadamente $0,03 \mathrm{~mm} /$ pixels . A iluminação técnica de fundo mostrou ser a condição ideal para se obter imagem fazendo com que a fronteira obtivesse melhor definição. As imagens foram adquiridas em uma seção longitudinal de valor aproximado $120 \mathrm{~mm}$ do tubo de perna quente de diâmetro externo 46,3 $\mathrm{mm}$ como mostrado na Figura 4.3.1.1(b) (Mesquita et. al., 2012).

\subsection{1 - Circuito de Circulação Natural (CCN)}

O Circuito de Circulação Natural (CCN), Figura 4.3.1.1, instalado no Instituto de Pesquisas Energéticas e Nucleares, IPEN/CNEN, é um circuito experimental projetado para fornecer dados termo-hidráulicos relacionados aos fenômenos de escoamento monofásico e bifásico em diferentes condições de circulação natural.

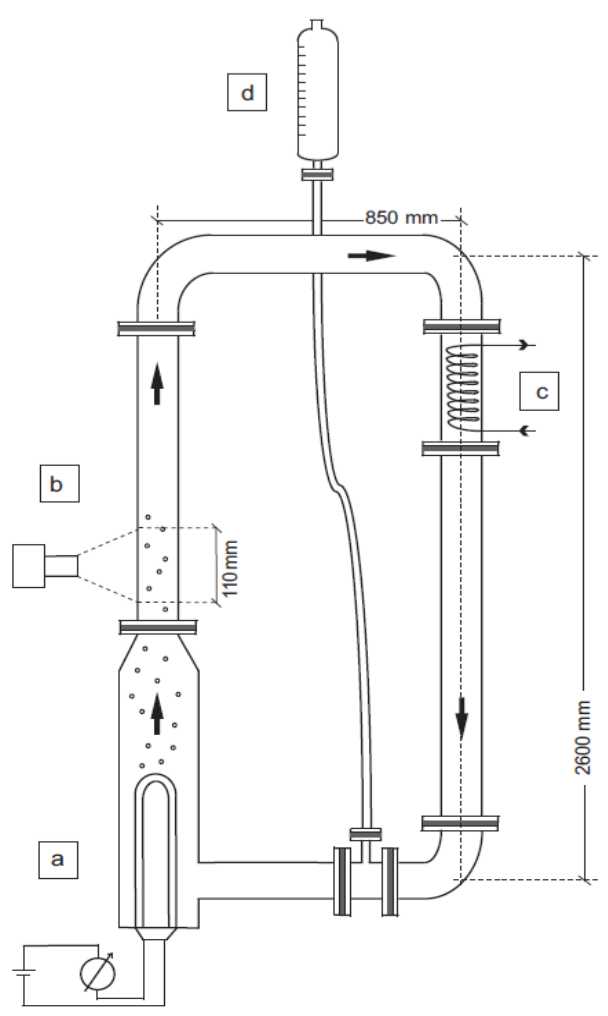

Figura 4.3.1.1: Esquema do Circuito de Circulação Natural (CCN): a) aquecimento elétrico, b) seção de visualização, c) seção de resfriamento e d) tanque de expansão (Mesquita et. al., 2012) 
O CCN, Figura 4.3.1.2, é um conjunto retangular com $2600 \mathrm{~mm}$ de altura e $850 \mathrm{~mm}$ de largura, de tubos de vidro de boro silicato, que são resistentes à temperatura, com 38,1 $\mathrm{mm}$ de diâmetro interno e $4,42 \mathrm{~mm}$ de espessura da parede.

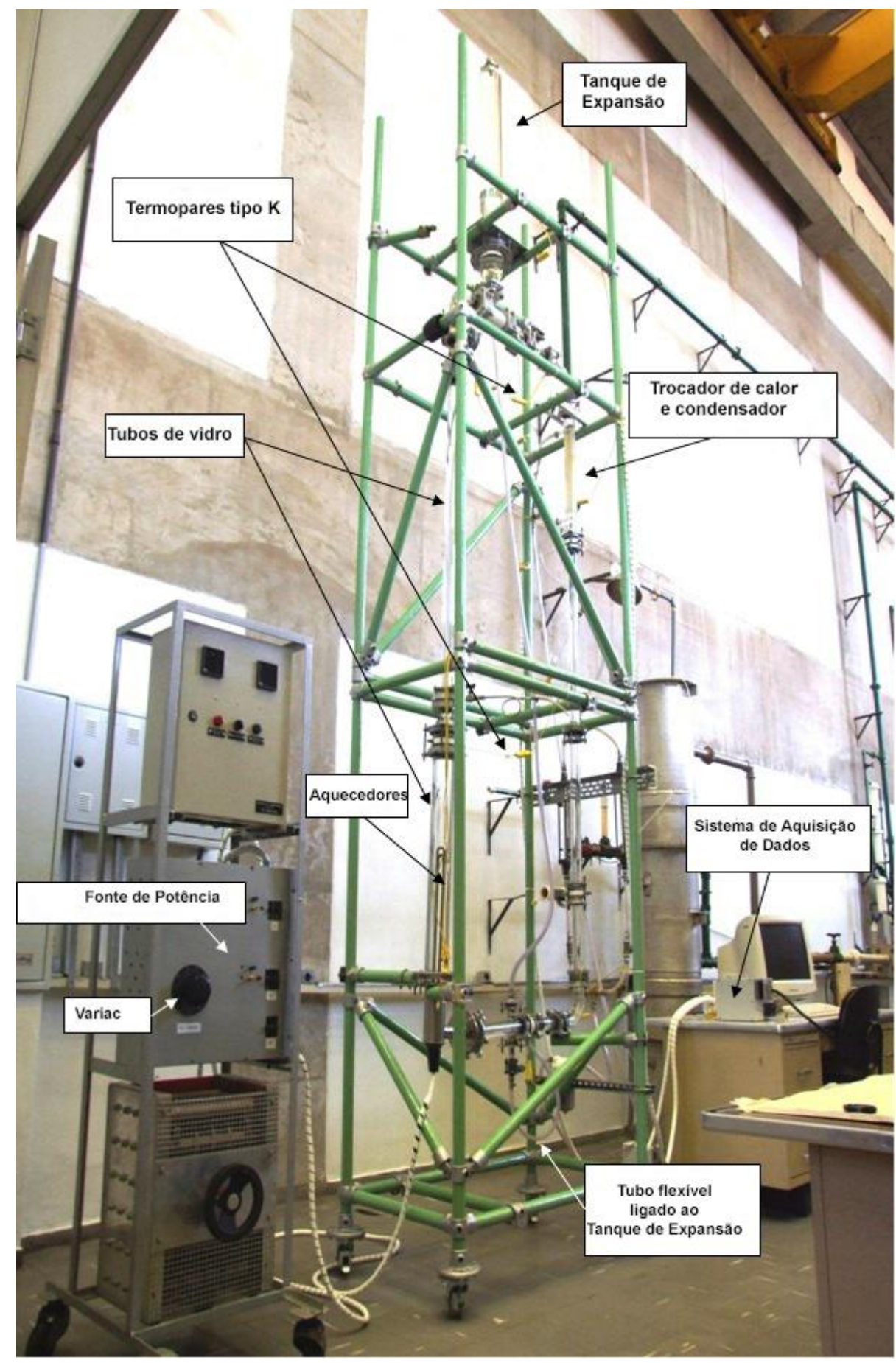

Figura 4.3.1.2: Imagem do CCN, com descrição de componentes do sistema (Torres et. al., 2010) 
O circuito tem uma seção aquecida, Figura 4.3.1.1 (a), também feita de tubo de vidro com $76,2 \mathrm{~mm}$ de diâmetro interno e $880 \mathrm{~mm}$ de comprimento. Esta seção tem dois aquecedores elétricos de liga $\mathrm{Ni}-\mathrm{Cr}\left(H_{1}\right.$ e $\left.H_{2}\right)$ em forma de $U$ e revestido de aço inoxidável.

A potência elétrica em $H_{1}$ pode ser ajustada numa faixa de $0-100 \%$ por um variador de voltagem Variac. Os aquecedores são compostos por resistências elétricas que podem entregar até $8000 \mathrm{~W}$. $\mathrm{O}$ aquecedor $\mathrm{H}_{2}$ opera em potência constante. A seção de resfriamento, Figura 4.3.1.1 (c), é constituída por um trocador de calor/condensador, também feito de vidro, com duas serpentinas internas que são alimentadas com vazão continua de água fornecida externamente. A água de resfriamento é mantida em temperatura ambiente, e bombeada a partir de um reservatório de $2 \mathrm{~m}^{3}$ ao trocador calor/condensador com a taxa de escoamento de resfriamento desejada, medida por dois rotâmetros.

O circuito tem um tanque de expansão, Figura 4.3.1.1 (d), aberto para a atmosfera a fim de acomodar as mudanças de nível de líquido devido à temperatura e alterações de fração de vazios. Este reservatório está ligado ao circuito através de um tubo flexível na sua região inferior com intuito impedir a entrada de vapor (Andrade et al., 2000). São utilizados aproximadamente $12 l$ de água desmineralizada para preencher o circuito. Quinze termopares de $1,5 \mathrm{~mm}$ do tipo $\mathrm{K}$ (Cromel - Alumel) são distribuídos ao longo do circuito do fluido, a fim de medir temperaturas ambientes. Três termopares tipo $K$ com junção exposta estão ligados à parede do tubo de vidro na perna quente.

Dois transdutores de pressão diferencial Validyne são usados para medir a pressão relativa na saída do aquecedor e o nível de água no tanque de expansão. Todos os instrumentos foram calibrados em laboratório. Um sistema de aquisição de dados montado com equipamentos de série SCXI da National Instruments é usado para adquirir dados dos sensores. A visualização é possível em todas as regiões do circuito, mas foi instalado a CCD (charged-couple device) em um ponto logo após o 
aquecedor do CCN. Esse local foi escolhido considerando que as instabilidades ocorrem nesta região com maior nitidez - Figura 4.3.3.1 (b).

As medições de temperatura e aquisição de imagens foram concomitantemente feitas, a fim de caracterizar padrões de transição de fases e correlacioná-los com a instabilidade periódica medida em período cíclico.

As instabilidades dos ciclos de circulação natural com escoamento bifásico são geralmente divididas em três fases diferentes chamadas de incubação, expulsão e períodos de reenchimento (Delhaye et al., 1981; Andrade et al., 2000; Nayak et al, 2008). Estas são instabilidades caracterizadas por expulsão periódica do líquido de arrefecimento a partir do canal. As condições experimentais foram ajustadas para sustentar um comportamento cíclico e periódico dessas instabilidades.

$\mathrm{Na}$ fase de incubação as bolhas de vapor crescem em número e tamanho. Nesta fase, no circuito a pressão cresce ligeiramente e expulsa o líquido da perna fria para o tanque de expansão, Figura 4.3.1.1 (d).

A última fase é caracterizada pela a inversão da direção causada pela diferença de pressão hidrostática, substituindo a água quente no aquecedor pela água fria oriunda do trocador de calor. O vapor produzido no aquecedor diminui e a parte horizontal da perna quente é novamente preenchida com água, reiniciando novo ciclo (Andrade et al., 2000). Estes comportamentos da oscilação de escoamento são periódicos e podem ser observados com facilidade devido à transparência dos tubos de vidro.

\subsection{2 - Extração de Características utilizando FFDCT}

Como já mencionado anteriormente (item 3.4.2) utilizou-se a transformada FFDCT para extrair as características das imagens de escoamento bifásico para efeito de classificação das instabilidades. Esta escolha se mostrou mais apropriada à medida que outras tentativas de utilização de propriedades estatísticas não obtiveram sucesso em classificar os padrões com um sistema Fuzzy. Tentou-se a 
caracterização adotada com os perfis de cinza tomados verticalmente ao longo da imagem (Mesquita et. al., 2012), mas o classificador a partir da SOM não se mostrou eficiente para estas características.

A escolha das imagens para classificação foi feita no tempo que representava o meio da fase da instabilidade, que se mostrou cíclica. Assim, apesar de representar a mesma fase de instabilidade, porém com características visuais diversas como pode ser observado no exemplo exibido na Figura 4.2.3 (e, f, g e h).

A utilização da transformada FFDCT se mostrou eficiente e adequada por representar com poucos coeficientes uma característica visual comum às imagens pertencentes à fase Expulsão, que é a presença de grandes vazios (presença de grande volume de vapor na mistura líquido/vapor). Estes volumes proporcionalmente grandes de vazio na imagem aparecem como áreas significativas de cor próxima ao branco como pode ser visto na Figura 4.2.3 (e,f,g e h) e na Figura 4.3.2.1. Nesta última figura, é possível verificar a imagem original (superior) seguida das imagens que são reconstruções a partir de coeficientes de FFDCT.

Verificou-se que com a utilização de poucos coeficientes FFDCT se conseguiu caracterizar os tipos de escoamentos disponíveis. A informação de baixa frequência da imagem (regiões em que existem transições mais suaves do nível de cinza) está registrada nos primeiros coeficientes. Ficou demonstrado que a presença destas grandes áreas de cores claras fica registrada na imagem reconstruída a partir de 12 coeficientes iniciais. Como já foi descrito anteriormente, sabe-se que estas transformadas têm um grande poder de compactação de informação, se apresentando com ótima técnica de compactação de imagens (Souza, 2007).

Desta forma, após vários testes observou-se que utilizando-se os primeiros doze (12) coeficientes da matriz FFDCT, coletados utilizando-se a técnica zig-zag (Figura 3.4.1.1), e montados na forma de um vetor, se conseguia caracterizar cada uma das imagens relativa aos três (3) tipos de instabilidades do experimento de circulação natural disponíveis (incubação, reenchimento e expulsão), sendo que para cada tipo de escoamento, (incubação, reenchimento e expulsão), dispunhamse de 32 imagens digitais totalizando 96 imagens. 


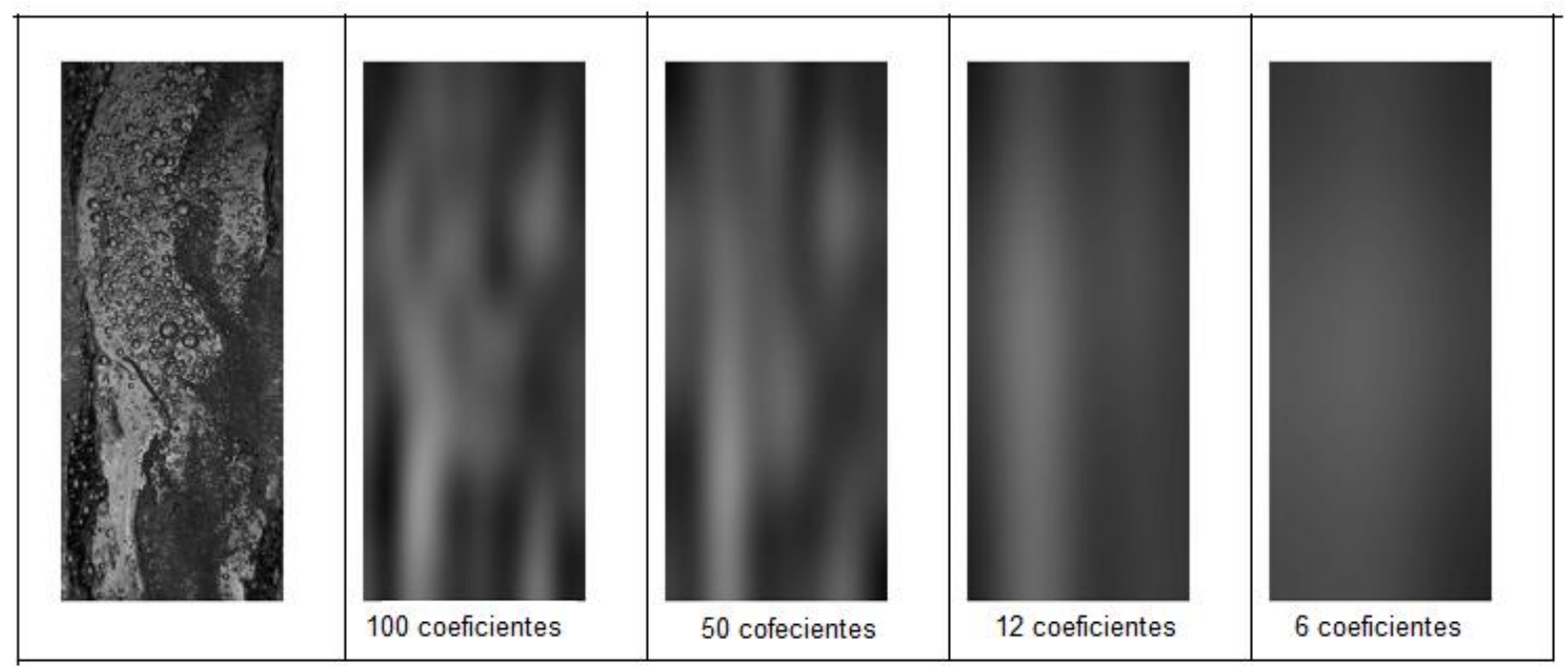

Figura 4.3.2.1 - Imagem original típica da fase Expulsão (E) seguida de suas imagens reconstruídas (da esquerda para a direita) usando 100, 50, 12 e 6 coeficientes FFDCT.

\subsection{Classificação de escoamento com a SOM}

Para treinamento da SOM, escolheu-se utilizar as porcentagens de $25 \%, 50 \%$ e 75\% do total das imagens disponíveis para cada tipo de escoamento, ou seja: 8, 16 e 24 imagens das 32 disponíveis. A estas imagens foi aplicada a função "DCTII" do software Matlab (The Mathworks, Inc., 2014) obtendo-se uma matriz dos coeficientes do FFDCT. Após as operações indicadas anteriormente, estes 12 coeficientes foram utilizados como entradas para a SOM, e as imagens restantes que não foram utilizadas para treinamento, foram utilizadas para se testar o treinamento realizado. Um exemplo de vetor FFDCT com 100 coeficientes está representado na Figura 4.4.1. Os experimentos de classificação utilizaram somente os 12 primeiros coeficientes. 


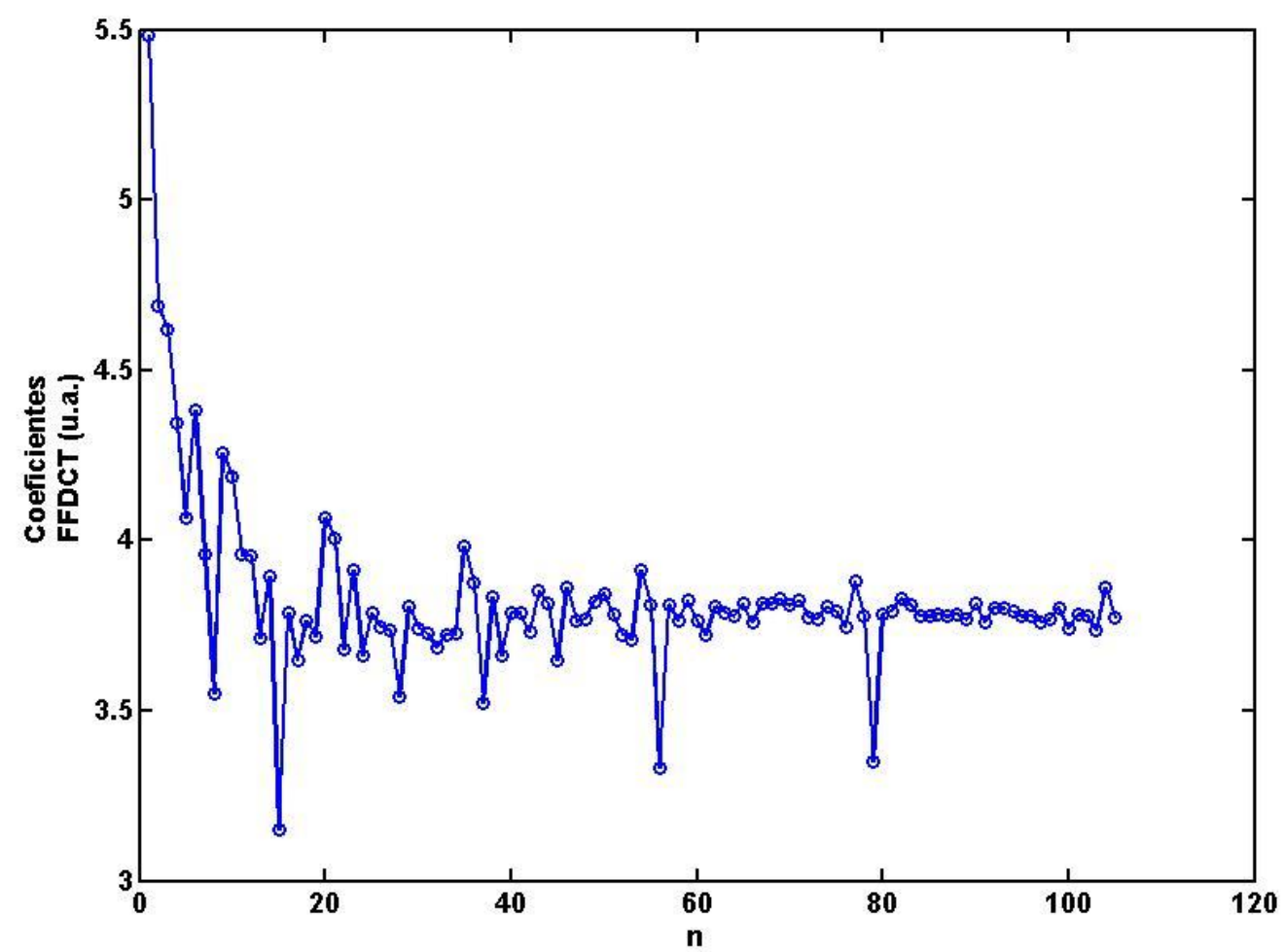

Figura 4.4.1 - Vetor característico com 100 coeficientes, obtido através da FFDCT utilizando a técnica de zig-zag da matriz M (Fig. 3.4.1.1).

Este processo foi constituído de diferentes treinamentos, no formato "crossvalidation" (validação cruzada) em que amostras randômicas proporcionais (mantendo a proporção entre os diferentes tipos na amostra) são feitas em toda a base de dados, havendo a reposição da amostra antes da próxima reamostragem. Este tipo de procedimento permitiu a execução de testes que fornecessem uma representatividade estatística quanto ao sucesso de classificação.

A classificação final (testes) foi feita em diferentes "experimentos" de 1000 repetições para cada tipo de amostragem do banco de dados. Numa primeira etapa foram realizados 1000 testes com uma só inicialização randômica da rede para cada proporção das amostragens $(25 \%, 50 \%$ e $75 \%$ ), chamados aqui de testes de inicialização única (seção 5.1.1). Numa segunda etapa foram realizados 1000 testes com inicializações randômicas diferentes da rede para cada proporção de amostragens (25\%, 50\% e $75 \%$ ), chamada neste trabalho de inicialização variada (seção 5.1.2). 
$\mathrm{Na}$ primeira parte dos testes (seção 5.1.1), as SOM's foram treinadas utilizando uma só inicialização. Assim, foi feita uma inicialização randômica inicial e em seguida foi repetido 1000 vezes o treinamento das redes baseado em amostragens randômicas diferentes do conjunto de treinamento.

Após cada uma das 1000 vezes em que o treinamento era realizado, um mapa com etiquetas (labels) e 15 cores era estabelecido com base em dois mapas: o primeiro com o agrupamento ("clusterização") realizado buscando 15 clusters (15 cores presentes na Figura 5.1.1.1.3, por exemplo); e o segundo com a informação das BMU's referentes aos tipos de instabilidade (etiquetas com indicação de tipo e número de BMu's em cada célula indicada na Figura 5.1.1.1.3).

Em seguida, outro mapa era construído (por exemplo o apresentado na Figura 5.1.1.1.4), seguindo a metodologia de etiquetar (ou nomear) todas as células de cada agrupamento ou cluster que contivesse a maioria das BMU's de um determinado tipo $(E$, I ou $R)$.

Baseado neste último mapa, um teste era realizado buscando a célula mais próxima (onde a distância euclidiana entre o protótipo da célula e o vetor-teste fosse menor). A letra identificadora da célula escolhida então era utilizada como identificadora do vetor-teste.

Após todos os vetores teste serem classificados, era contabilizado o erro de classificação do teste individual. O acerto de classificação foi calculado pela proporção de vetores-teste classificados corretamente dentre todos os vetores. Foram calculados erros por tipo e gerais.

Após cada experimento de 1000 testes foram gerados histogramas representativos das distribuições dos acertos de cada teste. Serão apresentados no capítulo 5 , estes histogramas junto com o acerto mínimo ( $A \downarrow$ ), o acerto máximo ( $A \uparrow$ ) e o acerto médio $(\bar{A})$ para cada tipo de instabilidade (Incubação (I), Expulsão (E) e Reenchimento (R)), e Geral (G) (Tabelas 5.1.1 a 5.1.6). 
Uma segunda parte dos testes (5.1.2) o mesmo procedimento acima foi realizado com a única diferença de que para cada um dos 1000 testes de cada amostragem, a inicialização da rede para o treinamento era refeita.

A figura 4.4.2 resume os passos da classificação utilizados neste sistema de classificação.

\section{Metodologia de Classificação SOM}

i) Organização da base de dados por tipo de instabilidade em diretórios contendo 32 imagens referentes ao instante da metade do tempo de cada fase de instabilidade (I, E e R);

ii) Cálculo dos coeficientes de FFDCT para cada imagem e criação de diretórios contendo os vetores correspondentes a cada imagem e tipo de fase de instabilidade;

iii) Amostragem de uma proporção $(25 \%, 50 \%$ ou $75 \%)$ dos vetores FFDCT para treinar a SOM;

iv) Inicialização inicial da rede (uma vez para 1000 "experimentos" de "inicialização única", e 1000 vezes para cada diferente amostragem de 1000 experimentos de "inicialização variada");

v) Treinamento da rede SOM para cada amostragem em 30000 iterações no total;

vi) Agrupamento do mapa em 15 clusters por proximidade euclidiana dos vetores utilizando o algoritmo $k$-means presente na função kmean_clusters.m do toolbox de SOM do Matlab (SOM Toolbox team, 2012); 
vii) Etiquetação do mapa agrupado ("clusterizado") com as BMU's referentes ao conjunto de treinamento;

viii) Etiquetação de todo o mapa por maioria de BMUS de cada tipo em cada cluster;

ix) Comparação de cada vetor-teste com os protótipos do mapa etiquetado;

x) Contabilização dos acertos de classificação por tipo, e geral;

xi) Elaboração dos histogramas de acertos.

Figura 4.4.2: Etapas de classificação utilizando a SOM

Os parâmetros de treinamento utilizados foram escolhidos de acordo com três índices obtidos no processo. O primeiro índice é o chamado erro de quantização $q_{e}$. Este índice mede a distância euclidiana média entre todos os vetores de treinamento e os protótipos das respectivas BMU (best match unit). O valor de $q_{e}$ é atualizado para cada iteração. Para o algoritmo de treinamento em lote utilizado (Seção 3.2.5.2), a atualização ocorre para as BMU e as unidades vizinhas incluídas no raio de atualização que gera a distribuição (em geral gaussiana) da ativação. Este raio começa maior na fase de treinamento inicial, chamada de "bruta", e é reajustado para valores decrescentemente menores na fase de ajuste "fino".

O erro de quantização é o principal índice de qualidade do treinamento do mapa, e, muitas vezes, se o número de unidades do mapa não é suficientemente grande para representar a distribuição dos dados, pode-se chegar a um erro final de treinamento relativamente elevado, mesmo com um tempo longo de treinamento. 
A proporção entre o número de unidades no mapa de Kohonen e a quantidade de vetores-treinamento é chamada por Kohonen (2001) de $m_{p d}$, sendo definido por:

$$
m_{p d}=\frac{m_{\text {units }}}{d_{\text {len }}}
$$

onde $m_{\text {units }}$ é o número de unidades no mapa, e $d_{l e n}$ é a quantidade de vetores de treinamento.

Ainda Kohonen recomenda a escolha do número de unidades para o mapa baseado na seguinte relação heurística:

$$
m_{\text {units_ini }}=5 d_{\text {len }}^{0,54321}
$$

e define os tamanhos típicos para os mapas. Ele define um mapa "pequeno" como contendo $m_{\text {units_ini }} / 4$ células, e um mapa "grande" aquele contendo $4 m_{\text {units_ini }}$.

Baseando-se no critério sugerido por Kohonen descrito acima e levando em conta que o número de vetores de treinamento variou neste trabalho, o valor considerado pequeno para $25 \%$ de amostragem (24 vetores), seria um mapa com 7 células. Um mapa grande teria 113 células. Para $50 \%$ de treinamento estes números dobrariam indo de um mínimo de 14 até 226 células, e finalmente para $75 \%$ dos vetores teríamos um mínimo de 28 células e um máximo de 452 células.

Pela experimentação e exploração de diversos tamanhos de rede, decidiu-se manter constante o tamanho do mapa em $8 \times 6$ (48 unidades hexagonais) para efeito de comparação entre os diferentes experimentos de inicialização. Assim em todos os 6000 experimentos de classificação, foi mantido constante o mapa de 48 células $(8 \times 6)$ e 30000 iterações. 


\section{CAPÍTULO 5 - Resultados e discussão}

\subsection{Resultados}

Para treinamento da SOM, como descrito anteriormente, escolheu-se utilizar as porcentagens de $25 \%, 50 \%$ e $75 \%$ do total das imagens disponíveis para cada tipo de escoamento, ou seja: 8,16 e 24 imagens do total de 32 imagens.

Em seguida, são apresentados os resultados referentes ao treinamento das SOM's. Estes resultados estão divididos em duas partes.

Na primeira (item 5.1.1) estão os resultados do treinamento onde as SOM's foram treinadas utilizando uma só inicialização. Assim, foi feita uma inicialização randômica inicialmente e em seguida foi repetido 1000 vezes o treinamento das redes baseados em amostragens randômicas diferentes do conjunto de treinamento. Os resultados apresentam mapas característicos (Figuras 5.1.1.1.1 até 5.1.1.3.4) destes treinamentos com inicialização única.

$\mathrm{Na}$ segunda parte (Item 5.1.2) são apresentados alguns mapas representativos dos 1000 diferentes amostragens da base de dados. Nesta seção de treinamento, a inicialização foi modificada para cada amostragem diferente.

Baseado nos mapas obtidos para cada amostragem foram elaborados um histograma representativo de cada experimento (1000 testes) que são apresentados na Seção 5.1.3. Os testes de classificação foram baseados no mapa treinado e etiquetado de acordo com as BMU's.

O tamanho do mapa se manteve em $8 \times 6$, com raio de atualização de vizinhança de 4 na fase bruta e de 2 na fase fina do treinamento. $O$ erro de quantização foi de 0.0912 e o erro topográfico foi de 0,0208 ao longo de todos os experimentos. 


\subsubsection{Treinamento com Inicialização Única}

5.1.1.1 Inicialização Única com 25\% de amostragem

Foram feitos 1000 experimentos de treinamento da SOM com uma única inicialização aleatória utilizando $25 \%$ dos dados disponíveis em cada amostragem feita para cada um dos experimentos..

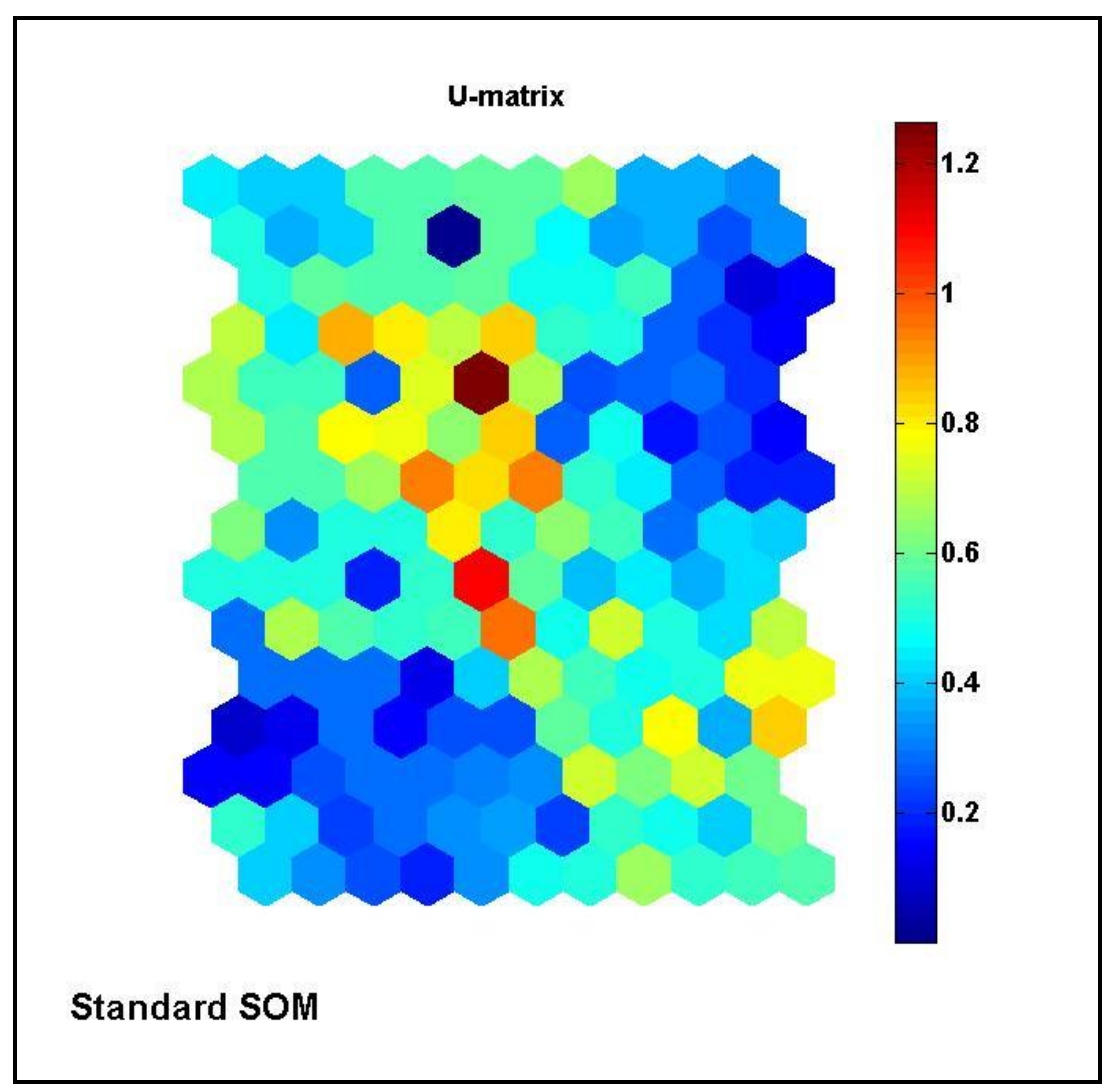

Figura 5.1.1.1.1: Mapa da Matriz Unitária com escala de proximidade (distância euclidiana normalizada) entre as células após treinamento - inicialização única com $25 \%$ das amostras.

O mapa de matriz unitária U-matriz (Figura 5.1.1.1.1) representa geometricamente as distâncias euclidianas dos vetores característicos das instabilidades do escoamento bifásico do CCN. Nota-se que há duas regiões de maior proximidade (código de cor azul) entre os protótipos treinados. Esta concentração em duas regiões mostram dois grandes grupos de protótipos (Figura 
5.1.1.2) que definem uma representação significativa do perfil dos vetores no banco de dados de treinamento utilizado.

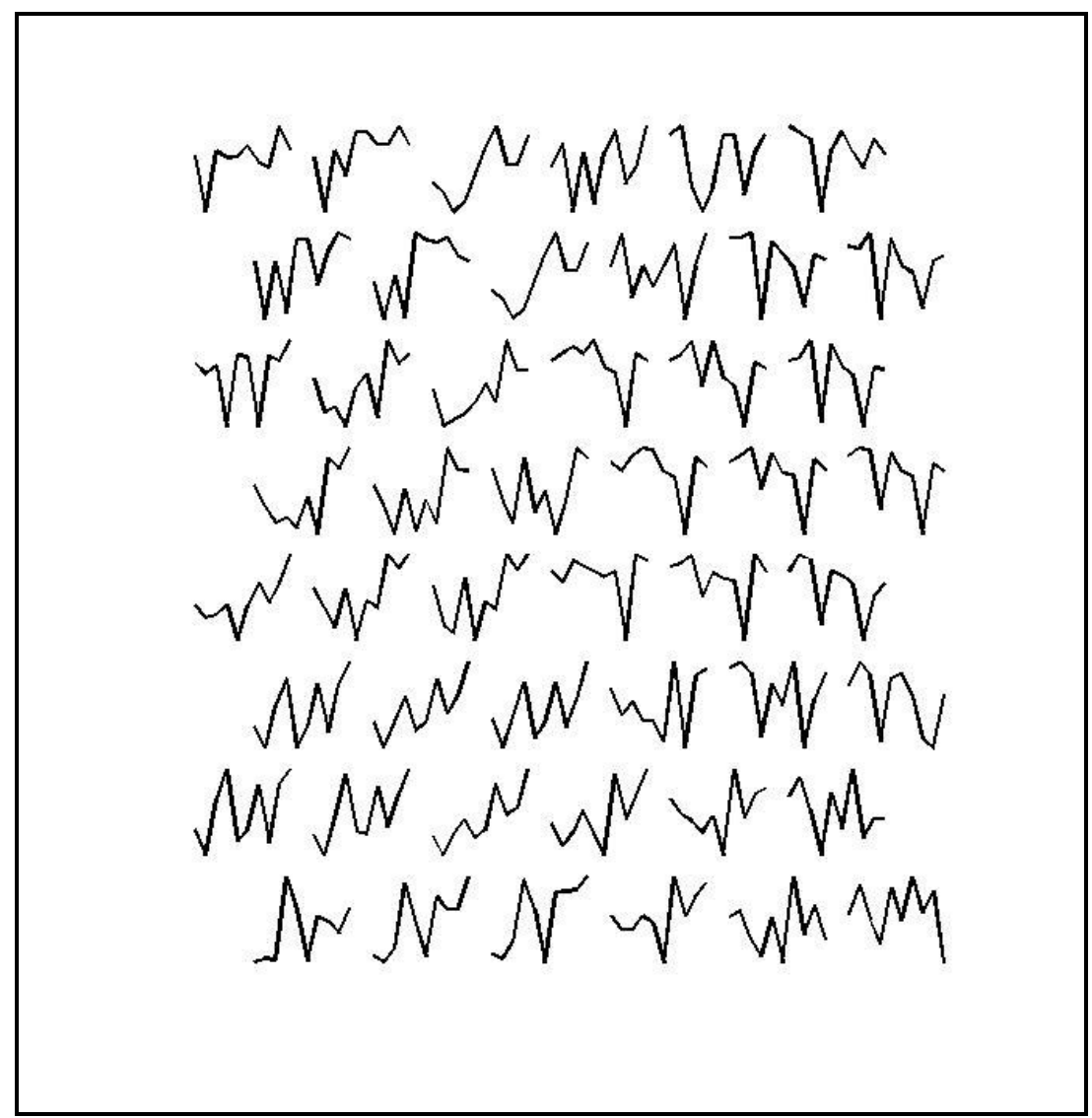

Figura 5.1.1.1.2: Mapa da SOM treinada com os protótipos obtidos referentes aos coeficientes FFDC - inicialização única com $25 \%$ das amostras.

Ao observarem-se as BMU's do mapa (Figura 5.1.1.1.3) nota-se que estes dois "clusters" representam predominantemente os coeficientes de FFDCT obtidos das imagens das fases de instabilidade Reenchimento (refill-R) e Incubação (incubation-I). Observa-se também, nesta mesma figura, que o padrão FFDCT relativo às imagens da fase Expulsão $(E)$ estão "espalhados" pelo resto do mapa em diferentes "clusters". Como definido anteriormente, o método de clusterização utilizado procurou 15 clusters como mostrado na Color Code - Figura 5.1.1.1.3, em 15 cores. Este espalhamento ou dispersão no mapa SOM significa corresponde ao que pode ser verificado visualmente nas imagens referentes à fase Expulsão. As imagens têm padrões mais heterogêneos, e por isto, mais difíceis de serem correlacionadas pelos vetores de características utilizados. 
Esta dispersão de formas é uma característica implícita do tipo de instabilidade que apresenta tipos de escoamento diferentes na mesma fase: tipo "aglomerados" (churn flow), pistonado (slug flow), e em alguns momentos bolhas empacotadas (packed bubbles).

A técnica, no entanto, foi direcionada para encontrar padrões da imagem que pudessem identificar aspectos comuns destes escoamentos que pudessem identificar a fase chamada Expulsão, onde ciclicamente a seção visualizada continha variações bruscas de fração de vazio e de temperatura, devido à reversão de escoamento intrínseca a esta fase de instabilidade.

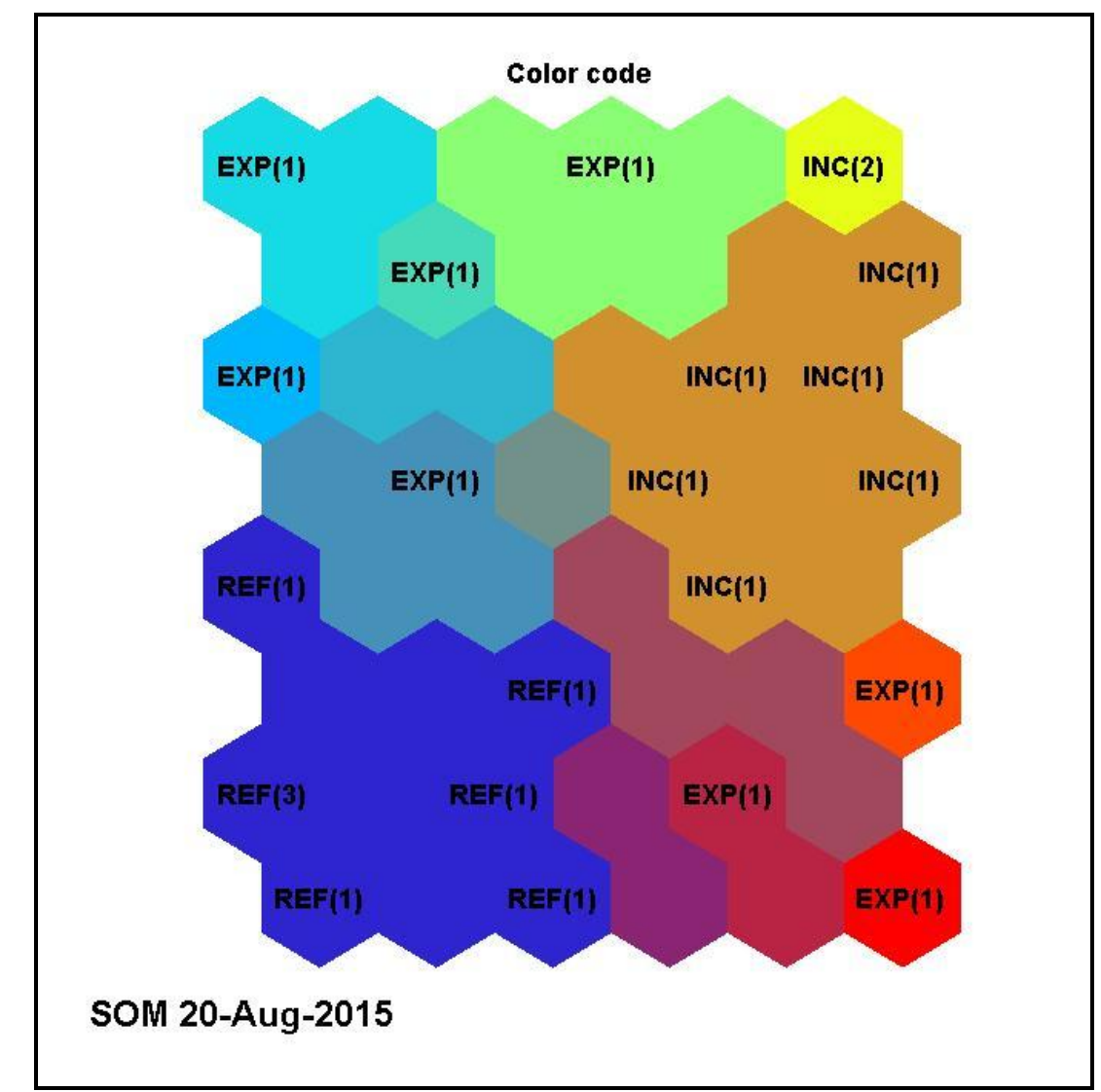

Figura 5.1.1.1.3: Mapa da SOM treinada com as unidades BMU's assinaladas para cada tipo de instabilidade classificada - inicialização única com $25 \%$ das amostras.

A partir destas das informações dos agrupamentos encontrados e das BMU's associadas ao banco de dados (que podem ser observadas nas duas figuras anteriores), foi gerado o mapa SOM a ser utilizado efetivamente para a classificação (um exemplo é apresentado na Figura 5.1.1.1.4). A partir deste mapa devidamente 
etiquetado (um mapa foi obtido para cada um dos 1000 experimentos), realiza-se a comparação com a base de dados de teste (com os $75 \%$ de dados restantes). Os resultados dos experimentos com amostras de $25 \%$ de toda a base estão descritos na tabela 5.1.3.1.

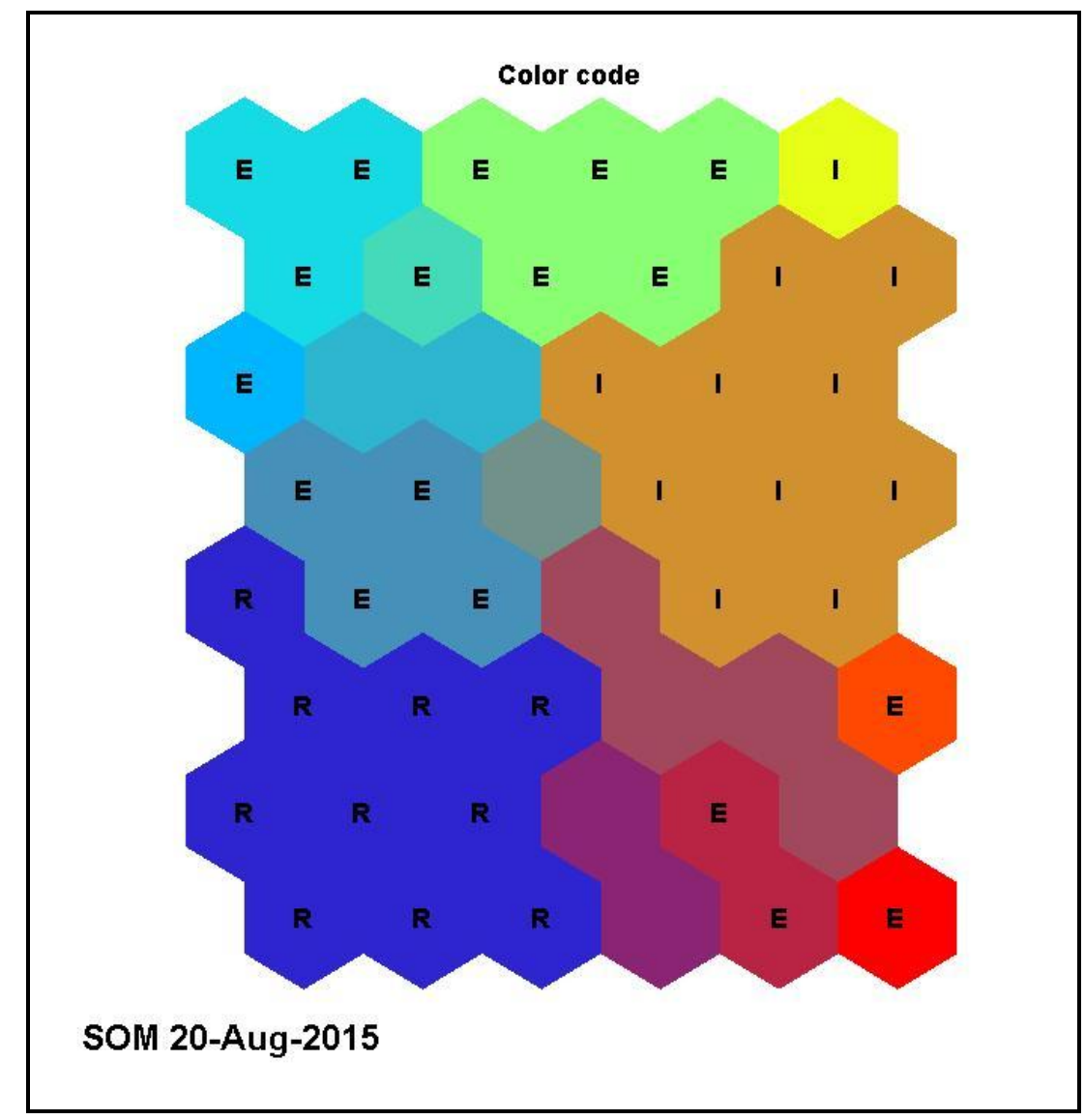

Figura 5.1.1.1.4: Mapa da SOM treinada com as unidades etiquetadas com cada tipo de instabilidade para classificação - inicialização única com $25 \%$ das amostras.

\subsubsection{Inicialização Única com 50\% de amostragem}

O mesmo procedimento descrito no item 5.1.1.1 foi realizado para uma amostragem de $50 \%$ do banco de dados. Neste item são apresentados exemplos de mapas obtidos dentre os 1000 experimentos de classificação realizados. A inicialização foi realizada aleatoriamente somente na primeira vez, e depois "reutilizada" no treinamento dos mapas para cada amostragem diferente. A Figura 5.1.1.2.1 mostra uma matriz $U$ obtida. 


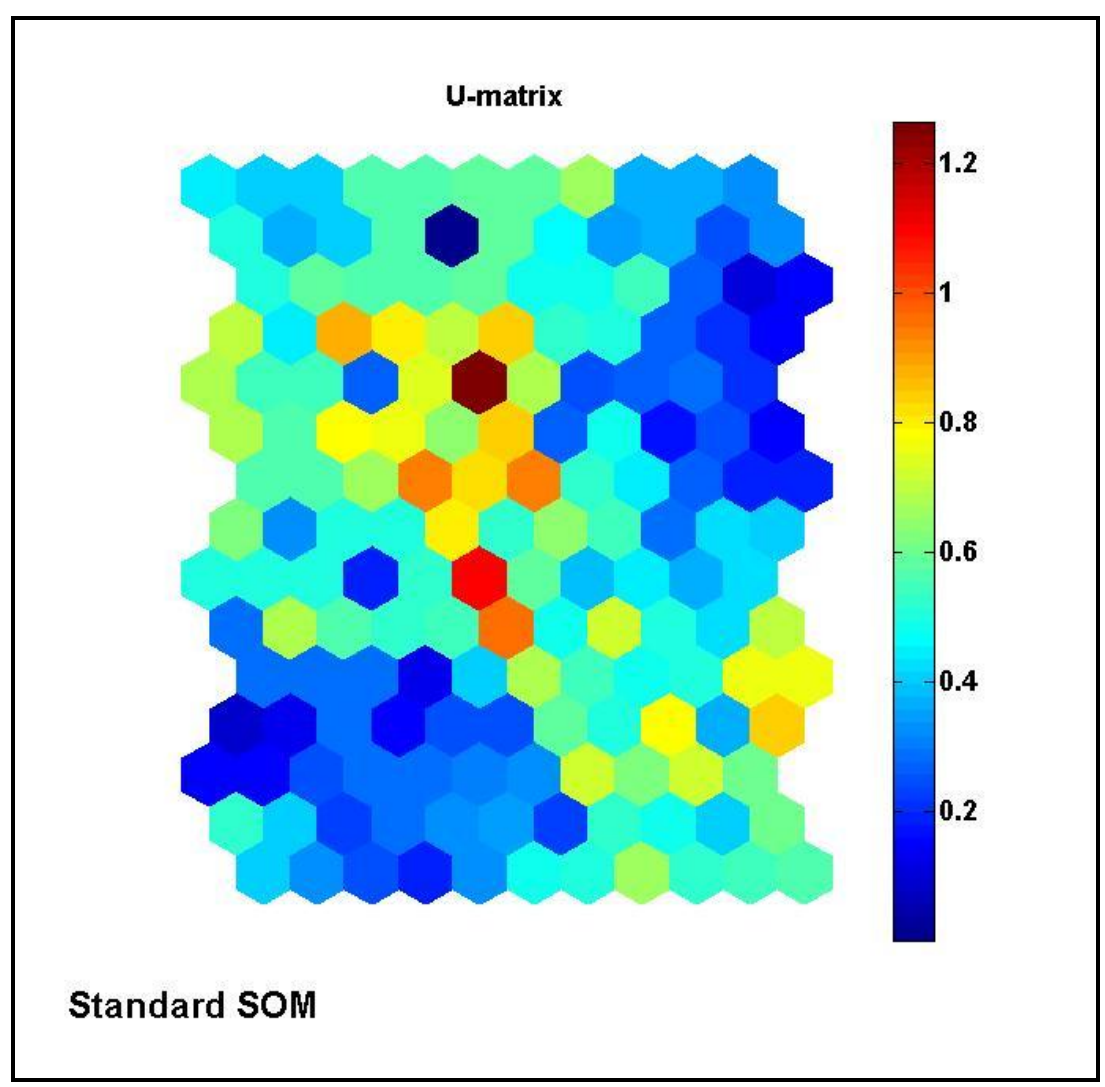

Figura 5.1.1.2.1: Mapa da Matriz Unitária com escala de proximidade (distância euclidiana normalizada) entre as células após treinamento - inicialização única com $50 \%$ das amostras.

O mapa de matriz unitária representa geometricamente as distâncias euclidianas dos vetores característicos das instabilidades do escoamento bifásico no CCN. Esta concentração em duas regiões (código de cor azul) mostram dois grandes grupos de protótipos (Figura 5.1.1.2) que definem uma representação significativa do banco de dados de treinamento utilizado. 


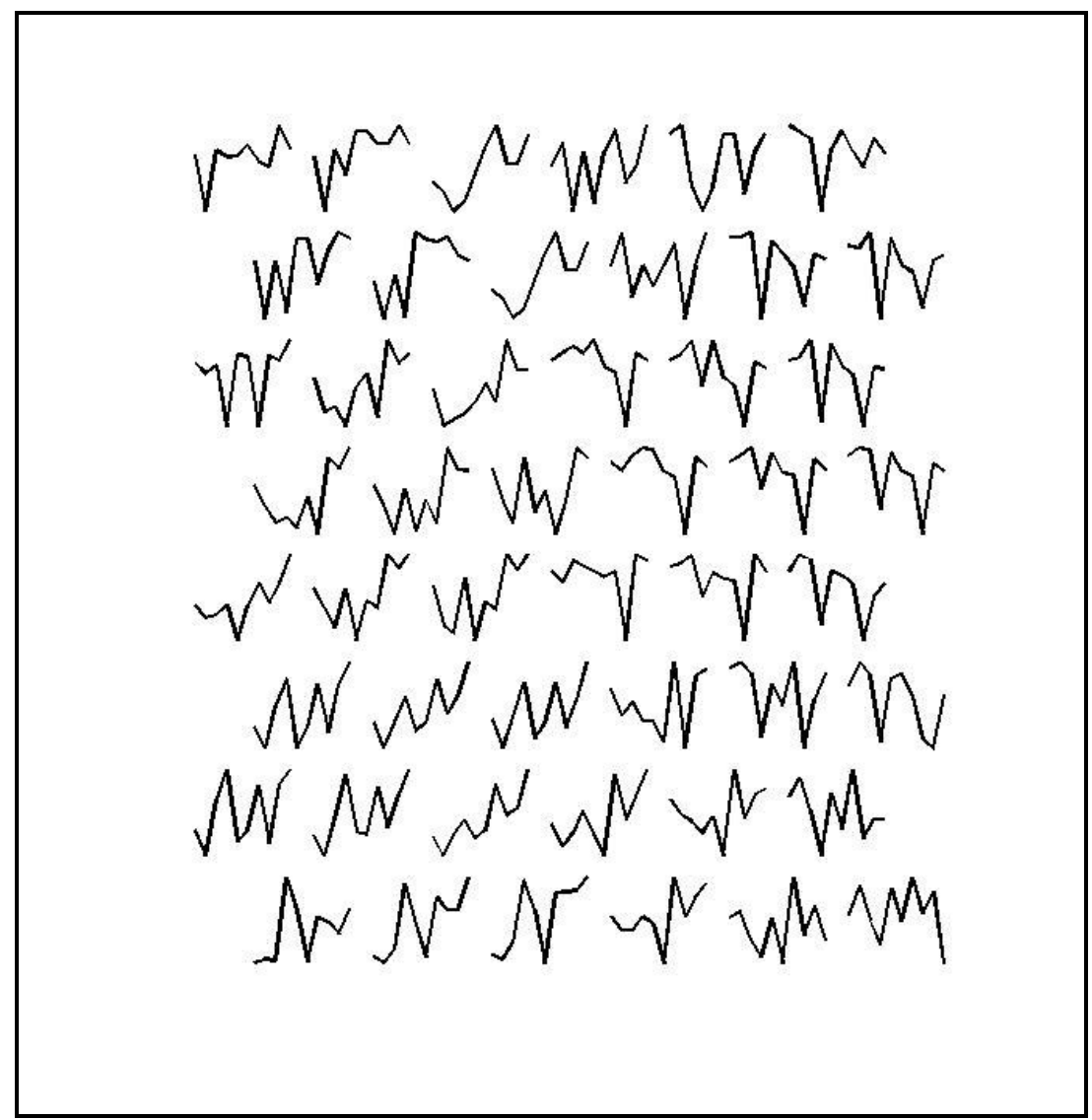

Figura 5.1.1.2.2: Mapa da SOM treinada com os protótipos obtidos referentes aos coeficientes FFDCT - inicialização única com $50 \%$ das amostras.

Ao observarem-se as BMU's do mapa (Figura 5.1.1.2.3) pode-se manter a mesma associação entre estes dois "clusters" com as fases de instabilidade Reenchimento (refill-R) e Incubação (incubation-I). O padrão FFDCT relativo às imagens da fase Expulsão (E) estão "espalhados" pelo resto do mapa em diferentes "clusters" da mesma forma que foi observado com $25 \%$ de amostragem.

Comparativamente, há uma forte semelhança dos mapas obtidos tanto utilizando $25 \%$ como $50 \%$ das amostras do banco de dados utilizado para treinamento. Esta semelhança entre os mapas mostra que existe coerência entre os dois experimentos, o que fica comprovado pela observação dos resultados apresentados na Tabela 5.1.3.2. 


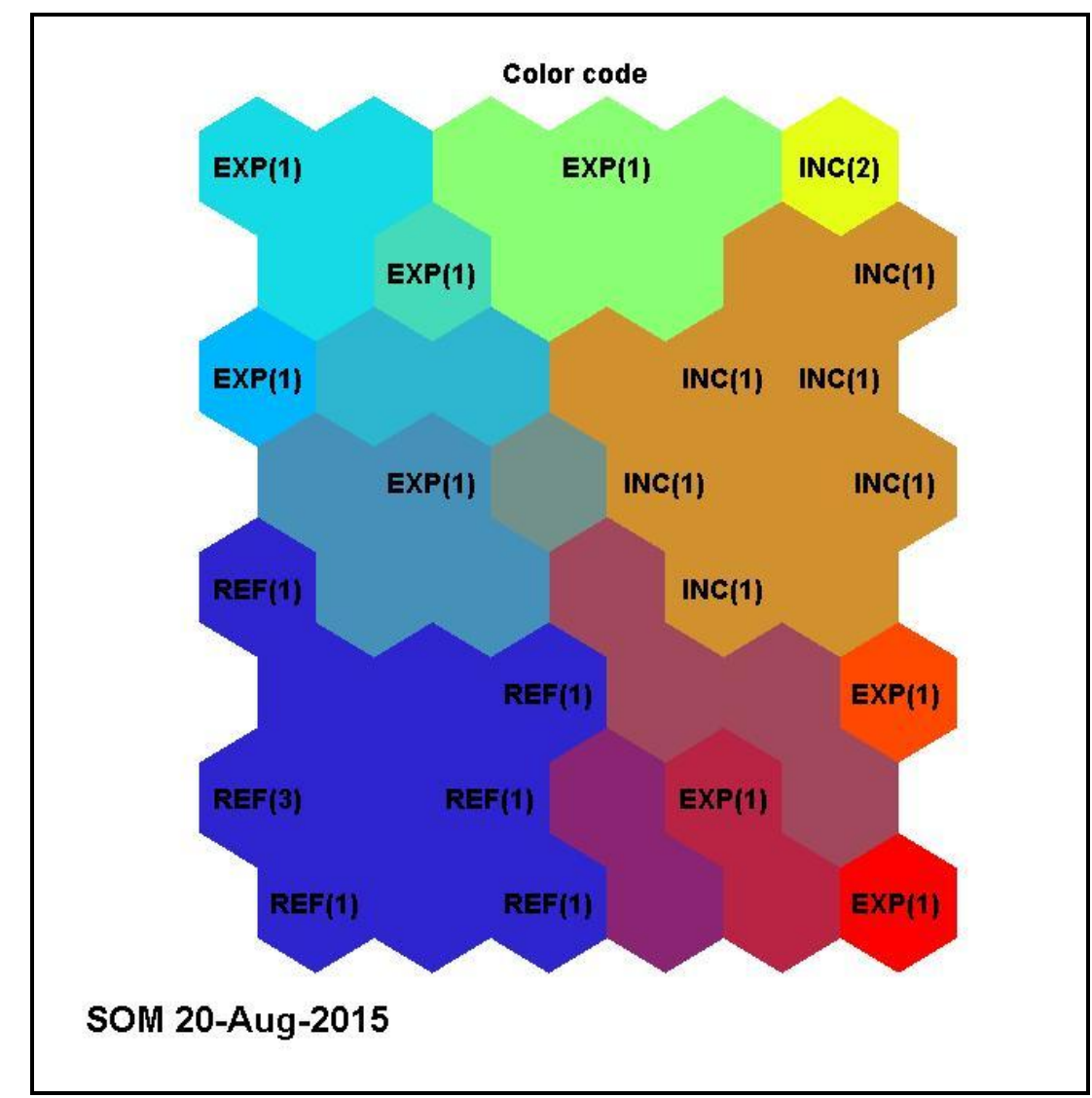

Figura 5.1.1.2.3: Mapa da SOM treinada com as unidades BMU's assinaladas para cada tipo de instabilidade classificada - inicialização única com $50 \%$ das amostras.

A Figura 5.1.1.2.3 mostra um mapa etiquetado típico obtido para classificação utilizando $50 \%$ de amostragem. Pode-se observar que ele é exatamente igual ao obtido com $25 \%$ de amostragem, mostrando coerência e repetibilidade do resultado de treinamento. No entanto, nem sempre estes mapas foram iguais. Com a inicialização única houve menos variabilidade nos resultados de classificação. As tabelas 5.1.3.1 e 5.1.3.2 mostram variações discretas observadas pelo histograma com valores discretos referentes ao acerto de classificação, onde algumas taxas de acerto não ocorreram em 1000 experimentos. 


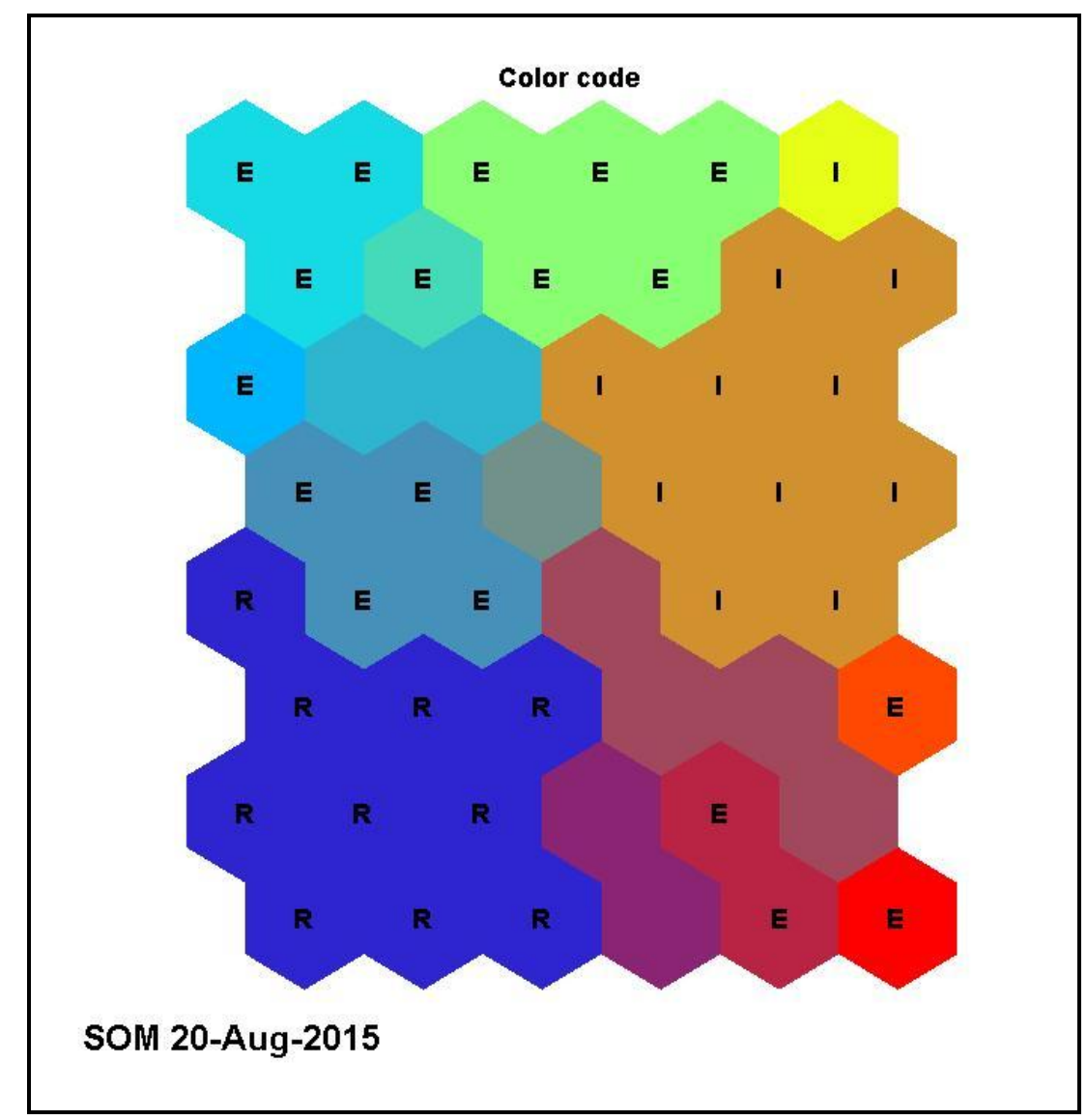

Figura 5.1.1.2.3: Mapa da SOM treinada com as unidades etiquetadas com cada tipo de instabilidade para classificação - inicialização única com $50 \%$ das amostras.

\subsubsection{Inicialização Única com 75\% de amostragem}

Nesta seção são apresentados os resultados para a inicialização única utilizando 75\% de amostragem em 1000 experimentos de classificação. Pode-se observar que os mapas obtidos (Figuras 5.1.1.3.1 a 5.1.1.3.4) com esta porcentagem amostral, em geral, repetiram o mesmo padrão anterior. Os mapas exibidos são exatamente iguais aos anteriormente obtidos. Isto não ocorreu em todos os experimentos. Ao observar-se os resultados apresentados nas tabelas 5.1.3.1, 5.1.3.2 e 5.1.3.3, pode-se perceber variações estatísticas no acerto de classificação representadas pelo histograma. Assim, fica evidenciada a grande influência da amostragem utilizada para treinamento, para o sucesso da classificação. Podem-se observar alguns experimentos onde houve acerto muito baixo para um dos escoamentos. Estes casos ocorreram quando houve baixa 
convergência e consequente dificuldade na obtenção de um mapa de classificação corretamente etiquetado.

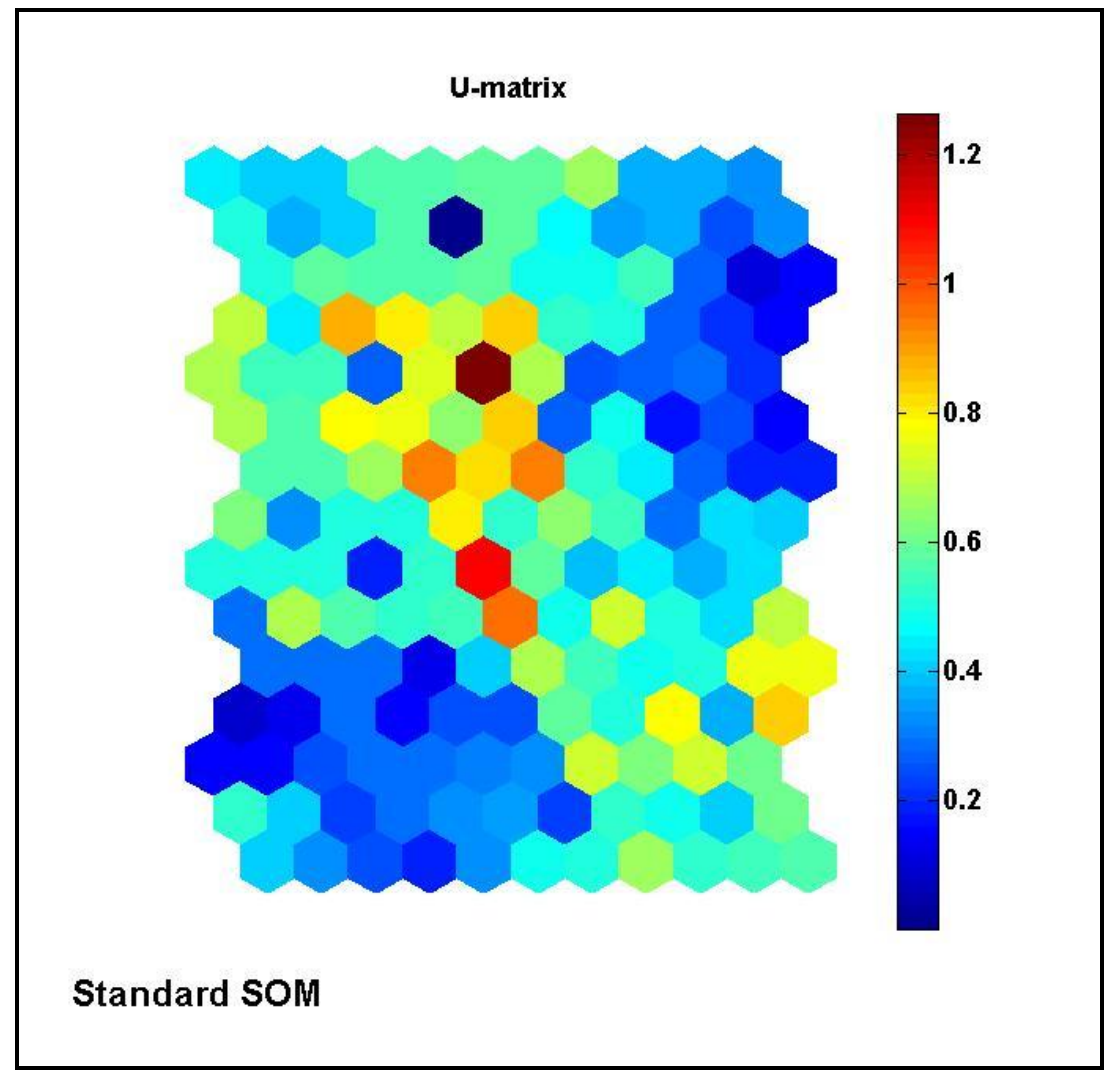

Figura 5.1.1.3.1: Mapa da Matriz Unitária com escala de proximidade (distância euclidiana normalizada) entre as células após treinamento - inicialização única com $75 \%$ das amostras. 


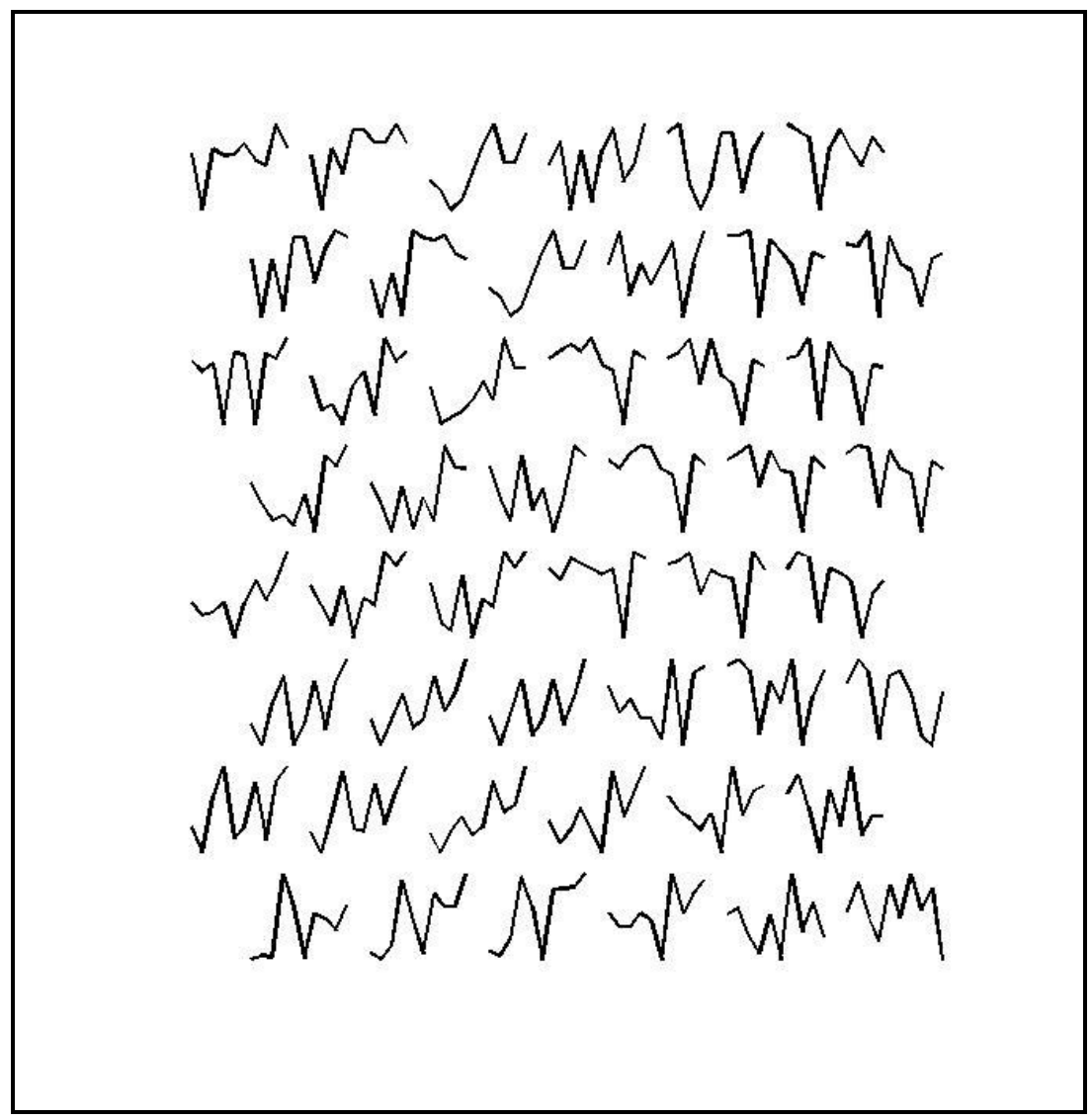

Figura 5.1.1.3.2: Mapa da SOM treinada com os protótipos obtidos referentes aos coeficientes FFDCT - inicialização única com $75 \%$ das amostras. 


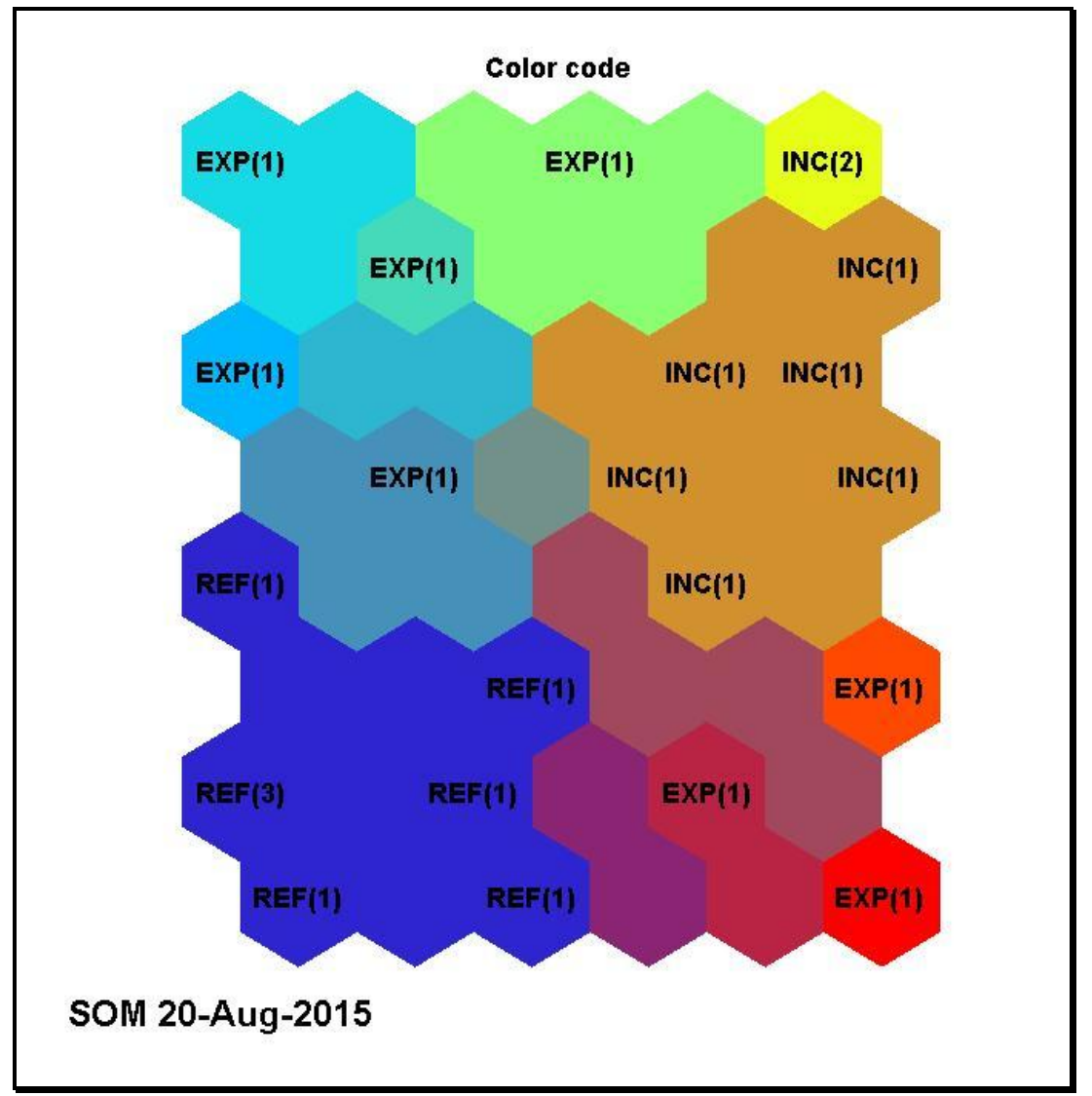

Figura 5.1.1.3.3: Mapa da SOM treinada com as unidades BMU's assinaladas para cada tipo de instabilidade classificada - inicialização única com 75\% das amostras. 


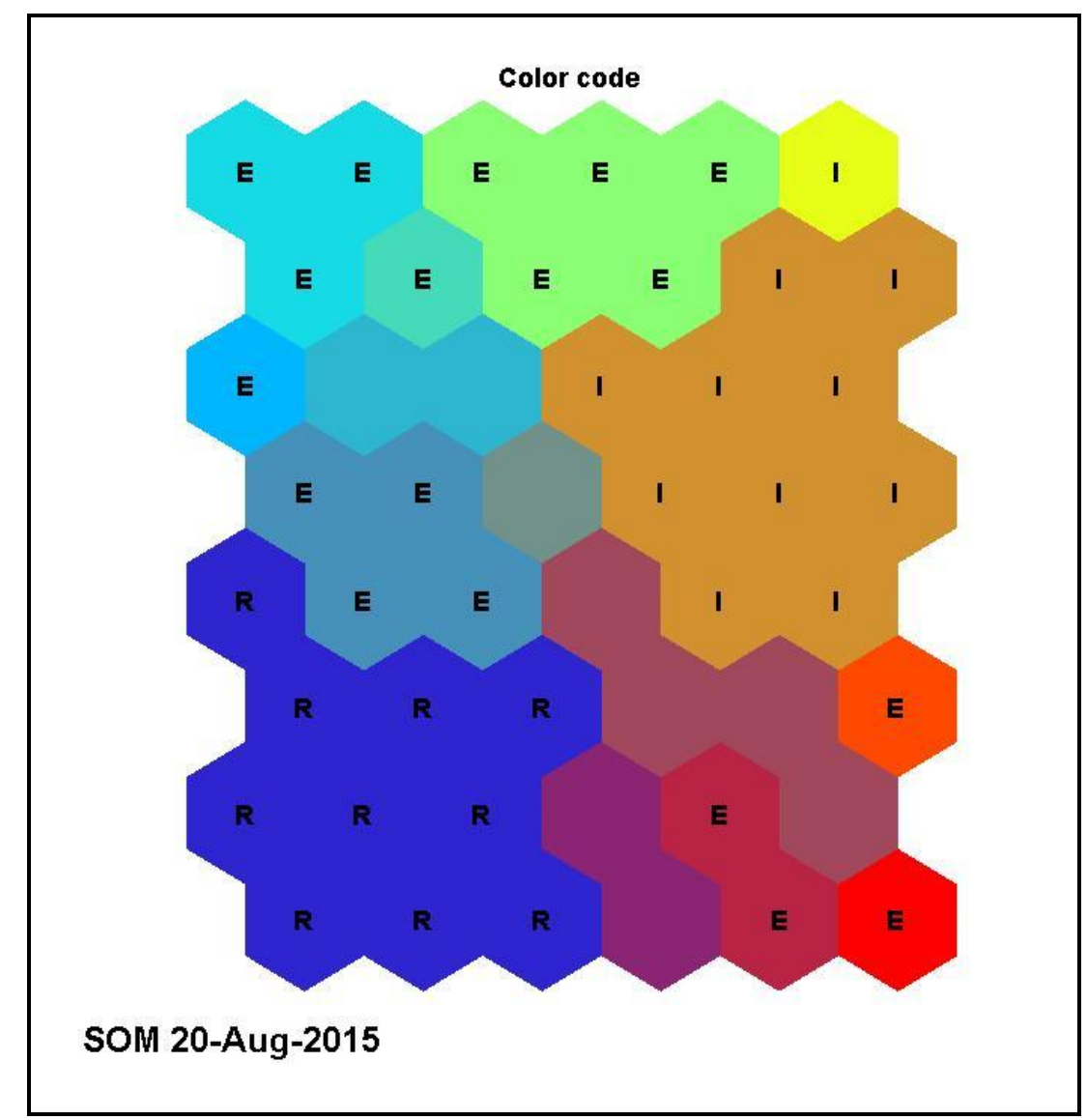

Figura 5.1.1.3.4: Mapa da SOM treinada com as unidades etiquetadas com cada tipo de instabilidade para classificação - inicialização única com 75\% das amostras.

\subsubsection{Testes com Inicialização Variada}

\subsubsection{Inicialização Variada com $25 \%$ de amostragem}

Foram feitos 1000 experimentos de treinamento da SOM com diferentes inicializações aleatórias utilizando $25 \%$ dos dados disponíveis. Sendo que a cada nova inicializações são utilizados nova amostra com $25 \%$ do banco de dados. Em todo o experimento o procedimento é repetido. 


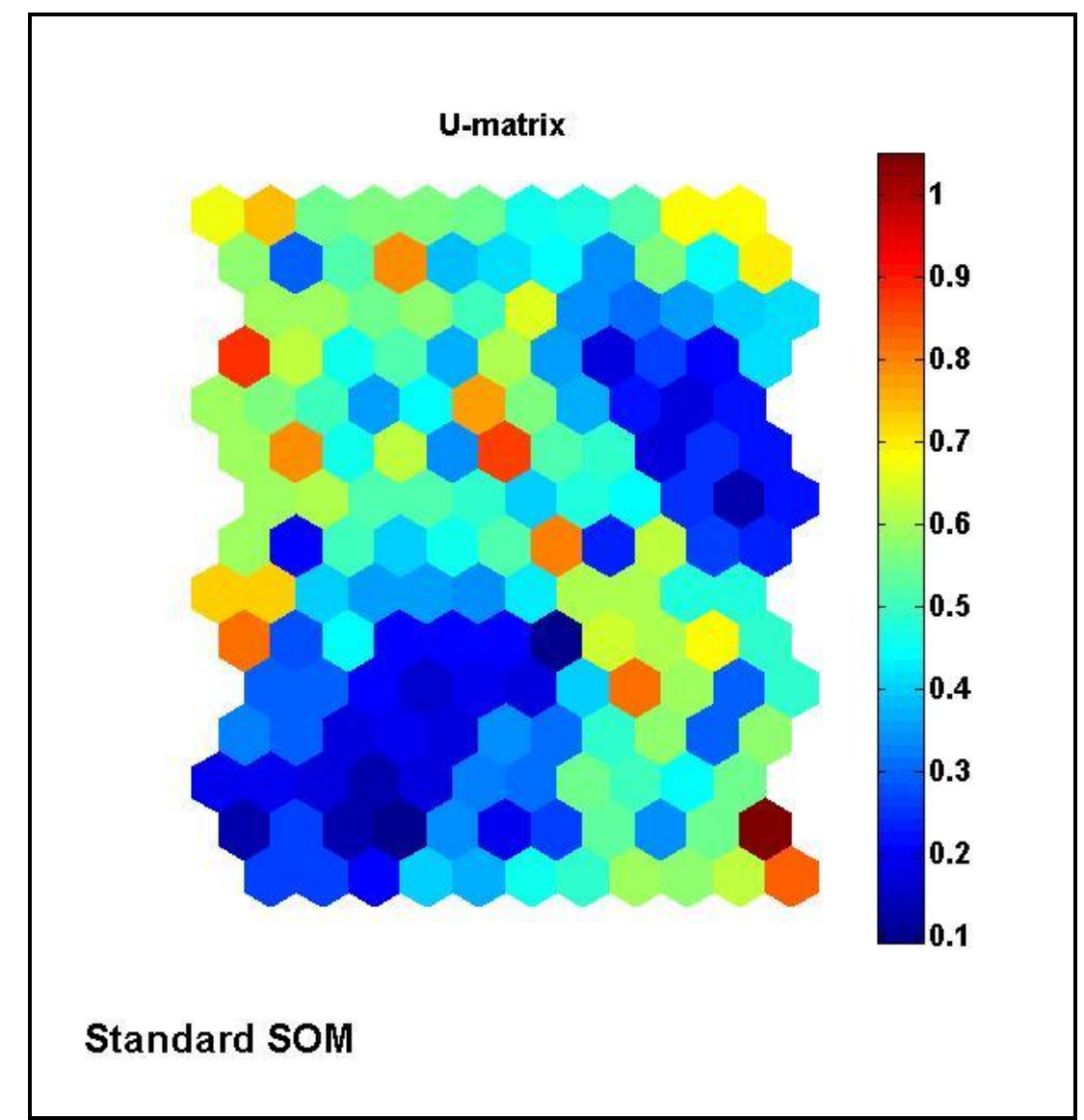

Figura 5.1.2.1.1: Mapa da Matriz Unitária com escala de proximidade (distância euclidiana normalizada) entre as células após treinamento - Inicialização Variada com 25\% de amostragem.

O mapa de matriz unitária U-matriz - (Figura 5.1.2.1.1) representa as distâncias euclidianas dos vetores característicos das instabilidades do escoamento bifásico do CCN. A concentração em duas regiões do mapa (código de cor azul) mostra dois grandes grupos de protótipos (Figura 5.1.2.1.2) são correspondentes aos mapas obtidos com inicialização única para as diferentes amostragens. 


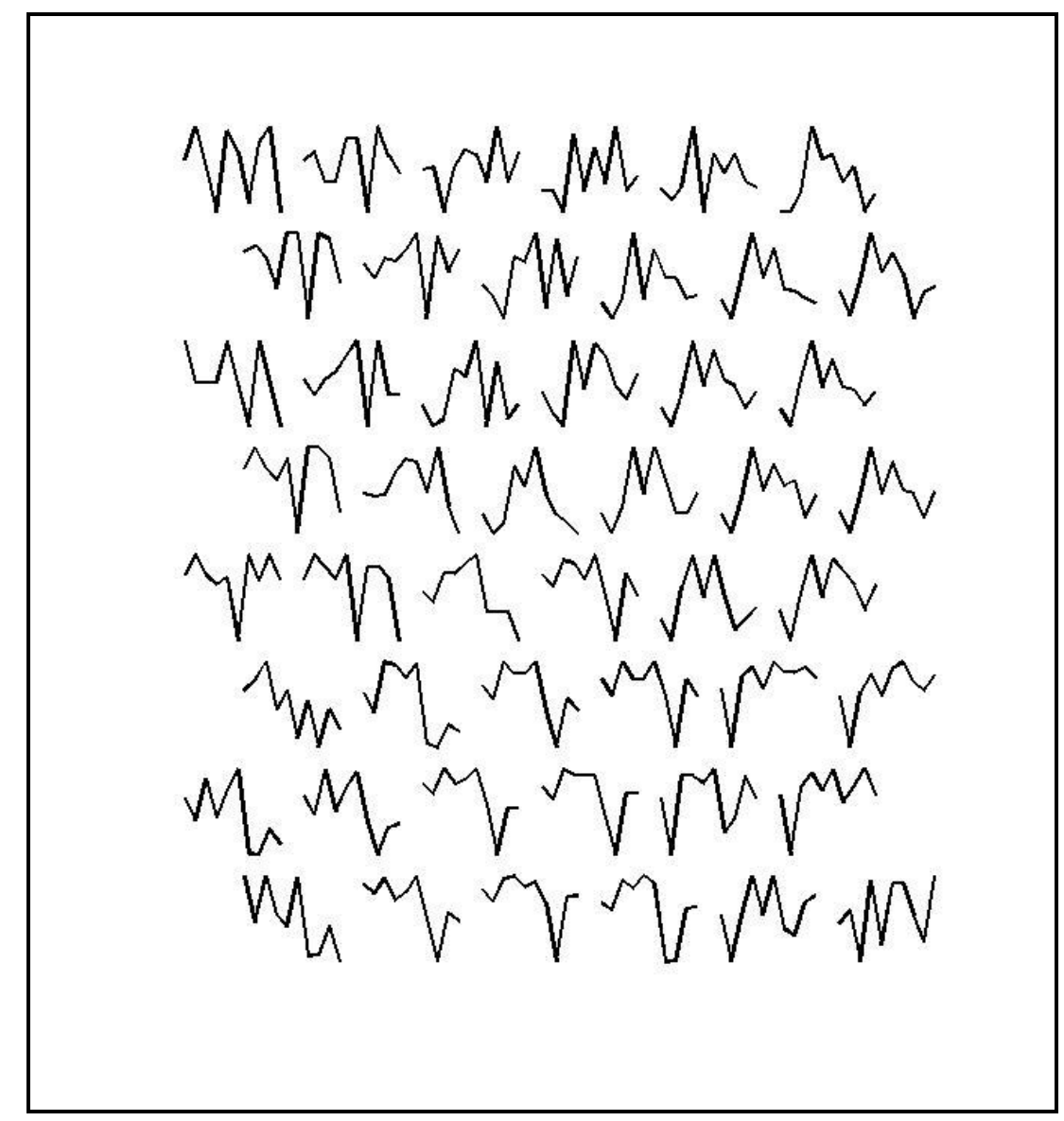

Figura 5.1.2.1.2: Mapa da SOM treinada com os protótipos obtidos referentes aos coeficientes FFDCT - Inicialização Variada com 25\% de amostragem 


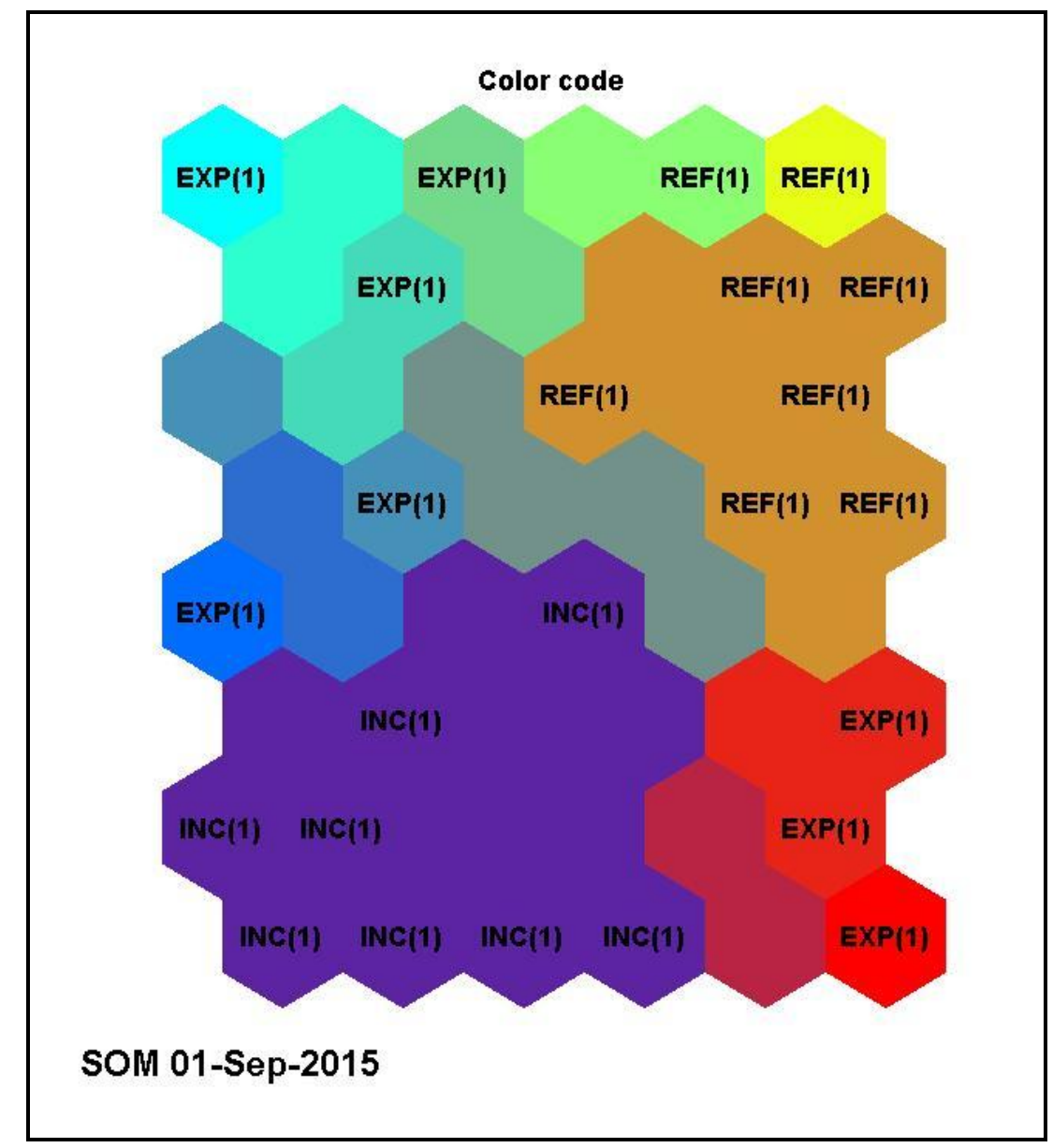

Figura 5.1.2.1.3: Mapa da SOM treinada com as unidades BMU's assinaladas para cada tipo de instabilidade classificada - Inicialização Variada com $25 \%$ de amostragem

As Figuras 5.1.2.1.3 e 5.1.2.4 mostram um mapa de BMU's e o mapa de classificação típico utilizado dentre os 1000 experimentos de teste feitos para amostragem de $25 \%$ do bando de dados. Os resultados dos experimentos com amostras de $25 \%$ de toda a base estão descritos na tabela 5.1.3.4. 


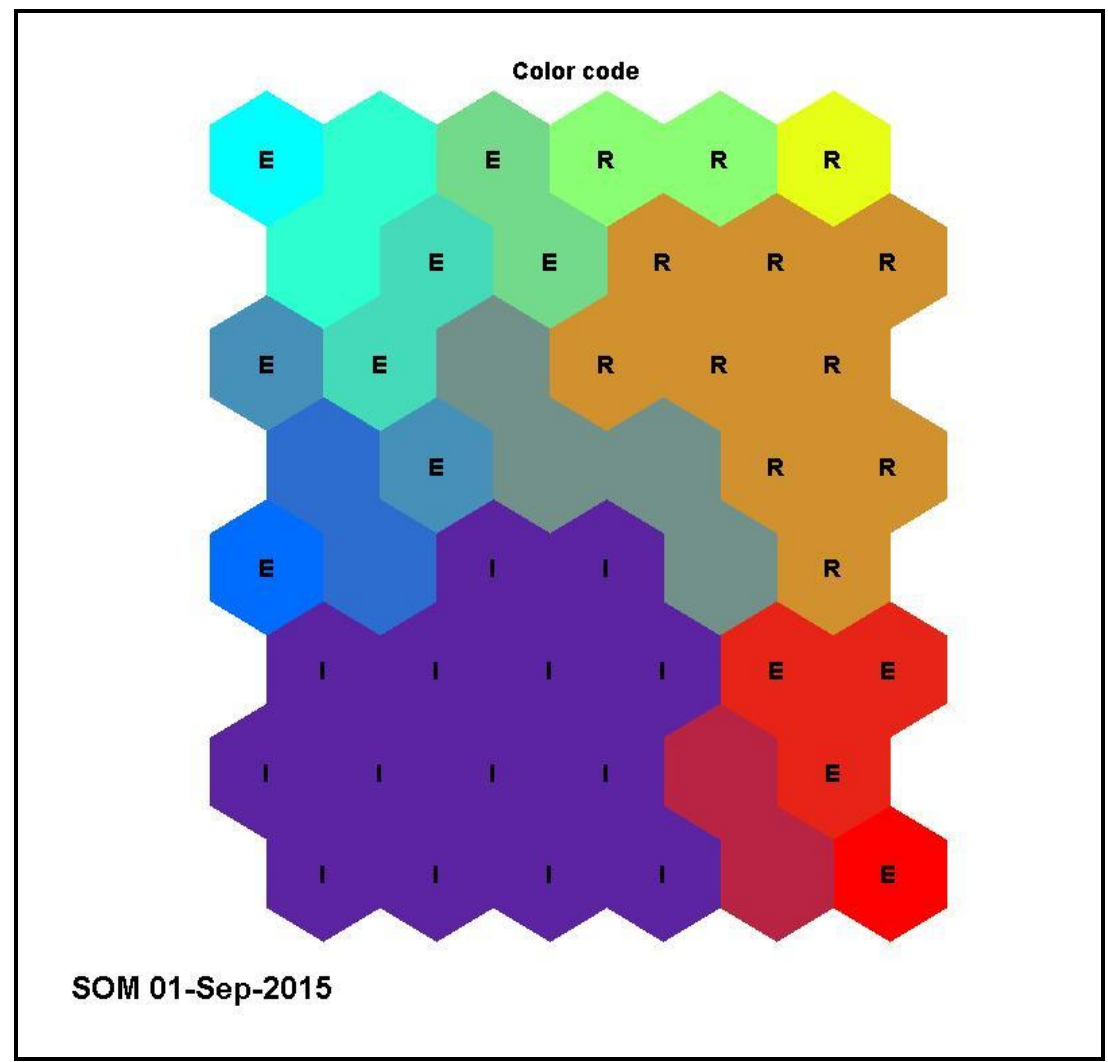

Figura 5.1.2.1.4: Mapa da SOM treinada com as unidades etiquetadas com cada tipo de instabilidade para classificação- Inicialização Variada com 25\% de amostragem 


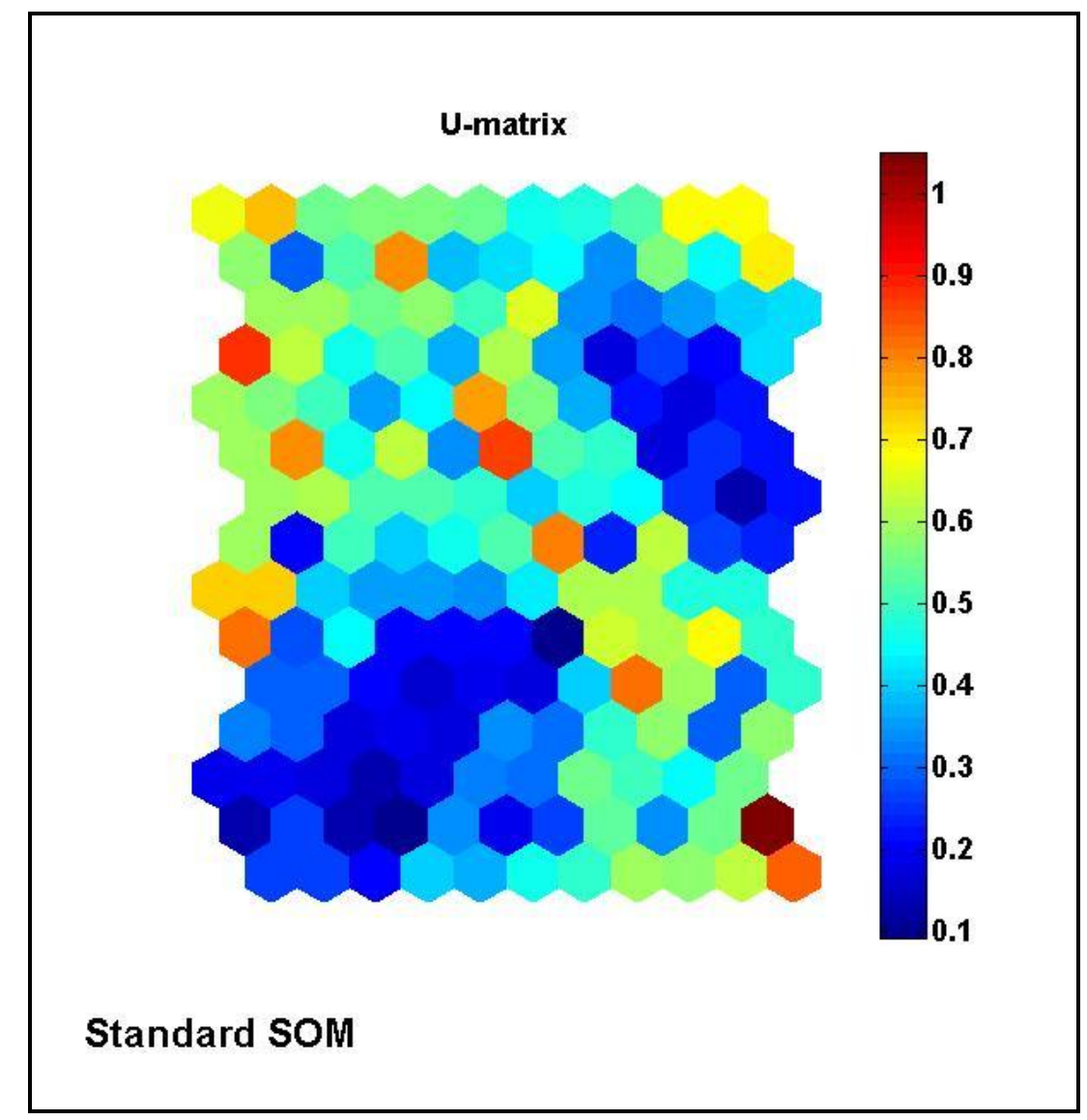

Figura 5.1.2.2.1: Mapa da Matriz Unitária com escala de proximidade (distância euclidiana normalizada) entre as células após treinamento- Inicialização Variada com $50 \%$ de amostragem

O mapa de matriz unitária U-matriz (Figura 5.1.2.2.1) representa as distâncias dos vetores característicos das instabilidades do escoamento bifásico. Existe muita semelhança com o obtido com $25 \%$ de amostragem, mas exibe variações quanto ao tamanho dos clusters. Em termos gerais os tipos de instabilidades observados no mapa de protótipos (Figura 5.1.2.2.2) em muito aos observados anteriormente. 


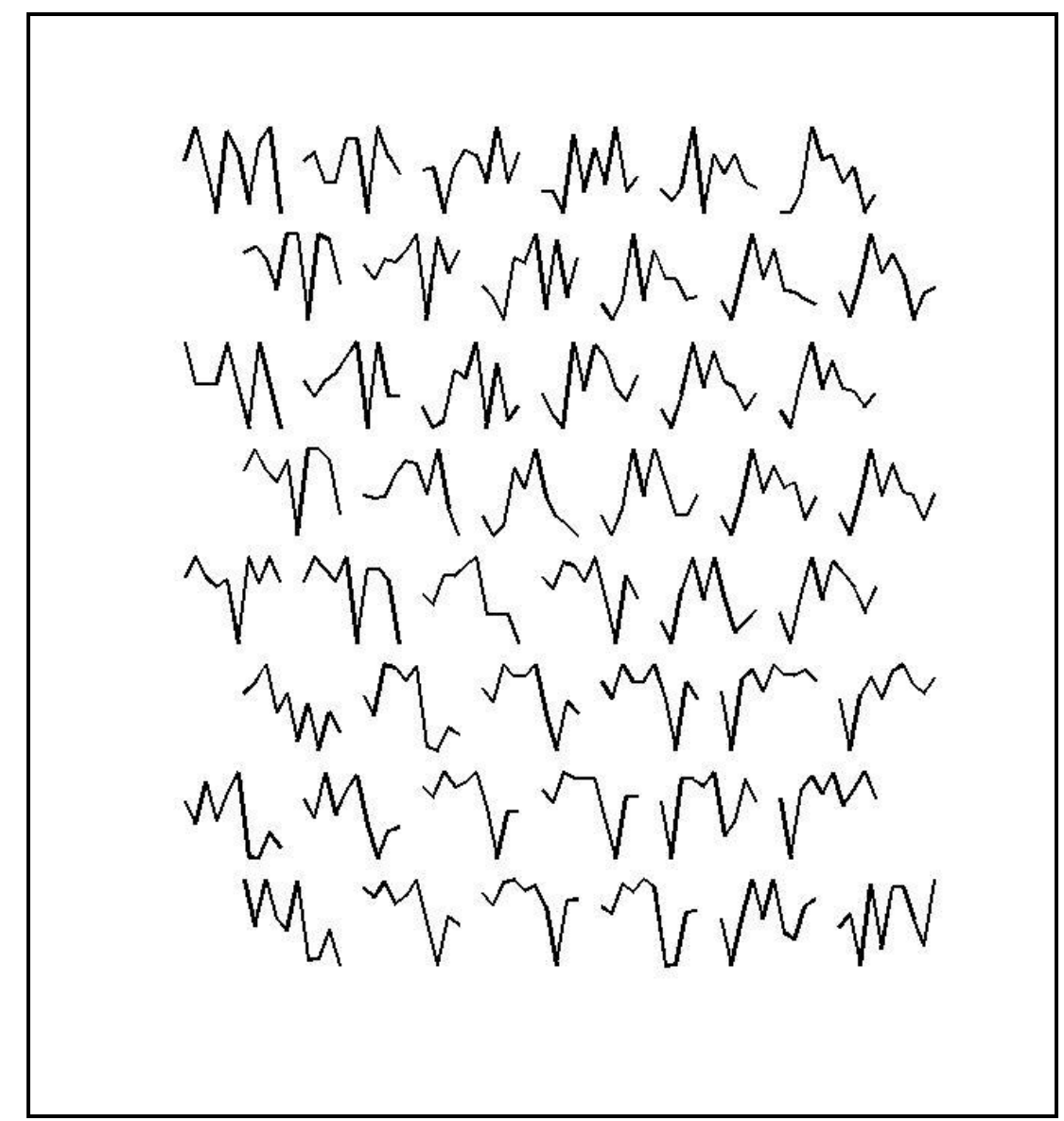

Figura 5.1.2.2.2: Mapa da SOM treinada com os protótipos obtidos referentes aos coeficientes FFDCT. - Inicialização Variada com 50\% de amostragem 


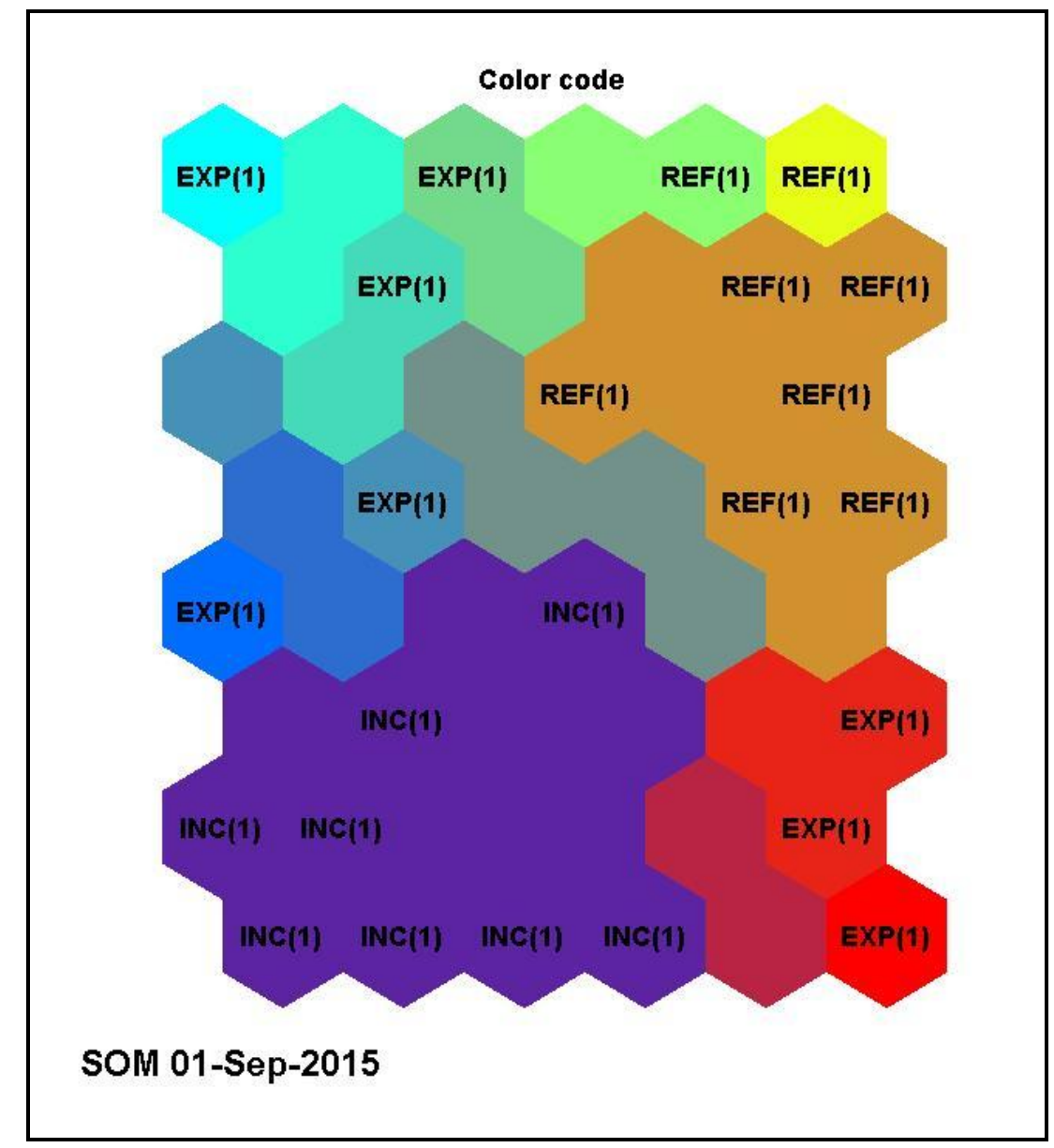

Figura 5.1.2.2.3: Mapa da SOM treinada com as unidades BMU's assinaladas para cada tipo de instabilidade classificada - Inicialização Variada com $50 \%$ de amostragem

Um mapa etiquetado com BMU's da SOM treinada com 50\% dos dados é apresentado na Figura 5.1.2.2.3. A partir deste mapa foi gerado o mapa de classificação mostrado na Figura 5.1.2.2.4. A partir de um mapa devidamente etiquetado, efetuou-se a comparação com a base de dados de teste. Este procedimento foi repetido 1000 vezes, fazendo-se uma inicialização aleatória nova para cada teste. Os resultados destes testes de classificação são apresentados na tabela 5.1.3.5. 


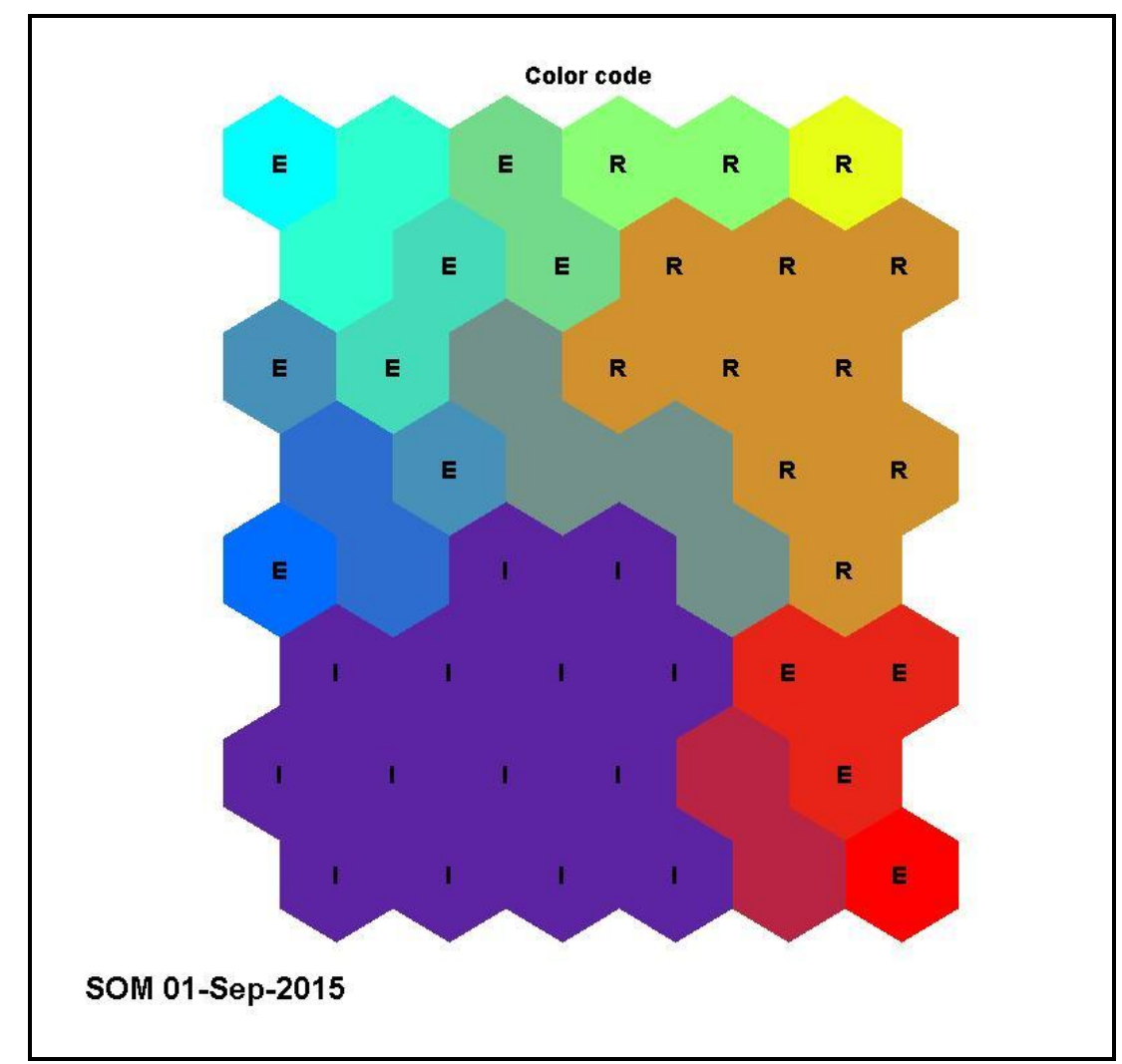

Figura 5.1.2.2.4: Mapa da SOM treinada com as unidades BMU's assinaladas para cada tipo de instabilidade classificada - Inicialização Variada com 50\% de amostragem.

\subsubsection{Inicialização Variada com $75 \%$ de amostragem}

Nesta seção são apresentados exemplos de mapas obtidos dentre os 1000 experimentos de classificação realizados para uma amostragem variada de $75 \%$. A Figura 5.1.2.3.1 mostra uma matriz $U$ obtida. Pode-se nitidamente observar uma maior homogeneidade nesta matriz de distâncias, onde os protótipos apresentam uma maior proximidade entre os protótipos gerados.

Apesar da aparente diferença em relação aos mapas apresentados anteriormente, a concentração em dois clusters se manteve, além disto, estes dois agrupamentos são referentes mais uma vez aos tipos Incubação e Reenchimento como pode ser visto nas Figuras 5.1.2.3.2, 5.1.2.3.3 e 5.1.2.3.4. 


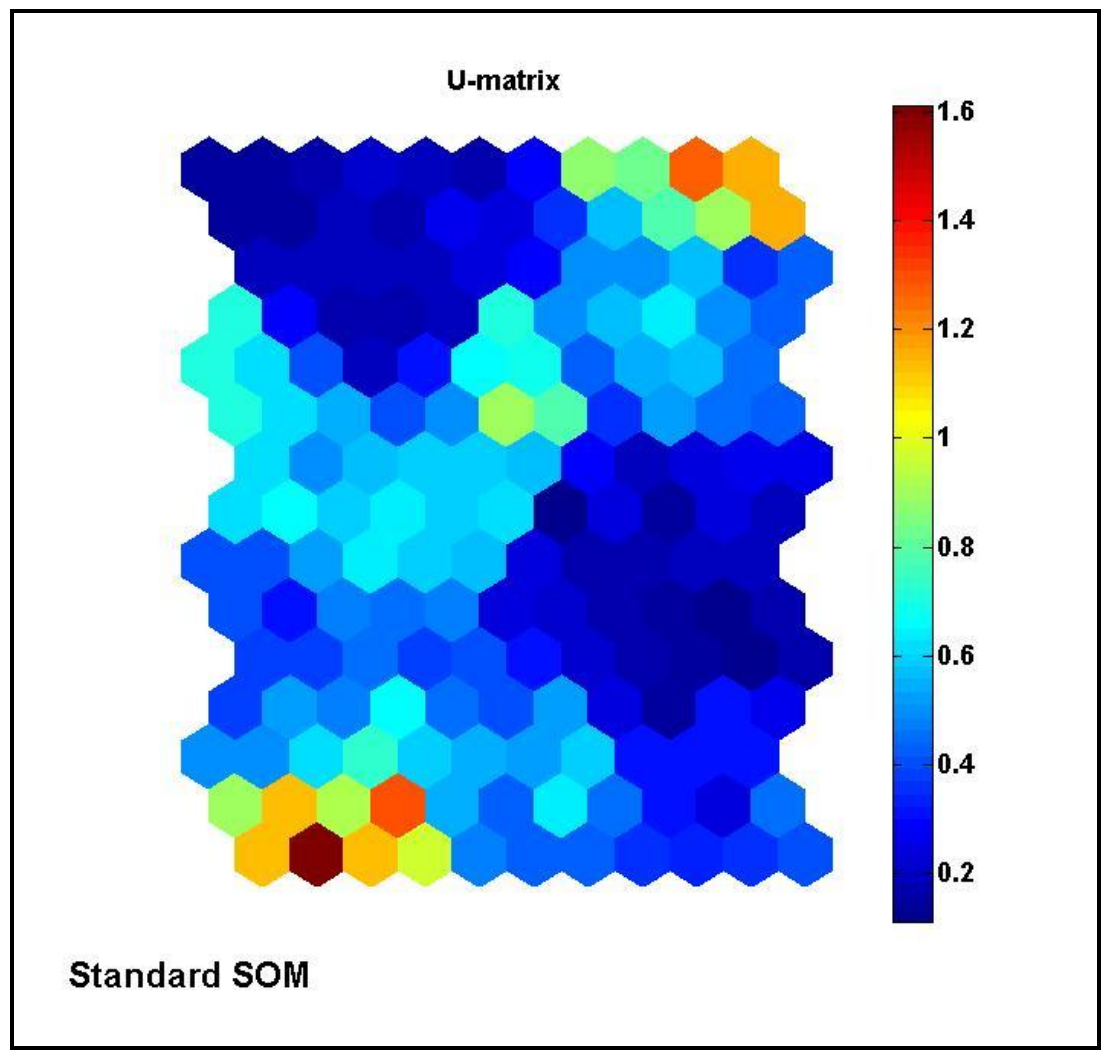

Figura 5.1.2.3.1: Mapa da Matriz Unitária com escala de proximidade (distância euclidiana normalizada) entre as células após treinamento - Inicialização Variada com 75\% de amostragem. 


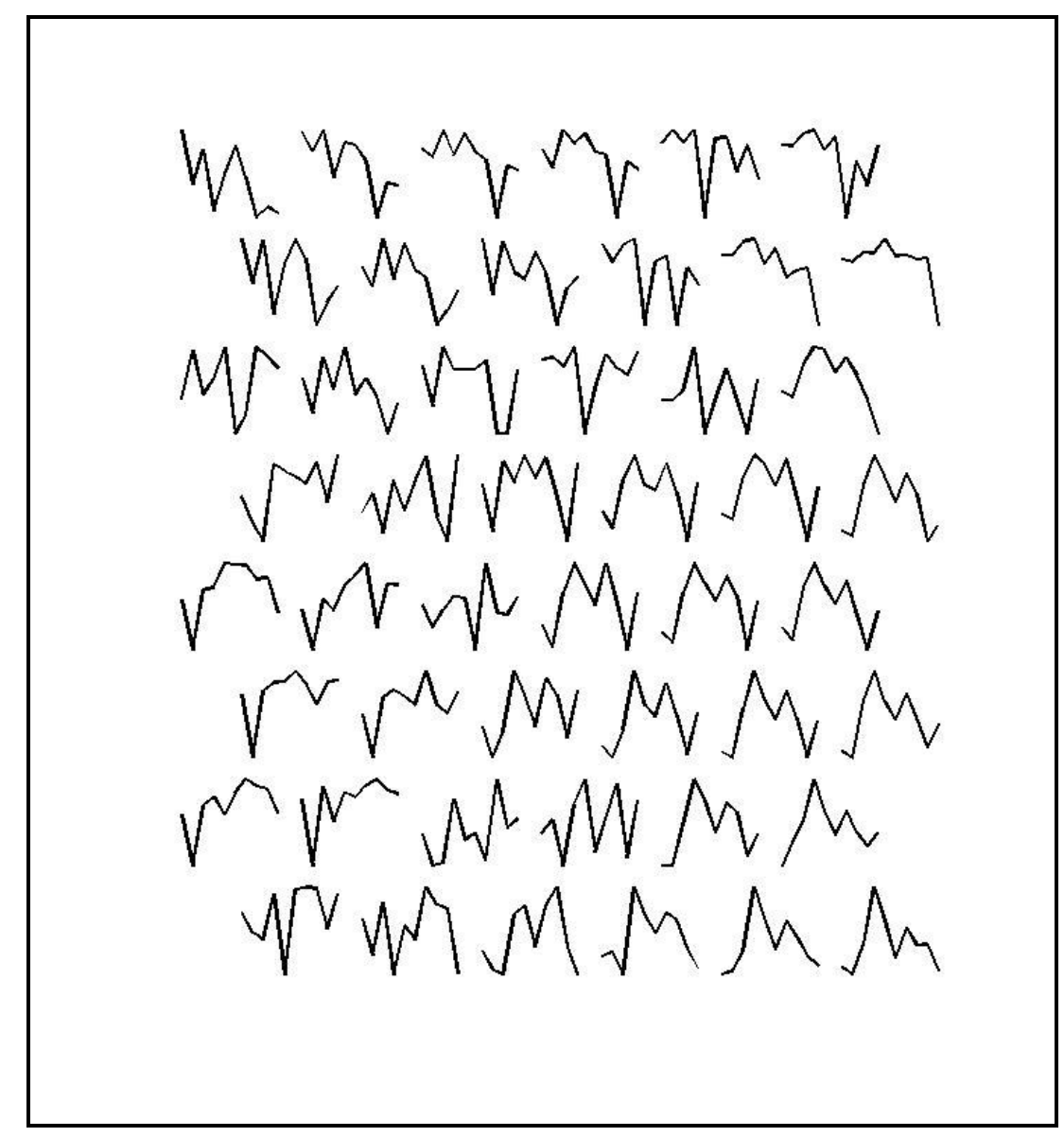

Figura 5.1.2.3.2: Mapa da SOM treinada com os protótipos obtidos referentes aos coeficientes FFDCT - Inicialização Variada com $75 \%$ de amostragem. 


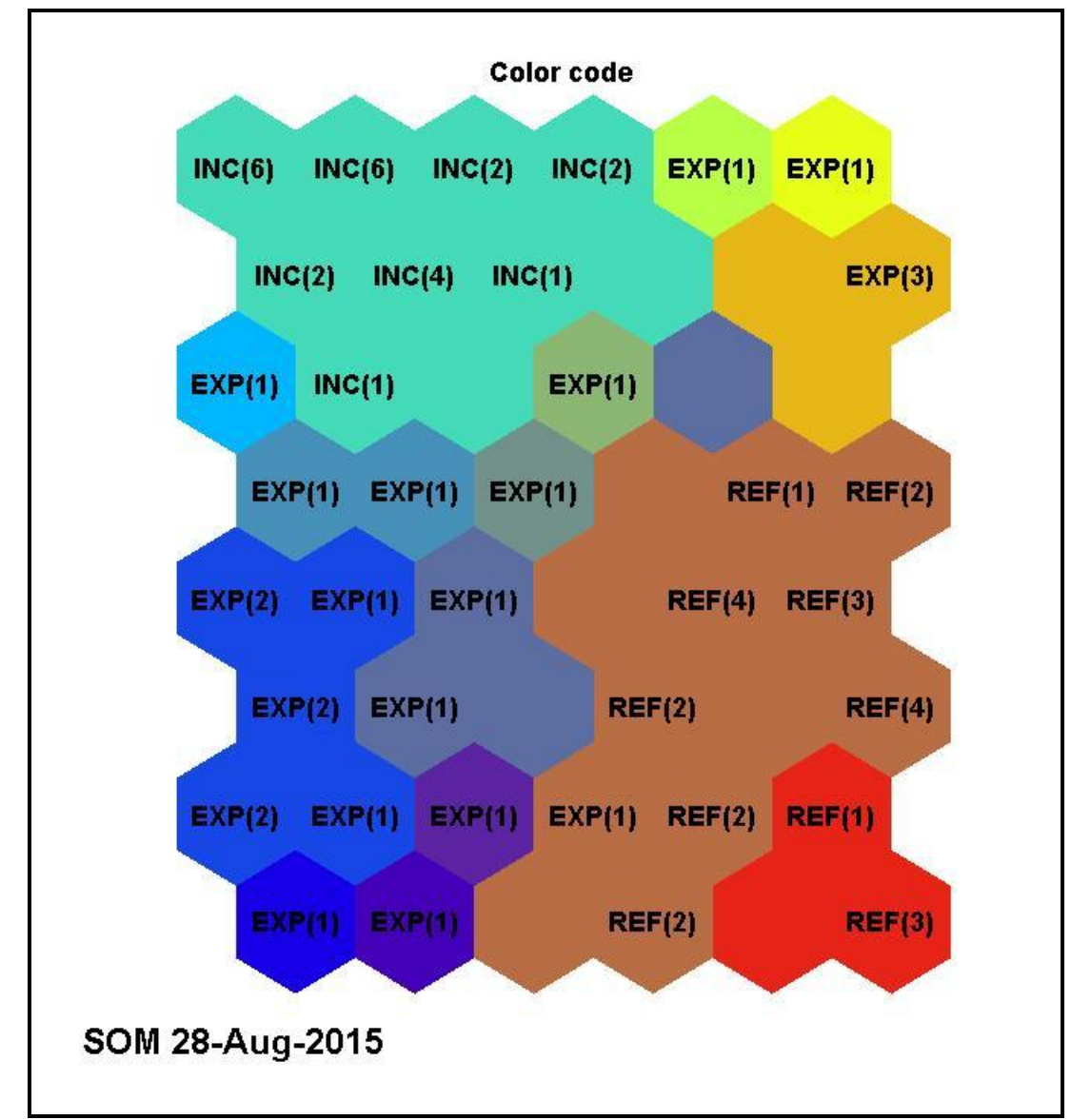

Figura 5.1.2.3.3: Mapa da SOM treinada com as unidades BMU's assinaladas para cada tipo de instabilidade classificada - Inicialização Variada com 75\% de amostragem.

Os resultados dos experimentos de classificação baseados em treinamento com inicialização variada com amostragens de $75 \%$ de toda a base estão descritos na tabela 5.1.3.6. 


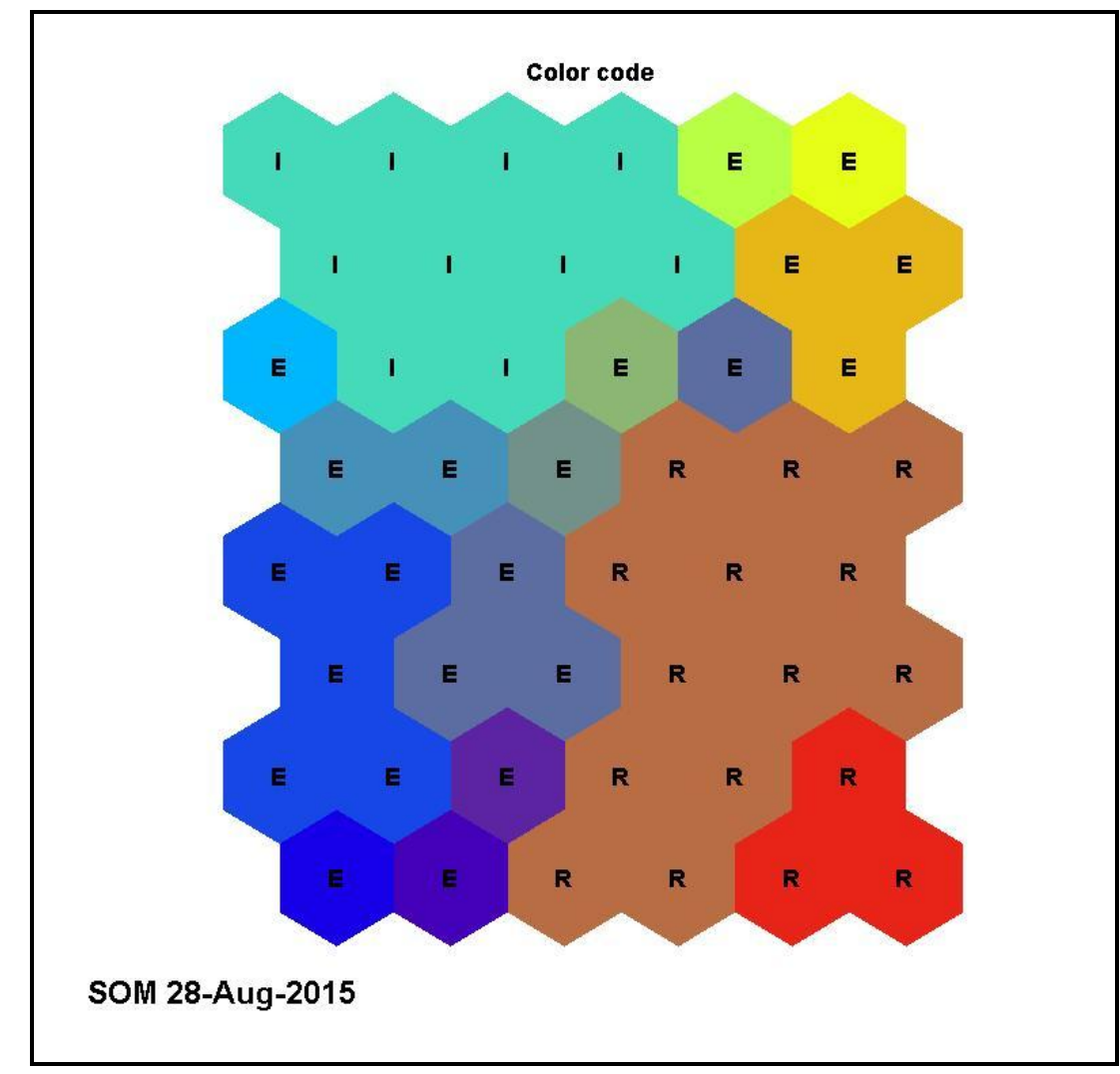

Figura 5.1.2.3.4: Mapa da SOM treinada com as unidades BMU's assinaladas para cada tipo de instabilidade classificada - Inicialização Variada com $75 \%$ de amostragem.

\subsubsection{Testes de Classificação para diferentes inicializações}

Para avaliar os resultados após o treinamento da SOM foram utilizadas métricas tais como a média, os valores de máximo e mínimo bem como o histograma, conforme apresentado nas tabelas (5.1.3.1 a 5.1.3.6).

Os resultados apresentam o sucesso de classificação, e como já foi discutido anteriormente, mostram que há um comportamento de melhor classificação (melhor taxa de acerto médio de classificação) quando a proporção de amostragem é maior. Assim, o acerto médio para os experimentos de classificação com inicialização única, foram 63,36\%, 88,85\% e 94,07\% (Tabelas: 5.1.3.1, 5.1.3.2 e 5.1.3.3) para as amostragens de 25\%,50\% e 75\% respectivamente. Pode-se observar também o espalhamento do histograma de acertos quando se refere ao tipo Expulsão. Coerentemente com os mapas anteriormente mostrado, onde sempre houve uma heterogeneidade na imagem e nos protótipos gerados pela rede, os acertos de 
classificação mostraram uma distribuição estatística dispersa, que mostra sua concentração para valores maiores quando a amostragem é de $75 \%$.

Outro aspecto importante dos resultados é que a utilização de inicializações variadas ocasionou histogramas mais distribuídos e homogêneos. Isto pode ter ocorrido pela geração de mapas diferentes e, portanto com condições iniciais diferentes os mapas de classificação gerados apresentavam variações maiores quando treinados. Assim observa-se que os resultados de classificação médios obtidos foram $64,24 \%$, $88,75 \%$ e $93,98 \%$ (Tabelas: 5.1 .3 .4 , 5.1.3.5 e 5.1.3.6) para $25 \%, 50 \%$ e $75 \%$ respectivamente. Estes valores são muito próximos dos obtidos com inicialização única, porém podemos observar os histogramas menos "quantizados", onde resultados de acertos foram obtidos para diversas faixas de acerto diferentes. 
Tabela 5.1.3.1 - Resultados da classificação da SOM (inicialização única) com 25\% das amostras

\begin{tabular}{|c|c|c|c|c|c|}
\hline & Amostra de treinamento & \multicolumn{3}{|c|}{$25 \%$} & \multirow{2}{*}{ Histograma } \\
\hline & Parâmetros estatísticos & $\bar{A}$ & $\mathrm{~A} \downarrow$ & $\mathrm{A} \uparrow$ & \\
\hline \multirow{4}{*}{ 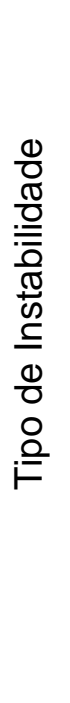 } & I & 96.3 & 0 & 100 & \\
\hline & $E$ & 48.35 & 8.33 & 95.83 & \\
\hline & $\mathrm{R}$ & 45.42 & 0 & 100 & \\
\hline & $G$ & 63.36 & 12.5 & 94.44 & \\
\hline
\end{tabular}


Tabela 5.1.3.2 - Resultados da classificação da SOM (inicialização única) com 50\% das amostras

\begin{tabular}{|c|c|c|c|c|c|}
\hline & Amostra de treinamento & \multicolumn{3}{|c|}{$50 \%$} & \multirow{2}{*}{ Histograma } \\
\hline & Parâmetros estatísticos & $\bar{A}$ & $\mathrm{~A} \downarrow$ & $\mathrm{A} \uparrow$ & \\
\hline \multirow{4}{*}{ 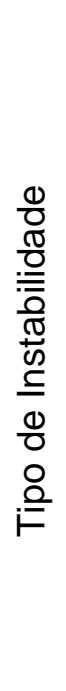 } & I & 98.24 & 0 & 100 & \\
\hline & $E$ & 76.04 & 25 & 100 & \\
\hline & $\mathrm{R}$ & 92.9 & 12.5 & 100 & \\
\hline & $G$ & 88.85 & 54.17 & 100 & \\
\hline
\end{tabular}


Tabela 5.1.3.3 - Resultados da classificação da SOM (inicialização única) com 75\% das amostras

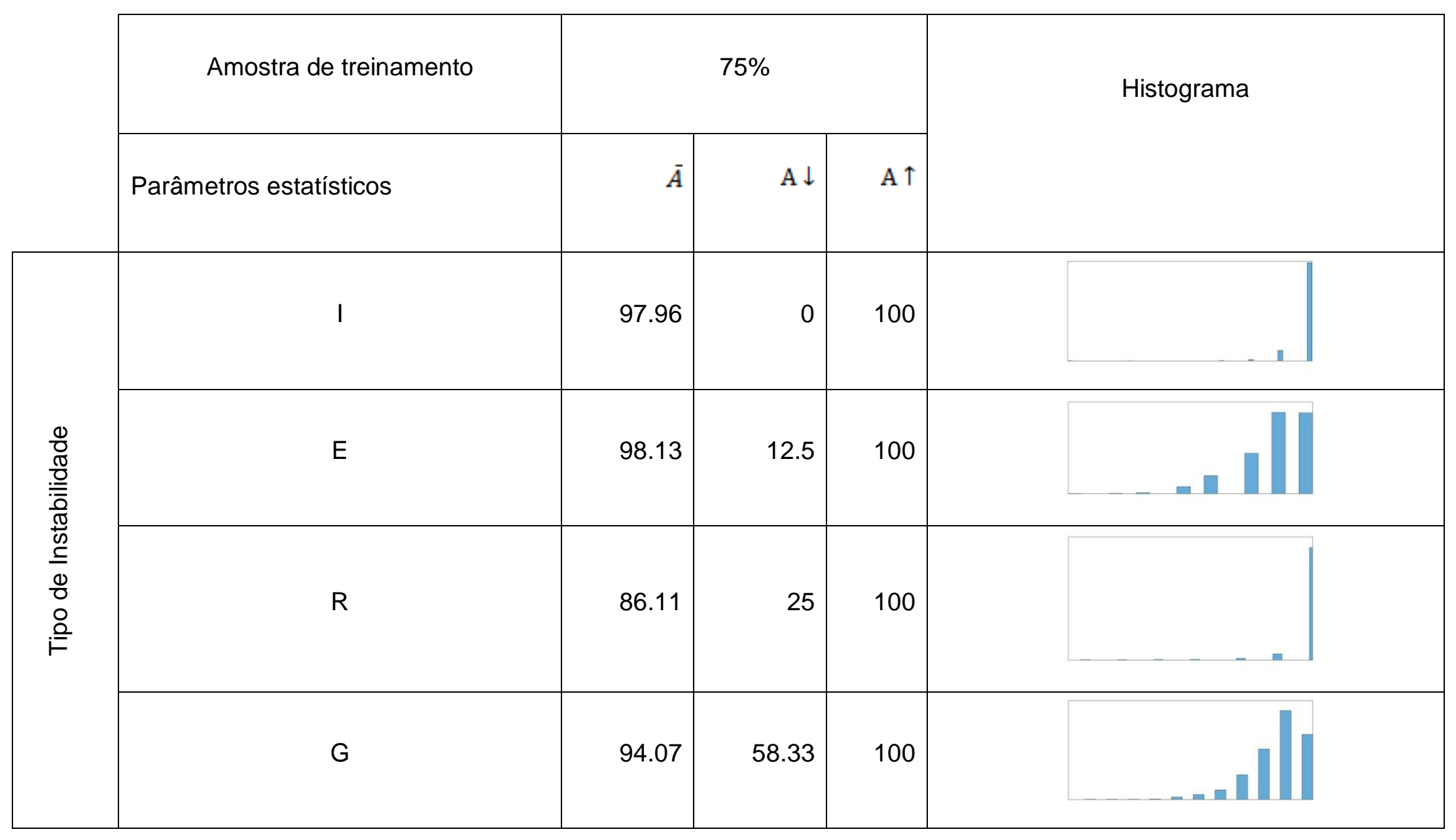


Tabela 5.1.3.4 - Resultados da classificação da SOM (inicialização variada) com 25\% das amostras

\begin{tabular}{|c|c|c|c|c|c|}
\hline & Amostra de treinamento & \multicolumn{3}{|c|}{$25 \%$} & \multirow{2}{*}{ Histograma } \\
\hline & Parâmetros estatísticos & $\bar{A}$ & $\mathrm{~A} \downarrow$ & $\mathrm{A} \uparrow$ & \\
\hline \multirow{4}{*}{$\begin{array}{l}\frac{0}{0} \\
\frac{\pi}{0} \\
\frac{0}{\overline{0}} \\
\frac{\pi}{00} \\
\frac{10}{0} \\
\frac{0}{0} \\
\stackrel{0}{0} \\
i=\end{array}$} & I & 96.39 & 40.42 & 100 & \\
\hline & $E$ & 47.78 & 10.83 & 85.42 & \\
\hline & $\mathrm{R}$ & 48.55 & 1.67 & 100 & \\
\hline & $\mathrm{G}$ & 64.24 & 35.14 & 90.56 & \\
\hline
\end{tabular}


Tabela 5.1.3.5 - Resultados da classificação da SOM (inicialização variada) com 50\% das amostras

\begin{tabular}{|c|c|c|c|c|c|}
\hline & Amostra de treinamento & \multicolumn{3}{|c|}{$50 \%$} & \multirow{2}{*}{ Histograma } \\
\hline & Parâmetros estatísticos & $\bar{A}$ & $\mathrm{~A} \downarrow$ & $\mathrm{A} \uparrow$ & \\
\hline \multirow{4}{*}{ 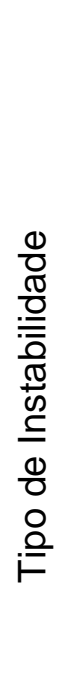 } & I & 98.74 & 70.63 & 100 & \\
\hline & $E$ & 75.61 & 41.25 & 98.75 & \\
\hline & $\mathrm{R}$ & 91.90 & 33.75 & 100 & \\
\hline & G & 88.75 & 67.92 & 99.58 & \\
\hline
\end{tabular}


Tabela 5.1.3.6 - Resultados da classificação da SOM (inicialização variada) com 75\% das amostras

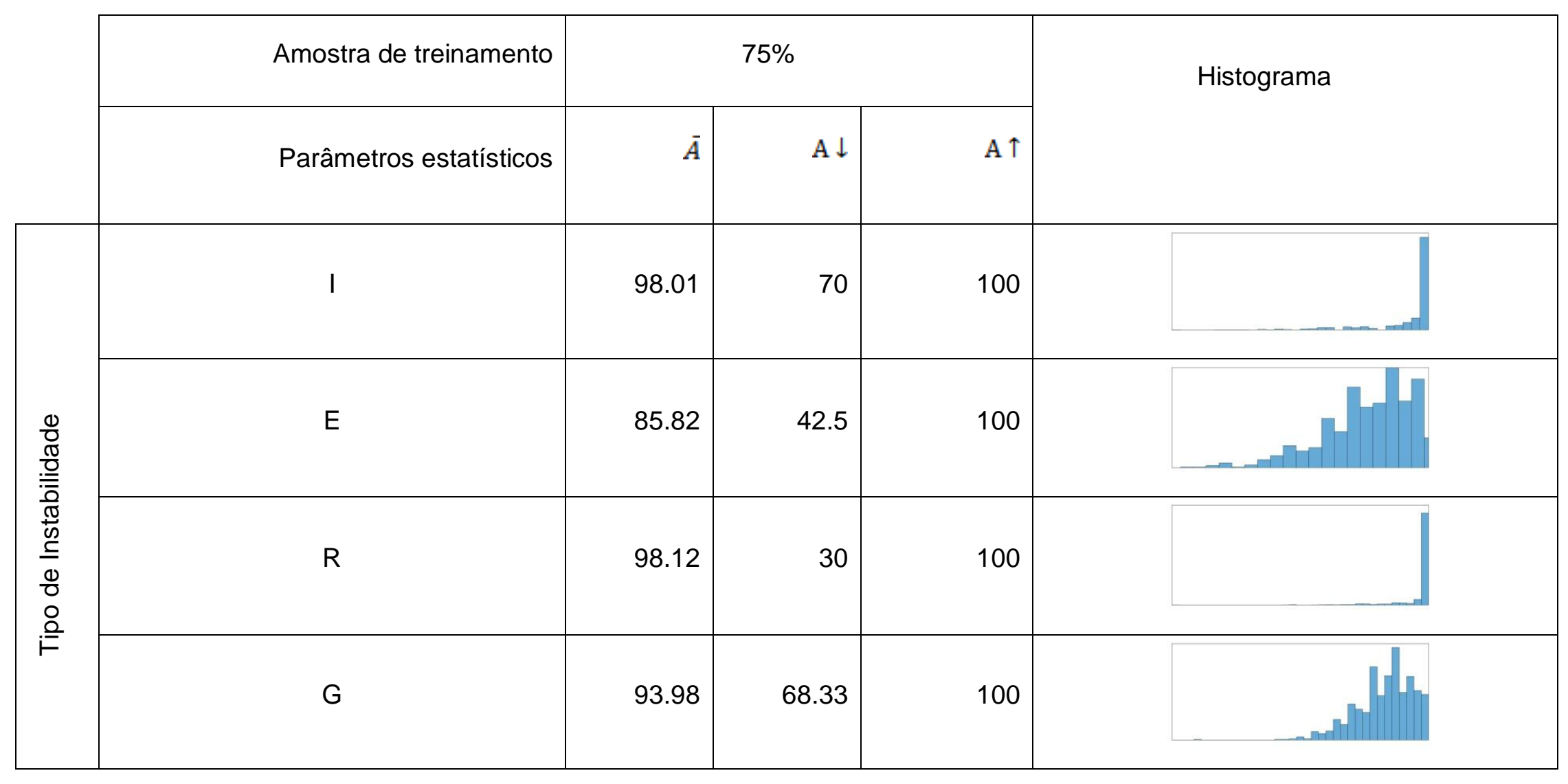




\section{CAPÍTULO 6 - Conclusões}

Foi desenvolvida uma metodologia para classificação das instabilidades produzidas nos escoamentos bifásicos no circuito de circulação natural baseando-se em Mapas Auto-organizáveis treinados em características de frequência de imagens digitais. A classificação deste tipo de instabilidade foi previamente obtida utilizandose um Sistema de Inferência Fuzzy (Mesquita et. al., 2012). Em geral, este tipo de classificação é baseada em parâmetros físicos experimentais como pressão, velocidade, gradiente de temperatura entre outros.

A classificação utilizando a SOM exigiu que as características extraídas das imagens fossem mais fortemente representativas de cada instabilidade do que quando se utilizou o Sistema de Inferência Fuzzy. Ao se tentar utilizar as mesmas características de imagem de caráter estatístico que foram utilizadas no trabalho de Mesquita et. al. (2012) a SOM não conseguiu separar as classes apropriadamente. As regras Fuzzy pareceram compensar a heterogeneidade das imagens referentes a cada tipo de instabilidade, o que este sistema não foi capaz. Deve-se ressaltar que as imagens referentes à instabilidade Expulsão apresentam características bem mais heterogêneas.

não se conseguiu o mesmo sucesso. As regras Fuzzy pareceram compensar a heterogeneidade das imagens referentes ao que este sistema não foi capaz. Devese lembrar que as imagens referentes à instabilidade Expulsão apresentam características bem mais heterogêneas.

A classificação proposta neste trabalho se baseou na utilização dos coeficientes da Transformada de Cosseno. Estes se mostraram muito eficazes na compactação da informação contida na imagem e possibilitaram a obtenção de protótipos característicos de cada instabilidade. Isto facilitou a obtenção de melhores resultados na classificação dos padrões. A utilização de alguns coeficientes desta transformada de quadro completo (FFDCT) como característica de entrada para um 
Mapa Auto-organizável se mostrou inédita na pesquisa bibliográfica feita. Verificouse ser uma boa solução a utilização da técnica FFDCT com a utilização de apenas 12 coeficientes para representar toda a imagem. Esta característica mostrou-se eficiente e de fácil aplicação com pouco demanda de recursos computacionais para a classificação após o treinamento da rede.

Foi implementada uma sistemática de teste de classificação com experimentos de 1000 testes, para se comparar a eficiência das características e a influência da inicialização das redes nos resultados de classificação.

Os resultados de classificação se mostraram muito bons com valores médios próximos de $90 \%$ tanto para inicializações únicas como para inicializações variadas. Os histogramas construídos mostraram coerência e robustez deste resultado.

Este procedimento permitiu a avaliação do desempenho do procedimento de classificação, particularmente no que se refere à certeza associada com a identificação de cada padrão de escoamento. Os padrões expulsão e reenchimento foram identificados com maior certeza, o que pode ser atribuído às suas geometrias características morfológicas de menor complexidade. Os menores índices de certeza foram obtidos para o padrão de instabilidade denominado de expulsão. Este por sua vez, apresenta uma variabilidade de padrão visual muito maior forçando que fossem aperfeiçoadas as técnicas para extração de característica que viessem a identificálo.

Estes resultados se mostraram promissores, e representam uma importante contribuição para a área - fortemente marcada pela multidisciplinaridade - de aplicações em monitoração de escoamentos multifásicos industriais. A possibilidade de monitoração em temo real e utilizando visualização tem sido reforçada por este campo de desenvolvimento 


\subsection{Trabalhos futuros}

Quanto à metodologia de análise de dados das instabilidades do escoamento bifásico com SOM, pode-se progredir a partir da adição de técnicas auxiliares para aperfeiçoar a extração de características. Essa por sua vez demonstrou um dos fatores limitantes para que seja possível a obtenção satisfatória do reconhecimento de padrões das instabilidades discutidas nesse trabalho. Faz-se necessário, também, a análise dos agrupamentos através de diferentes pontos de vista partindose de diferentes configurações do Mapa Auto-Organizável, incluindo-se neste contexto as redes com aprendizagem sequencial e com topologias dinâmicas, e a partir de diferentes algoritmos de detecção automática de agrupamentos através do SOM.

Esperamos estar ampliando ainda mais o conjunto de possibilidades de trabalhar para obtenção de reconhecimento de padrões de escoamento bifásico para uma variedade maior de aplicações, disponibilizando assim mais um instrumento de auxílio a áreas que necessitem dessas técnicas.

Finalmente, como proposta para futuros trabalhos, gostaríamos de salientar duas linhas de atuação:

- $\quad$ Montagem de um sistema autônomo que possa reconhecer em tempo real as instabilidades do CCN, com intuito de promover uma ferramenta de monitoramento.

- Expandir o modelo de reconhecimento através de outras formas de sinal e não somente de imagens. De tal forma, que a utilização do modelo computacional possa ter uma gama maior de utilização. 


\section{Referências bibliográficas}

Ahmad, M. S., 2009 - Iris Recognition Using the Discrete Cosine Transform and Artificial Neural Networks," Journal of Computer Science (JCS), 5(4): 369-373.

Anderson, J., Pellionisz, A.; Rosenfeld, E., 1990 - Neurocomputing 2: Directions for Research. Cambridge Massachusetts, MIT Press.

Andrade, D. A., Belchior, JR. A, Sabundjian, G., Bastos, J. L. F., 2000 - Two-phase instabilities in a natural circulation rectangular loop. In: Proc. 8th International Conference on Nuclear Engineering, Baltimore, MD.

Astel, A. S., Tsakovski, P., Barbieri, V., Simeonov, 2007 - Comparison of self organizing maps classification approach with cluster and principal components abalysis for large environmental data sets. Water Research, 41(19), p. 4566 - 4578.

Barbosa, P. R., Crivelaro, K. C. O. e JR. Seleghim, P., 2010 - On the application of self- organizing neural networks in gas-liquid and gas-solid flow regime identification Journal of the Brazilian Society of Mechanical Sciences and Engineering. J. Braz. Soc. Mech. Sci. \& Eng. vol.32 no 1 Rio de Janeiro Jan./Mar.

Beretta, G., Konstantinides, K., Lee, D.T., Lee, H.J.; Mutz, A.H., Bhaskaran, V., Natarajan, B.K., 1995 - New Group 3 color facsimile standard: protocol testing and performace. In SID 1994 Intern. Symposium Digest of Techinical Papers. SiD, May.

Bernardes, L. E., 2003 - Estudo de escoamento bifásico vertical descendentes utilizando medidor de composição - UFRJ- RJ.

Bouré, J. A. E., Tong B. A., L., 1973 - Review of two-phase flow instability. Nucl. Eng. Des. 25, 165-192. 
Bueno, E. I., 2006 - Utilização de redes neurais artificiais na monitoração e detecção de falhas em sensores do reator IEA - R1, Dissertação (Mestrado), Instituto de Pesquisas Energéticas e Nucleares - IPEN, São Paulo.

Castro, L. F., Cunha, K. de P., Delvonei, A. A., Sabundjian, G., Torres, W. M., Macedo, L. A., Rocha, M. S., Masoti, P. H., Mesquita, R N de - SELF-organizing maps applied to two-phase flow on natural circulation loop studies - IPEN / CNEN International Nuclear Atlantic Conference - INAC- São Paulo, outubro 2015.

Chen, W. H. and Pratt, W. K. - Scene adaptive coder - IEEE Transactions on Communications, vol. COM-32, pp. 225-232, March, 1984.

Crivelaro, K. C. O., Seleghim JR., P., Hervieu, E., 2002. Detection of horizontal twophase flow patterns though a neural network model. J. Braz. Soc. Mech. Sci. 24 (1), 70-75.

Da SILVA, M. A. S., 2008 - Dissertação de Mestrado do Curso de Pós-Graduação em Computação Aplicada, orientada pelos Drs. Antônio Miguel Vieira Monteiro e José Simeão de Medeiros, INPE, São José dos Campos.

Dasari, A., Desamala, A. B., Dasmahapatra, A. K., Mandal, T. K., 2013 Experimental Studies and Probabilistic Neural Network Prediction on Flow Pattern of Viscous Oil-Water Flow through a Circular Horizontal Pipe - Industrial \& Engineering Chimistry Reseach.

Delhaye, J. M., Giot, M., Riethmuller, M. L., 1981 - Thermohydraulics of Two-Phase Systems for Industrial Design and Nuclear Engineering. McGraw-Hill, New York (Chap. 17).

DeSieno, D., 1998 - Adding a Conscience to Competitive Learning Proceedings of the International Conference on Neural Networks In Neural Networks, IEEE International Conference , pp. 117-124, by Duane. 
Dong, F., Xu, Y., Hua, L., Wang, H., 2006 - Two methods for measurement of gasliquid flows in vertical upward pipe using dual-plane ert system. IEEE Trans. Instrum. Meas. 55, 1576-1586.

Echalar, F. A. M., 1991 - Estudo da estrutura de fontes de aerossóis em Cubatão com o uso de PIXE e modelos receptores. Dissertação de Mestrado, IF-USP.

Filho, B. D. B., Redes Neurais para Controle de Sistemas de Reatores Nucleares, Tese, Instituto de Pesquisas Energéticas e Nucleares - IPEN - São Paulo, 1998.

Fritzke, B., 1997 - The LBG-U method for vector quantization - an improvement over LBG inspired from neural networks. Neural Processing Letters, February, Volume 5, Issue 1, pp 35-45.

Forgy, E. W. - Cluster analysis of multivariate data: efficiency vs interpretability of classifications. Biometrics, v.21, p.768-769, 1965.

Fujiwara, A., Minato, D., Hishida, K., 2004 - Effect of bubble diameter on modification of turbulence in an upward pipe flow. Int. J. Heat Fluid Flow 25, 481-488.

Ghanbarzadeh, S., Hanafizadeh, P., Saidi, M. H., Ghanbarzadeh, S., Hanafizadeh, P., Saidi, M. H., 2012 - Intelligent Image-Based Gas-Liquid Two-Phase Flow Regime Recognition - Jounarl of Fluids Engineering-Transactions of The Asme.

Gonzalez, R., Woods, P., 2002 - Digital Image Processing. Prentice Hall, 2nd ed Addison Wesley, Inc.,93.

Grossberg, A. F. S., and Mingolla, E., 2009 - View-invariant object category learning, recognition, and search: How spatial and object attention are coordinated using surface-based attentional shrouds - Cognitive Psychology. 58: 1-48.

Hebb, D.,1949 - Organization of Behavior, New York: John Wiley.

Hopfield, J. J., 1982 - Proceeding of the National Acadamy of Sciences of Unite United States of America, vol 79, No 8 - Apr. 15. 
Kohenen, T., 1981 - Automatic formation of topological maps of patterns in a self organizing system. In: Oja, E. e Simula, O., Eds. Proc. 2SCIA, Scand. Conf. on Image Analysis, p 214 - 220, Helsinki, Finland.

Kohonen, T., 1988 - An Introduction to neural computing. Neural Networks, v.l, p.316.

Kohonen, T., 1988 - The Neural Phonetic Typewriter, Computer, v.21, n.3, p.11-22.

Kohonen, T., 1993 - Things you haven't heard about the self-organizing maps. In: International Conference on Neural Networks, p.1147-1156.

Kohonen, T., 2001 - Self-organizing maps. 3.ed. Springer-Verlag Berlin Heidelberg New York, $501 \mathrm{p}$.

Kohonen, T.; Mäkisara, K.; Saramäki, T., 1984 - Phonotopic Maps - insightful representation of phonological features for speech recognition. In: $7 \mathrm{t} \mathrm{h}$ International Conference on Pattern Recognition, p.182-185.

LeCun, Y., 1982 - Une procédure d'apprentissage pour réseau a seuil asymmetrique (a Learning Scheme for Asymmetric Threshold Networks), Proceedings of Cognitiva 85, 599-604, Paris, France.

Linde, Y.; Buzo, A.; Gray, R. M., 1980 - An algorithm for vector quantizer design. IEEE Transactions on Communications, v.28, p.84-95.

Lloyd, S.P., 1957 - Least squares quantization in PCM's. Bell Telephone Laboratories Paper. New Jersey: Murray Hill.

MacQueen, J. B., 1967 - Some Methods for classification and Analysis of Multivariate Observations, Proceedings of 5-th Berkeley Symposium on Mathematical Statistics and Probability", Berkeley, University of California Press, 1:281-297. 
Martinez, T. and Schulten, K.,1991 - A neural-gas - network learns topologies. In Kohonen, T., Mäkisara, K., Simula, O., and Kangas, J., editors, Artificial Neural Networks. Proceedings of ICANN'91, International Conference on Artificial Neural Networks, volume I, pages 397-402. North-Holland, Amsterdam.

Martinez, T. and Schulten, K.,1994 - Topology representing networks. Neural Networks, 7:507-522.

McCulloch, W. and Pitts, W. (1943). A logical calculus of the ideas immanent in nervous activity. Bulletin of Mathematical Biophysics, 5:115-133.

Mesquita, R. N., Libardi ,R. M. P., Masotti, P. H. F., Sabundjian, G., Andrade, D. A., Umbehaun, P. E., Torres, W. M., Conti, T. N., Macedo, L. A., 2009 - Two-Phase Flow Patterns Recognition and Parameters Estimation Through Natural Circulation Test Loop Image Analysis, ECl International Conference on Boiling Heat Transfer Florianópolis-SC-Brazil.

Masche, G., 1971 - Systems Summary of a Westinghouse Pressurized Water Reactor Nuclear Power Plant. Westinghouse Electric Corporation, First Edition.

Mesquita, R. N. de, 2002 - Classificação de Defeitos em Tubos de Gerador de Vapor de Plantas Nucleares Utilizando Mapas Auto-Organizáveis - São Paulo.

Mesquita, R. N. de, Masotti, P. H. F., Penha, R. M. L., Andrade, D. A., Sabundjian G., Torres, W. M., Macedo L. A., 2012 - Classification of natural circulation two-phase flow patterns using fuzzy inference on image analysis

Mingotil, A. S., 2005 - Análise de dados através de métodos de estatística multivariada: Uma abordagem aplicada, Ed UFMG, Belo Horizonte.

Minsky, M. L. and S. A., Papert, 1969 - Perceptrons: An Introduction to Computational Geometry, The MIT Press, Cambrigidge MA, first edition. 
Nam, J.Y., Rao, K.R. 1991 - Image coding using a classified DCT/VQ based on twochannel conjugate vector quantization. IEEE Transactions on Circuits and Systems for Video Technology, 1(4):325-336.

Nayak, A. K. and Sinha, R. K., 2007 - Role of passive systems in advanced reactors. Progress in Nuclear Energy, vol.49, pp.486-498.

Nelson, M., 1991 - The Data Compression Book: Featuring fast, efficient data compression techniques in C. M\&T Books.

Oliveira, A. F. da S., 2012 - Estudo da Circulação Natural para o projeto de um reator de pesquisa utilizando as técnicas de fluidodinâmica computacional e computação evolucionária - tese de Mestrado - Rio de Janeiro.

Omohundro, S. H., 1990 - Geometric laerning algorithms, Physica D 42: 307 - 321.

Ozbayoglu, A. M., Yuksel, H. E., Ozbayoglu, A. M., Yuksel, H. E., 2012 - Analysis of gas-liquid behavior in eccentric horizontal annuli with image processing and artificial intelligence techniques - Journal of Petroleum Science and Engineering

Ritter, H., 1991 - Asymptotic level density for a class of vector quantization processes. IEEE Transactions on Neural Networks, 2:173-175.

Rosemblatt, F., 1958 - The Perceptron: a probabilistic model for information storage \& organization in the brain. Psychological Review, 65, p. $386-408$.

Rumelhart, D. E., Hinton G. E., WILLIAMS, R. J., 1986 - Learning representations by back-propagating errors - Institute for Cognitive Science, C-015, University of California- October.

Seleghim, JR. P., Hervieu, P., Santos, A. M., 1998 - Time-Frequancy Characterisation of Two-Phase Horizontal Air-Water Flow Regimes. Journal of the Brazilian Society of Mechanical Sciences. Brasil: vol.20, n,3, p.1 -14. 
Schlichting, H., Gersten, K., 2003 - Technology \& Engineering - Navier-Stokes Equations If the transport equations (constitutive relations). The above equations were first set up by M. Navier (1827) and S.D. Pois- son Nelson, Mark - The Data Compression Book: Featuring fast, efficient data compression techniques in C. M\&T Books, 1991.

Schulten, K. and Martinetz, T., 1991 - A neural gas - network learns topologies. Artificial Neural Networks. Elsevier. pp.397-402.

Schuabb, P. G., 2015 - Criação de Redes Neurais para classificação de bolhas de Taylor em escoamentos ascendentes utilizando simulações em Monte Carlo na etapa de treinamento - UFRJ - março 2015.

SOM Toolbox team, 2012. SOM Toolbox 2.1 for Matlab, Aalto University, Department of Information and Computer Science, Aalto, Finlândia.

Souza, S. C., 2007 - Estudos de Técnicas de Realce de Imagens digitais e suas aplicações - II Congresso de Pesquisa e Inovação da Rede Norte Nordeste de Educação Tecnológica João Pessoa, PB.

Sunde, C., Avdic, S., Pazsit, I., 2005 - Classification of Two-phase Flow Regimes Via Image Analysis and A Neuro-wavelet Approach, Progress in Nuclear Energy, 46(34): $348-358$

Tobiszewski, M., Tsakovski, S., Simenov, V., Namiésnik, J., 2010 - Surface water quality assessment by the use of combination of multivariate statistical classification and expert information. Chemosphere, 80, p.740-746.

Tong, L. S., 1997 - Boiling Heat Transfer and Two-phase Flow, cap. 7, p. 201-216.

Torres, W. M., Macedo, L. A., Mesquita, R. N., Masotti, P. H., Sabundjian, G., Andrade, D. A., Umbehaun, P.E., 2010. Thermohydraulic Phenomenology in a Natural Circulation Circuit. $2^{\circ}$ EBECEM, São Carlos, Sp. 
The Mathworks, Inc., 2014. MATLAB Version: 8.3.0.532 (R2014a), Natick, Massachussets, Eua.

Yeoh, G. H., Tu, J. Y., Lee, T., Park, G. C., 2002 - Prediction and measurement of local two-phase flow parameters in a boiling flow channel. Numer. Heat Transfer A 42, 173-192.

Ursenbacher, T., Wojtan, L., Thome, J. R., 2004 - Interfacial measurements in stratified types of flow. Part I. New optical measurement technique and dry angle measurements. Int. J. Multiphase Flow 30, 107-124.

Watson, A. B. - DCT: quantization matrices visually optimized for individual images in Human Vision, Visual Processing, and Digital Display IV, B. E. Rogowitz, ed. (SPIE, Bellingham, WA, 1994).

Werbos, P. J. Beyond Regression: New Tools for Prediction and Analysis in the Behavioral Sciences. Boston, 1974. Tese (Doutorado) - Harvard University, USA.

Widrow, B.; Hoff, M. E., 1988 - Adaptive switching circuits. In: Anderson J.A.; Rosenfeld E. IRE Convention Record. New York, 1960. p.96-104. (Reimpresso em: Neurocomputing. Cambridge: MIT Press).

Taitel, T.; Barnea, D.; Dukler, A. E., 1980 - Modelling flow pattern transitions for steady upward gasliquid flow in vertical tubes. AIChEJ, [S.I.], v. 26, p. 345-54. 
Anexo I: Banco de imagens - Tipo de escoamento: Incubação.

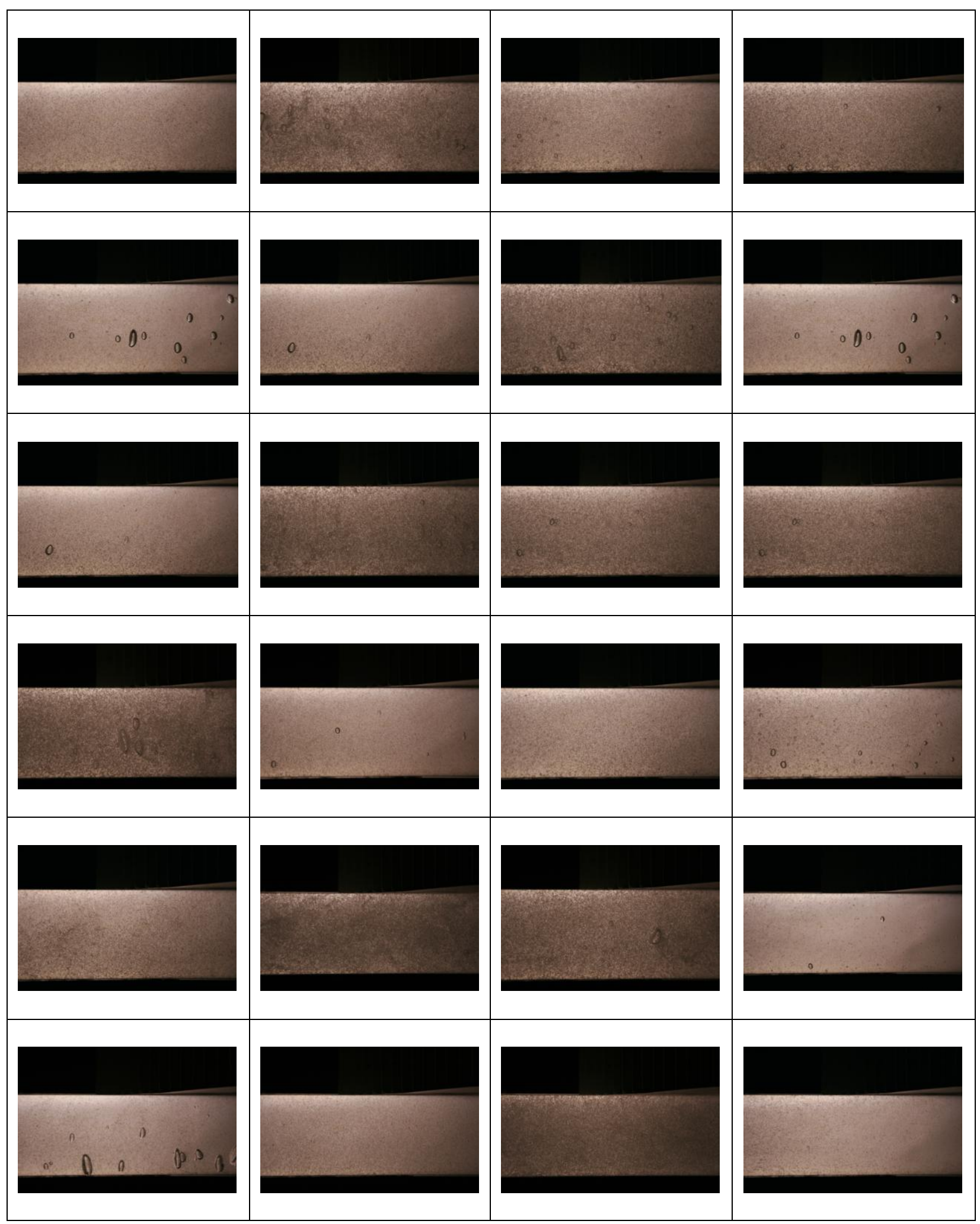




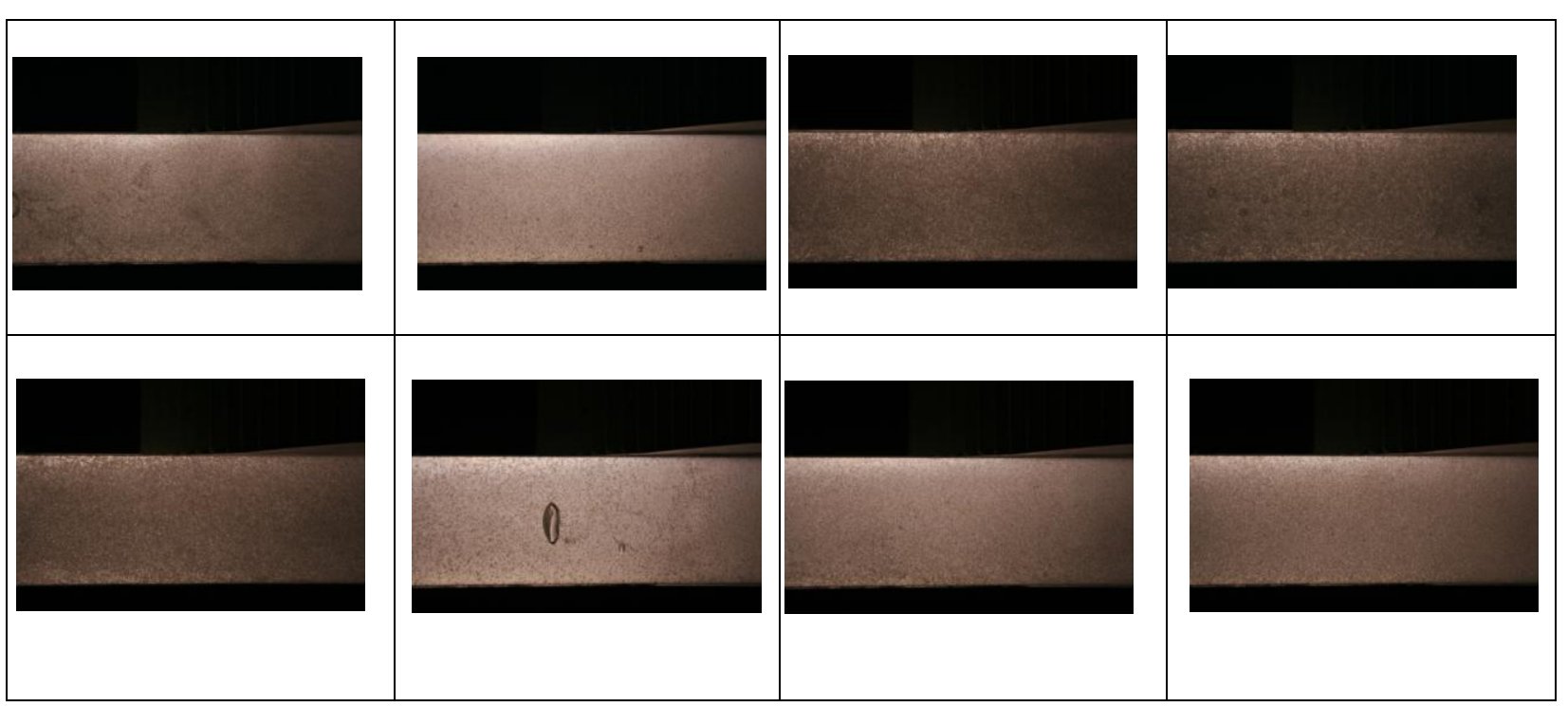


Anexo II: Banco de imagens - Tipo de escoamento: Expulsão.

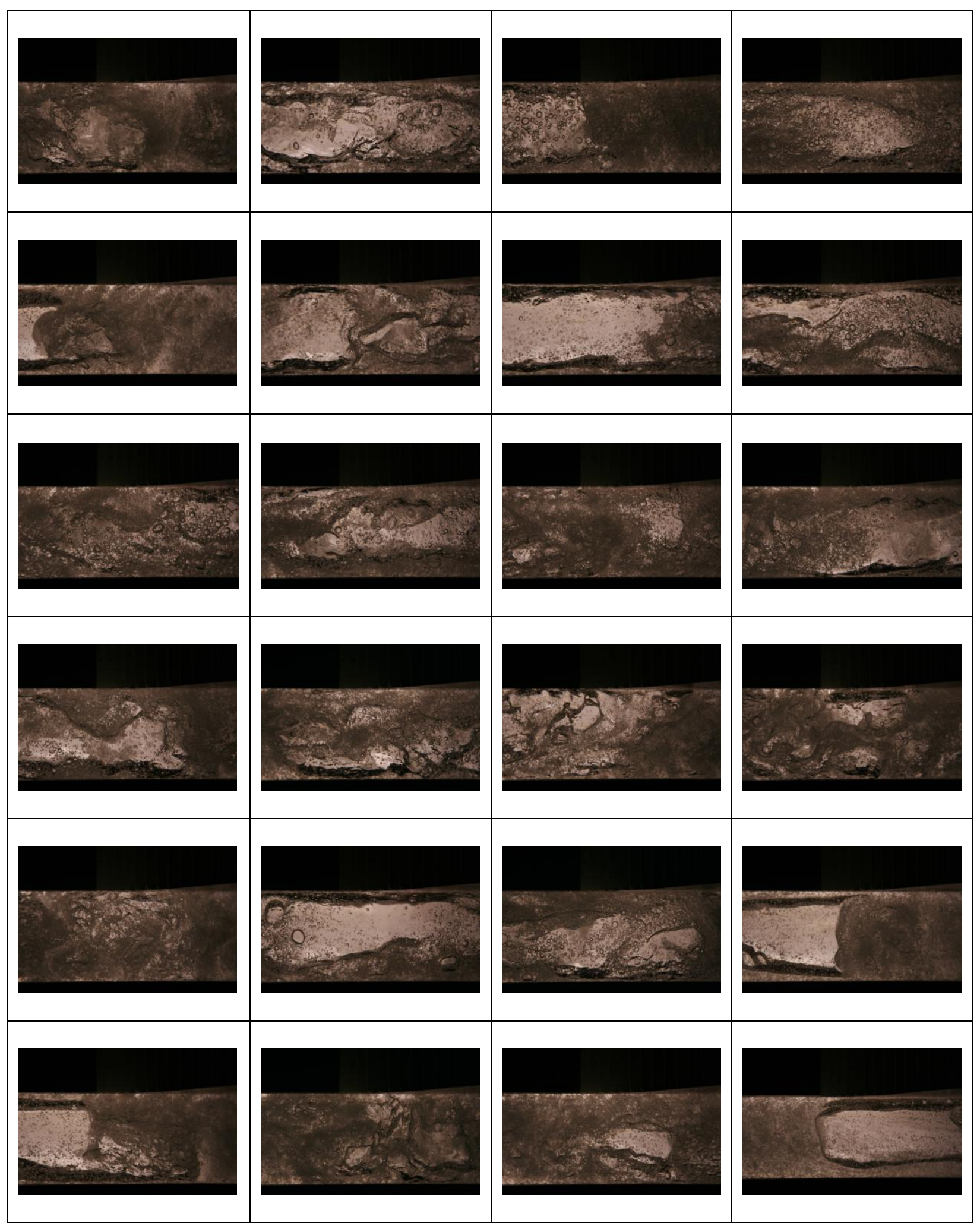




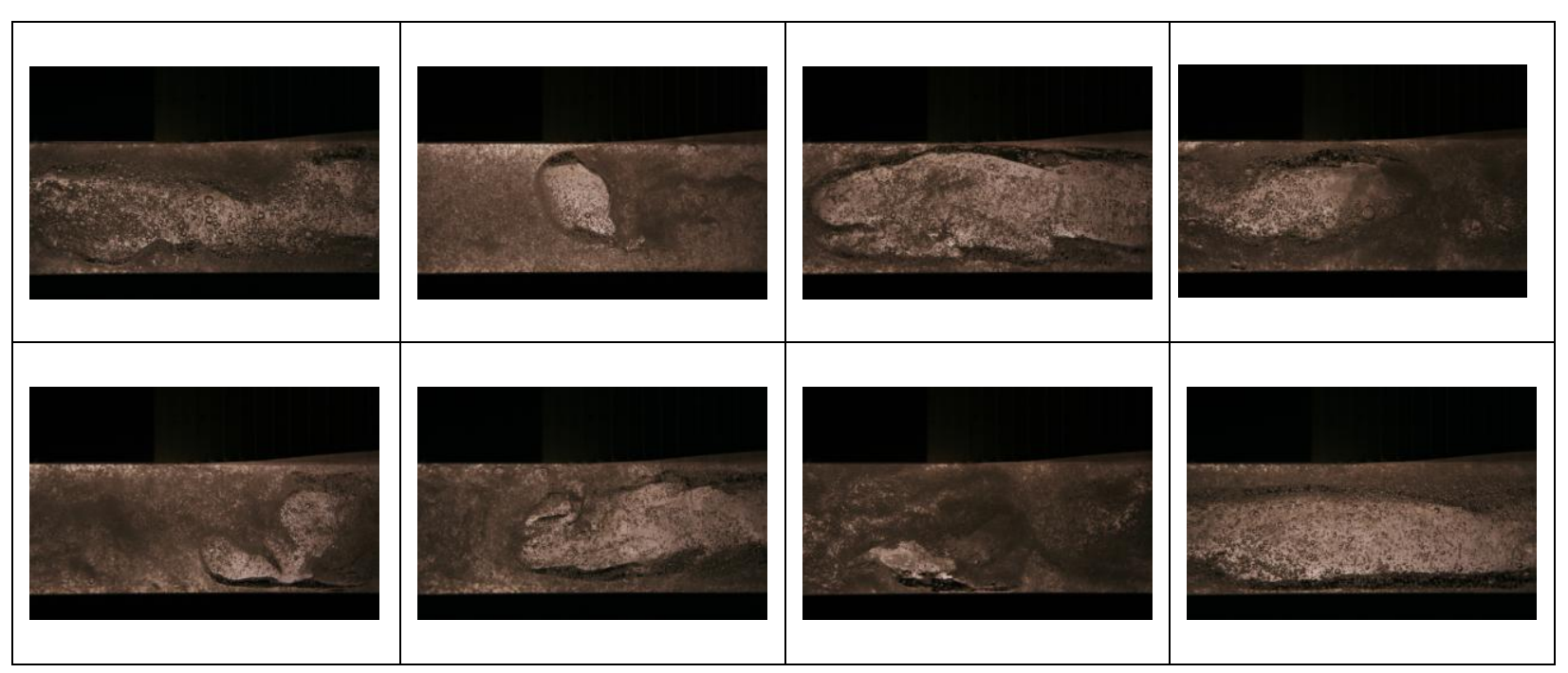


Anexo III: Banco de imagens - Tipo de escoamento: Reenchimento.

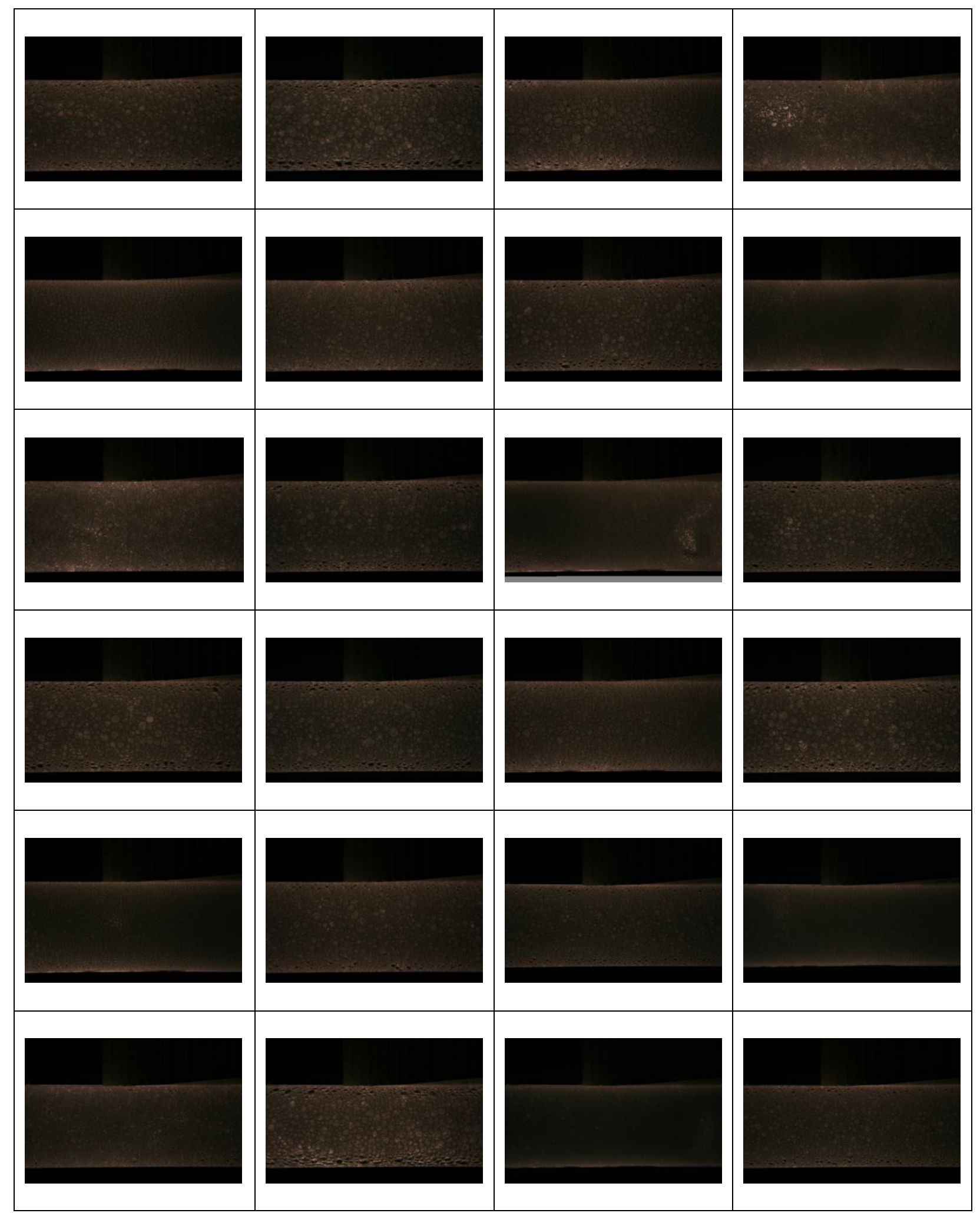




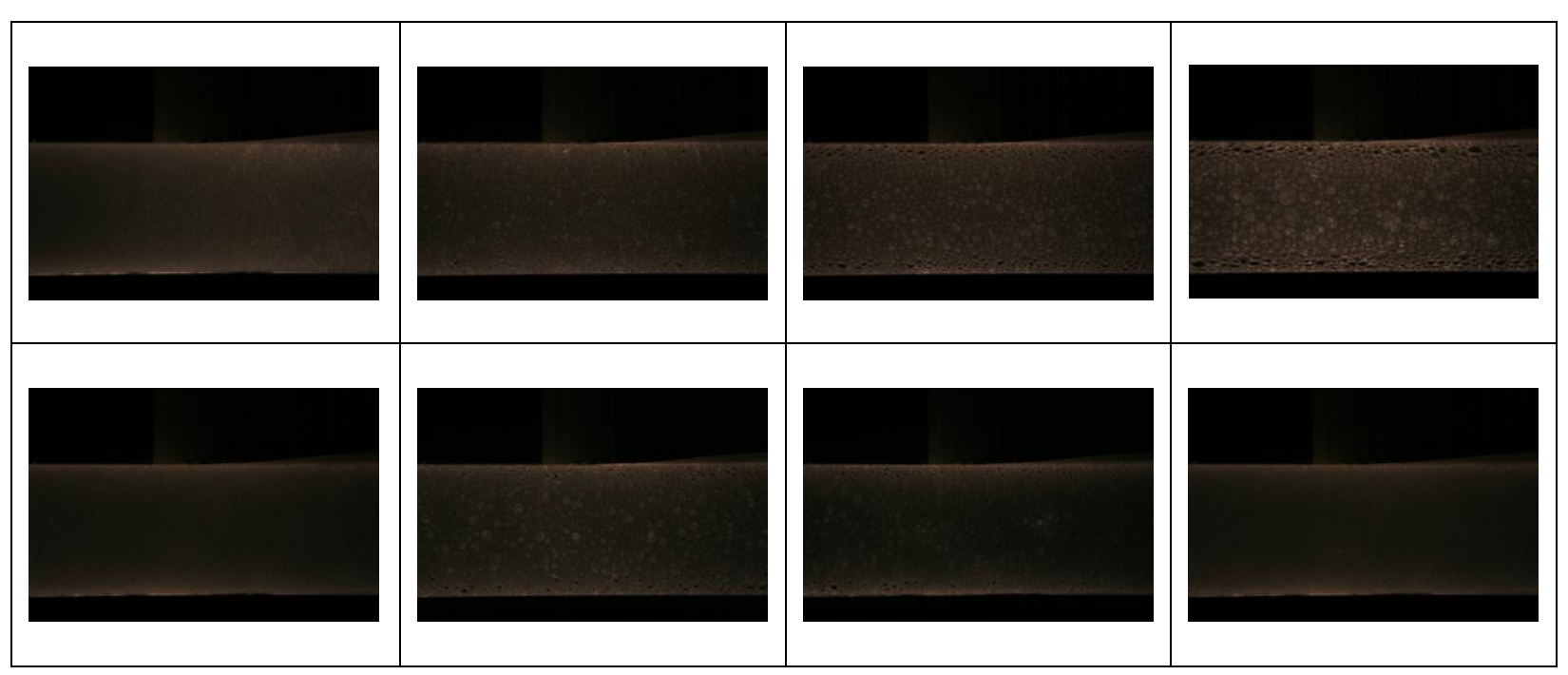

